FABIANA MARTINS E MARTINS

\title{
AVALIAÇÃO CLINICA DE ALTERAÇÕES BUCAIS EM PACIENTES SOROPOSITIVOS PARA O HTLV
}




\section{Fabiana Martins e Martins}

Avaliação clinica de alterações bucais em pacientes soropositivos para o HTLV

Dissertação apresentada à faculdade de Odontologia da Universidade de São Paulo, para obter titulo de Mestre pelo Programa de PósGraduação em Odontologia.

Área de Concentração: Patologia Bucal

Orientadora: Prof $^{a}$ Dr $^{a}$ Karem López Ortega

São Paulo 


\section{FOLHA DE APROVAÇÃO}

Martins FM. Avaliação clinica de alterações bucais em pacientes soropositivos para o HTLV [Dissertação de Mestrado]. São Paulo: Faculdade de Odontologia da USP; 2008.

São Paulo, / /2008.

\section{Banca Examinadora}

1)Prof(a). Dr(a).

Titulação:

Julgamento: Assinatura:

2) $\operatorname{Prof}(a) \cdot \operatorname{Dr}(a)$.

Titulação:

Julgamento: Assinatura:

3)Prof(a). Dr(a).

Titulação:

Julgamento: Assinatura: 


\section{DEDICATÓRIA}

Ao Marcio, o amor da minha vida,

Meu companheiro de profissão e de vida acadêmica,

Meu melhor amigo,

Você é um exemplo de profissional, cientista e sobretudo de ser humano.

Obrigado por sempre ter me apoiado nos momentos mais difíceis durante O período de elaboração deste trabalho.

Ao meu irmão Gustavo,

Meu príncipe, minha eterna fonte de inspiração.

Aos meus pais, Walmir e llza,

Vocês são meu alicerce, os meus grandes amores e

Exemplos a serem seguidos.

Obrigada pelos ensinamentos, amor e por terem moldado a pessoa que me tornei hoje. 


\section{AGRADECIMENTOS}

Á Prof ${ }^{\mathrm{a}} \mathrm{Dr}^{\mathrm{a}}$ Karem López Ortega pela orientação, amizade e por ter-me incentivado a trilhar o caminho acadêmico.

Á Prof ${ }^{a} \operatorname{Dr}^{a}$ Marina Magalhães, que com seu curso de especialização em pacientes portadores de necessidades especiais, me deu a oportunidade de conhecer o CAPE, e conseqüentemente, me apaixonar por ele.

Á Prof ${ }^{\mathrm{a}} \mathrm{Dr}^{\mathrm{a}}$ Nathalie Rezende pela amizade e pelos conselhos valiosos.

Ao Prof. Dr. Jorge Casseb por ter me recebido tão bem em seu ambulatório no IIER.

Colegas do CAPE e da pós-graduação, pelo companheirismo e apoio tanto em momentos felizes, quanto em momentos de tensão.

As funcionárias do CAPE, muito queridas e sempre muito prestativas.

Ao CNpQ pela bolsa de Mestrado. 
Martins FM. Avaliação clinica de alterações bucais em pacientes soropositivos para o HTLV [Dissertação de Mestrado]. São Paulo: Faculdade de Odontologia da USP; 2008.

\section{RESUMO}

O HTLV-1 (Human T-Lymphotropic Virus) foi o primeiro retrovírus descoberto. Sua patogenia é relacionada à infecção das células T CD4+ e T CD8+ e sua disseminação depende da expansão clonal destas células. A imortalização celular e a resposta imune inflamatória direta contra o vírus levam os pacientes a desenvolverem a leucemia/ linfoma de células $T$ do adulto (ATL) e paraparesia espástica tropical/mielopatia (TSP/HAM) respectivamente. Ainda que o vírus seja conhecido desde 1980, não existem trabalhos na literatura que evidenciem possíveis manifestações bucais associadas. Alguns estudos clínico-epidemiológicos, realizados em regiões altamente endêmicas para o vírus, apontam a possibilidade de associação entre o HTLV e a síndrome de Sjögren (SS). Este estudo objetivou conhecer melhor uma população HTLV+ identificando possíveis alterações estomatológicas. Foram avaliados 139 pacientes do Instituto de Infectologia Emilio Ribas, sendo que 112 (80,5\%) eram HTLV-1+, 26 eram (18,7\%) HTLV-2 + e 1 paciente era soropositivo para ambos os tipos virais. Entre os pacientes HTLV-1+, $88(64,7 \%)$ eram assintomáticos e $48(35,3 \%)$ apresentavam TSP/HAM. As alterações bucais mais freqüentes foram: xerostomia $(26,5 \%)$, candidíase $(25,4 \%)$, língua fissurada $(22,1 \%)$ e língua depapilada $(12,4 \%)$. Modelos de regressão logística multivariada confirmaram a TSP/HAM como um fator de risco independente para xerostomia $(p=0,02)$, apresentando, pacientes TSP/HAM+, 3 vezes mais chances de desenvolver xerostomia quando comparados com pacientes sem TSP/HAM $(\mathrm{OR}=2,69 ; 95 \% \mathrm{IC}=1,17-6,17)$.

Palavras-Chave: HTLV, ATL, TSP/HAM, Epidemiologia 
Martins FM. Avaliação clinica de alterações bucais em pacientes soropositivos para o HTLV [Dissertação de Mestrado]. São Paulo: Faculdade de Odontologia da USP; 2008.

\section{ABSTRACT}

HTLV-1 (human T-lymphotropic virus), the first retrovirus discovered, is associated with adult T cell leukemia/lymphoma (ATL) and tropical spastic paraparesis / HTLV associated myelopathy (TSP / HAM). Clinical studies and case reports in endemic areas showed the development of oral ALT and Sjögren's syndrome in this patients. The aim of this study was to investigate the oral cavity of HTLV seropositive patients in São Paulo city. The present study was approved by the Institute of Infectious Diseases Emílio Ribas ethics committee. All patients answered a questionnaire designed for the study. Demographic and clinical data were recorded and then analyzed using Epi info (3.3.4 version) and SPSS - Statistical Package for Social Sciences (v16.0). One hundred and thirty nine oral examinations were performed, $112(80,5 \%)$ were HTLV-1 +, 26 were (18,7\%) HTLV-2 + and one patient presented both types of HTLV. Sixty four $(56,7 \%)$ were asymptomatic HTLV-1 seropositive patients, fourty nine $(43,3 \%)$ patients were positive for HTLV-1 and TSP/HAM. HIV and HCV co-infection and comorbities were observed in $110(79,1 \%)$ cases. Xerostomia $(26,5 \%)$, candidosis $(25,4 \%)$, oral fissured tongue $(22,1 \%)$ and papillary atrophy of the tongue $(12,4 \%)$ were the most prevalent oral manifestations found in these patients. Models of multivariate logistic regression confirmed the TSP / HAM as an independent risk factor for xerostomia $(p=0.02)$. Patients with TSP / HAM + were 3 times more likely to develop xerostomia when compared with patients without TSP / $\mathrm{HAM}(\mathrm{OR}=2.69,95 \% \mathrm{Cl}=1.17-6.17)$.

Keywords: HTLV, ATL, TSP/HAM, Epidemiology 


\section{LISTA DE ILUSTRAÇÕES}

Figura 2.1 - A estrutura do HTLV

Figura 2.2 - Distribuição geográfica do HTLV-1 no mundo

Figura 5.1 - Distribuição em porcentagem de 139 pacientes HTLV+ segundo o sexo.... 39

Figura 5.2- Distribuição em porcentagem dos pacientes HTLV+ segundo a década de vida $(n=139)$

Figura 5.3 - Distribuição porcentual dos pacientes HTLV+ segundo a cor da pele $(n=139)$

Figura 5.4 - Regiões brasileiras de maior prevalência nos pacientes Estudados 44

Figura 5.5 - Distribuição porcentual da categoria de exposição ao HTLV relatada pelos pacientes 45

Figura 5.6 - Freqüência de co-morbidades apresentadas por 80 pacientes soropositivos para o HTLV. 48

Figura 5.7 - Freqüência de co- infecções apresentadas por 54 pacientes portadores do HTLV

Figura 5.8 - Drogas utilizadas por 97 pacientes HTLV+ que faziam uso regular de medicações

Figura 5.9 - Freqüência dos tipos de HTLV entre os pacientes estudados. 53 
Figura 5.10 - Proporção de pacientes com sinais e sintomas relativos à TSP/HAM segundo o tipo de HTLV

Figura 5.11 - Drogas utilizadas no tratamento sintomático de 49 pacientes portadores de HTLV-1 com TSP/HAM 55

Figura 5.12 - Alterações bucais mais freqüentes em 74 pacientes soropositivos para o HTLV 56

Figura 5.13 - Distribuição das alterações bucais encontradas ente os tipos virais estudados 58

Figura 5.14- Relação entre fatores modificadores e alterações bucais observadas em pacientes soropositivos para o HTLV. 58

Figura 5.15- Incidência porcentual, segundo o tempo de seguimento no IIER, de pacientes que apresentavam alterações bucais 59 


\section{LISTA DE TABELAS}

Tabela 2.1 - Distribuição geográfica do HTLV no Brasil

22

Tabela 2.2 - Doenças associadas ao HTLV (Adaptado de VERDONCK et al., 2007) ......26

Tabela 2.3 - ATLL em cavidade bucal. 28

Tabela 5.1 - Prevalência de pacientes HTLV+ segundo a faixa etária e o sexo em números absolutos e porcentagem 40

Tabela 5.2 - Grau de instrução declarado por 134 pacientes HTLV+ segundo o sexo ... 42

Tabela 5.3 - Estado civil dos pacientes HTLV+ segundo o sexo 42

Tabela 5.4 - Distribuição geográfica em território brasileiro de 136 pacientes soropositivos para o HTLV, segundo sua naturalidade.

Tabela 5.5 - Categoria de transmissão relatada pelos pacientes HTLV+ segundo o sexo $(n=135)$ 46

Tabela 5.6 - Freqüência do motivo da realização do teste anti-HTLV em 138 pacientes soropositivos para o HTLV. 
Tabela 5.8: Tempo de seguimento clínico de 139 pacientes HTLV+

Tabela 5.9: Sintomas e sinais presentes em 48 pacientes portadores de HTLV-1 e TSP/HAM 54

Tabela 5.10: Análise Descritiva das variáveis quantitativas nos grupos de estudo, assim como os resultados referentes ao Teste de Kruskal-Wallis comparando os valores dos indivíduos que apresentam ou não a alteração bucal 61

Tabela 5.11: Comparação das diversas alterações bucais com as variáveis em estudo 62

Tabela 5.12: Relação entre níveis de CD4 em pacientes HIIV positivos. .64

Tabela 5.13: Relação entre positividade para HIV e candidíase 64

Tabela 5.14: Relação entre níveis de CD4 e candidíase em pacientes HIIV positivos ...65

Tabela 5.15: Modelos de regressão logística multivariada para a alteração xerostomia e candidíase 


\section{LISTA DE ABREVIATURA E SIGLAS}

\begin{tabular}{ll} 
HTLV & do inglês - Human T-cell lymphotropic Virus \\
ATLL & do inglês - adult T-cell leukemia / lymphoma \\
TSP/HAM & do inglês - tropical spastic paraparesis / HTLV-1 associated \\
& myelopathy \\
SS & síndrome de Sjögren \\
RNA & do inglês - ribonucleic acid \\
Tax & transativadores da transcrição viral \\
Rex & reguladores da expressão \\
RNAm & RNA mensageiro \\
LTCs & Linfócitos T citotóxicos \\
LCP & leucemia de células pilosas \\
STLV & vírus linfotrópicos T símios \\
EIA & ensaio imunoenzimático \\
WB & Western Blot \\
IFI & imunoflurescência indireta \\
RIPA & radioimunoprecipitação \\
PCR & polimerase em cadeia \\
CD4 & cluster of differentation 4 \\
CD8 & cluster of differentation 8 \\
IL-2 & interleucina 2 \\
IL-15 & interleucina 15 \\
CV & carga viral \\
\hline
\end{tabular}




\begin{tabular}{ll} 
SNC & sistema nervoso central \\
IIER & Instituto de Infectologia Emílio Ribas \\
CAPE & Centro de Atendimento a Pacientes Especiais \\
FOUSP & Faculdade de Odontologia da Universidade de São Paulo \\
HIV & do inglês - Human immunodeficiency virus \\
HCV & do inglês - Hepatiis C virus \\
HBV & Do inglês - Hepatitis B vírus \\
CDC & Centers for Disease Control \\
SPSS & Statistical Package for Social Sciences \\
UDI & Uso de drogas injetáveis \\
HAS & Hipertensão arterial sistêmica \\
ARV & Antirretrovirais \\
PCR-RT & Do inglês- polymerase chain reaction-reverse transcriptase \\
Anti-SS-A & Anticorpos contra o antígeno Ro \\
Anti-SS-B & Anticorpos contra o antígeno La \\
\hline
\end{tabular}




\section{SUMÁRIO}

p.

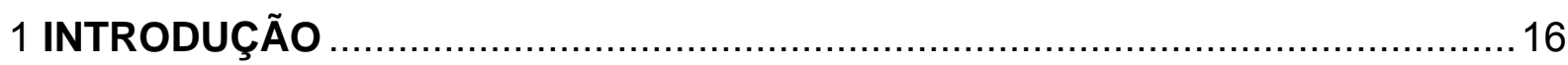

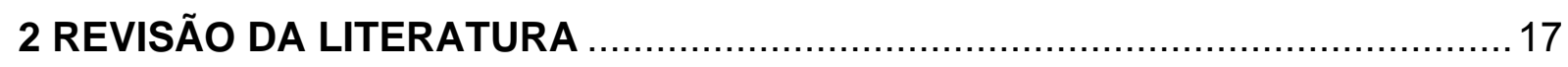

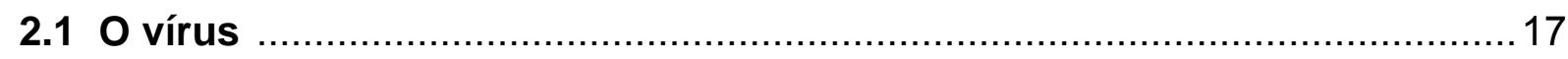

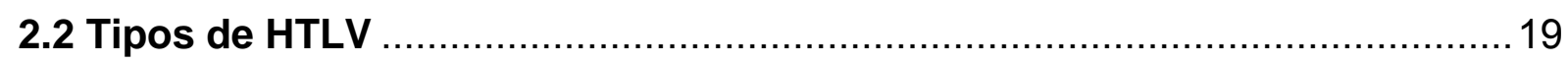

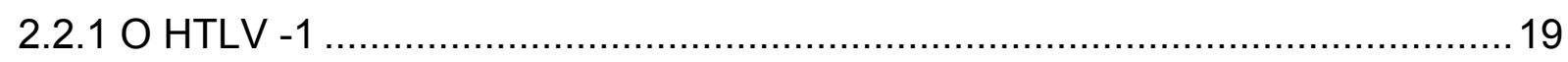

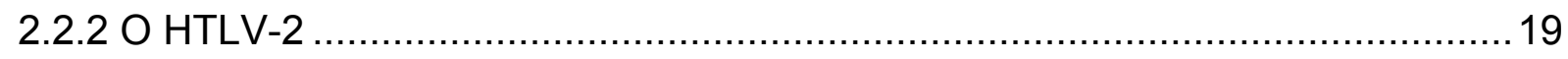

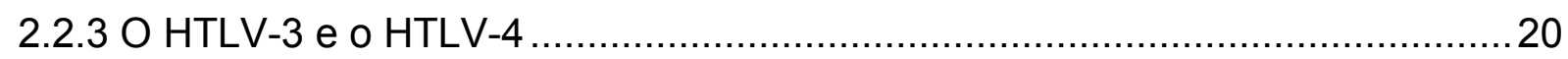

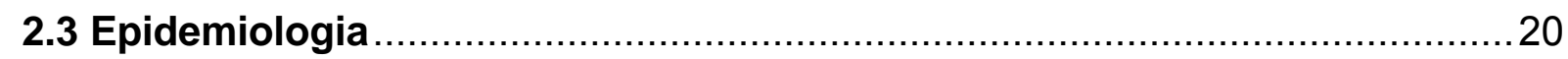

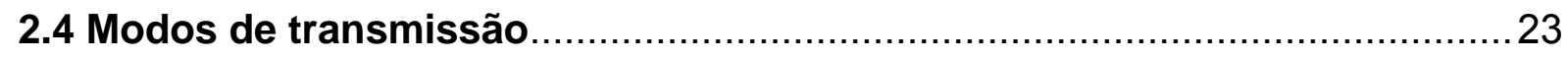

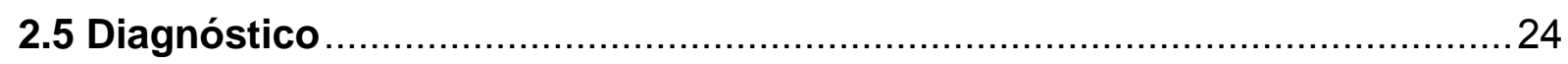

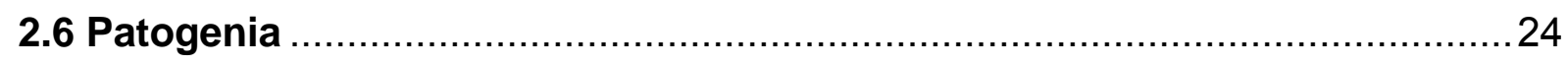

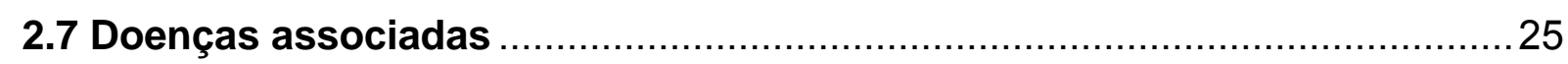

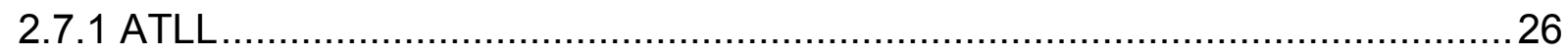

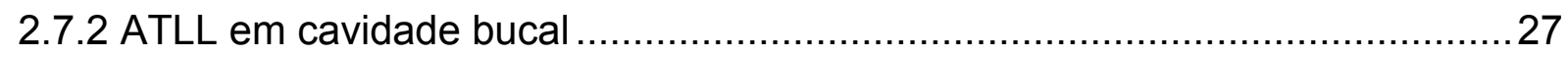

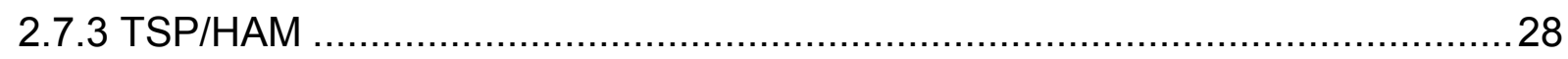

2.7.4 Patogênese das doenças inflamatórias associadas ao HTLV-1 ....................29

2.7.5 Alterações bucais relacionadas ao HTLV ............................................... 29

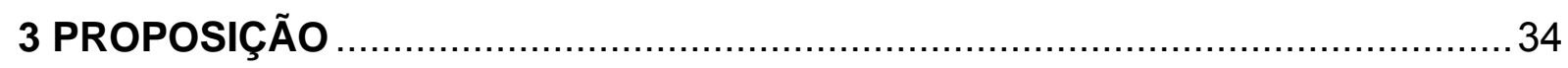

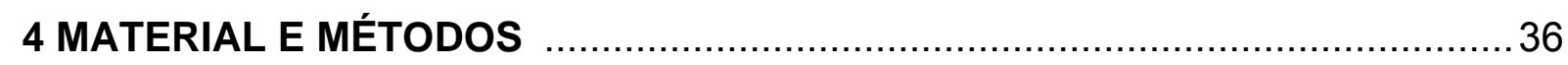

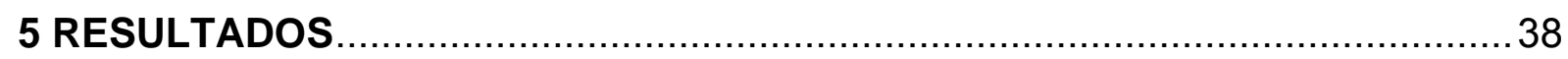

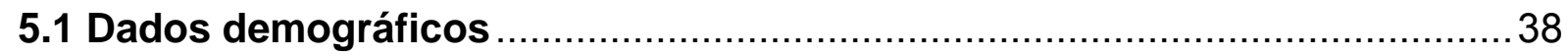

5.2 Dados médico-clínicos relativos à infecção pelo HTLV ...........................44

5.3 Dados relativos às alterações bucais..................................................... 55

5.4 Avaliação de interferência de cv e idade .............................................. 61

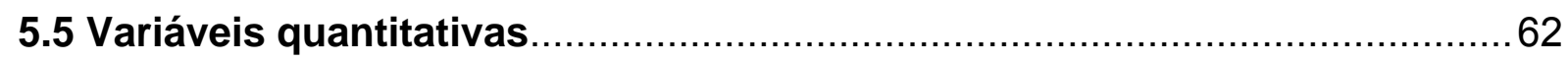

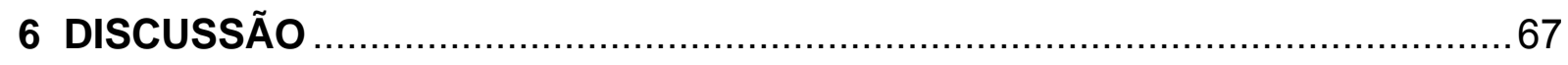

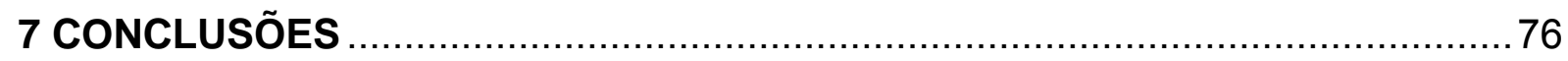




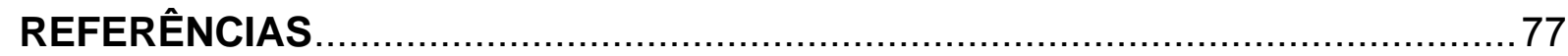

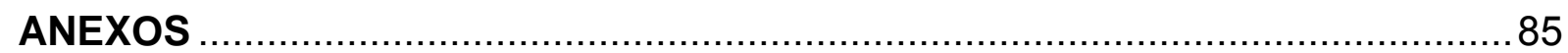




\section{INTRODUÇÃO}

O HTLV-1 foi isolado em 1980 em uma linhagem de células T de um paciente portador de linfoma cutâneo de células T do adulto (ATLL) (POIESZ et al., 1980). Além de estar relacionado ao ATLL, o HTLV-1 também é associado à outra doença incurável, a paraparesia espástica tropical/mielopatia associada ao HTLV (TSP/HAM) (BANGHAM, 2000).

Posteriormente em 1982 foi descoberto o HTLV-2 que é associado a poucos tipos de doenças (FEUER; GREEN, 2005). Recentemente foram identificados o HTLV tipo 3 e o HTLV- 4, em pacientes provenientes do continente africano (CALATTINI et al., 2005; WOLFE et al., 2005).

Estima-se que atualmente 15 a 20 milhões de pessoas estejam infectadas com o vírus, sendo considerados endêmicos os países localizados principalmente na África central, Caribe, alguns países da America do Sul e o sudoeste japonês (MURPHY et al., 2005).

O HTLV-1 e o HTLV-2 são transmitidos através de contato sexual, com sangue e hemoderivados, e através da via vertical, sendo a amamentação o meio mais eficaz de transmissão (EDLICH; ARNETTE; WILLIAMS, 2000).

Além da ATLL e a TSP/HAM, o HTLV-1 é relacionado a doenças auto-imunes, infecciosas e outros tipos de neoplasias (VERDONCK et al., 2007).

As alterações bucais descritas na literatura são a ATLL e a síndrome de Sjögren (SS), sendo que geralmente estas manifestações foram identificadas em pacientes oriundos de países altamente endêmicos para o vírus (SEGAMI et al., 1990; TERADA et al., 1994). 


\section{REVISÃO DE LITERATURA}

\subsection{0 vírus}

O HTLV (Human T- Lymphotropic Virus) pertence à família Retroviridae, subfamília Orthoretrovirinae, gênero Deltaretrovirus (ICTVdB Management, 2006).

O HTLV é considerado um retrovírus complexo, possui envelope viral e possui duas copias de fitas simples de RNA no interior do core. Seu genoma é formado por 9032 nucleotídeos e, assim como outros retrovírus, apresenta em sua estrutura genética os genes gag, pol e env que codificam, respectivamente, as proteínas do core, a enzima transcriptase reversa e as proteínas do envelope viral (Figura 2.1). Entretanto o HTLV possui na extremidade 3' de seu genoma os genes tax transativadores da transcrição viral e rex - reguladores da expressão viral que codificam as proteínas reguladoras tax e rex (BANGHAM, 2003; FRANCHINI, 1995).

A proteína rex está localizada na região nuclear e esta associada à expressão da estrutura viral, codificam proteínas que favorecem a expressão do RNA mensageiro (RNAm) viral que ainda não passaram pela fase de splicing e aumenta a capacidade de transporte intracelular do RNAm maiores (EDLICH; ARNETTE; WILLIAMS, 2000). 


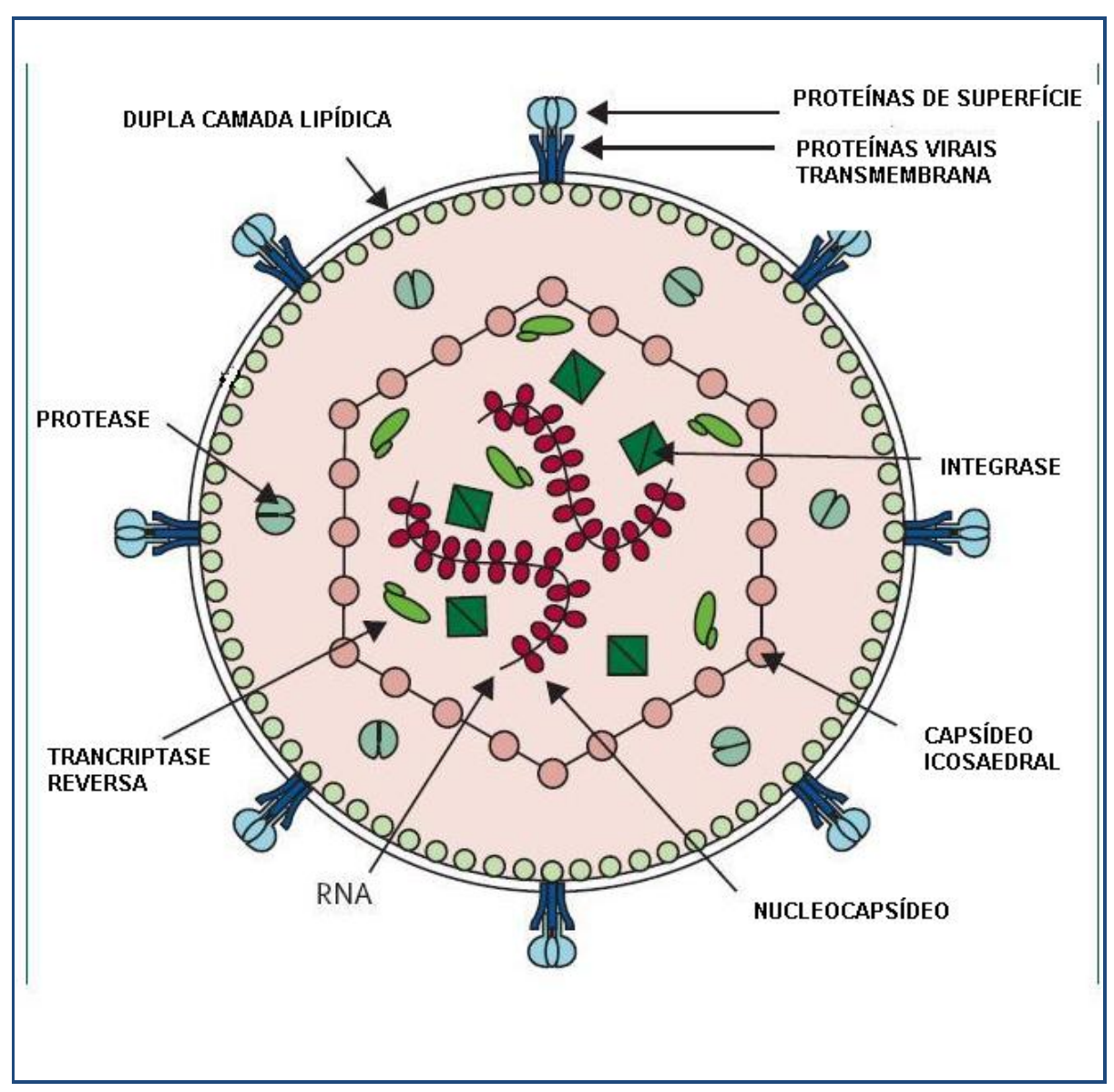

Figura 2.1- A estrutura do HTLV (Adaptada de VERDONCK et al., 2007)

A proteína tax é associada diretamente com a transcrição viral, promovendo a imortalização das células $\mathrm{T}$ e sendo vinculada ao aparecimento da paraparesia espástica tropical (TSP/HAM) e ao linfoma/leucemia de células T do adulto (ATLL) (FEUER; GREEN, 2005). Ao contrário da rex, a proteína tax é apontada como o principal alvo das células T citotóxicas (CTCs) (BANGHAM, 2003). Essas proteínas combinadas irão regular a expressão viral transitória e seqüencial (YOSHIDA, 2005).

A estrutura do genoma do HTLV-1 e do HTLV-2 exibe grande similaridade, sendo que $70 \%$ da seqüência de nucleotídeos são homólogos. Ambos possuem os genes virais essenciais gag, pol e env (FEUER; GREEN, 2005). 


\subsection{Tipos de HTLV}

\subsubsection{O HTLV -1}

Foi o primeiro retrovírus descrito na literatura associado diretamente a malignidades, sendo isolado em 1980 em um paciente que apresentava linfoma cutâneo de células T (MATSUOKA; JEANG, 2007).

O HTLV-1 esta vinculado ao aparecimento de doenças, sendo a TSP/HAM e a ATLL as patologias de maior ocorrência (WONG-STAAL; GALLO, 1985).

\subsubsection{O HTLV-2}

O HTLV-2 é considerado muito menos patogênico que o HTLV-1, sendo associado a doenças neurológicas semelhantes à TSP/HAM e a alguns casos variantes da leucemia de células pilosas (LCP) (FEUER; GREEN, 2005).

A leucemia de células pilosas é uma doença linfoproliferativa crônica de ocorrência rara sendo que os pacientes portadores da LCP apresentam perda de peso, esplenomegalia e pancitopenia (GONSALEZ et al., 1998).

O diagnóstico da LCP é confirmado através da punção aspirativa da medula óssea ou na análise do sangue periférico onde é observada a presença de linfócitos neoplásicos com alterações em sua morfologia nuclear, contendo em sua membrana finas projeções que se assemelham a pêlos (GONSALEZ et al., 1998). 


\subsubsection{O HTLV-3 e o HTLV-4}

Os vírus linfotrópicos T humanos dos tipos 1 e 2 são diretamente relacionados às linhagens dos vírus linfotrópicos T símios (STLV) dos tipos 1 e 2 respectivamente, sugerindo a hipótese da transmissão do HTLV-1 através do contato entre humanos e primatas não humanos (CALATTINI et al., 2005; WOLFE et al., 2005).

Foram realizados testes sorológicos em habitantes de comunidades rurais pertencentes a Republica dos Camarões (África Central) onde foram identificados dois novos tipos de HTLV: o HTLV-3 e 4 (CALATTINI et al., 2005; WOLFE et al., 2005).

O HTLV-3 foi considerado geneticamente similar ao STLV-3, entretanto, o HTLV-4 aparentemente representa um novo tipo de Deltavírus, não apresentando um vírus símio homólogo (SWITZER et al., 2006).

\subsection{Epidemiologia}

Acredita-se que aproximadamente 15 a 20 milhões de pessoas estejam infectadas com HTLV em todo o mundo (PROIETTI et al., 2005).

A infecção pelo HTLV-1 é considerada endêmica no sudoeste do Japão, Caribe, Irã, alguns países da América Latina e regiões central e sul da África. A infecção pelo HTLV-2 é mais freqüente em tribos indígenas das Américas Central, Norte e Sul (MURPHY et al., 2005; PROIETTI et al., 2005). A Figura 2.2 mostra a 
distribuição geográfica mundial do HTLV, onde em vermelho estão representadas as áreas endêmicas para o virus, enquanto em cor de rosa são observados os países onde já foram realizados estudos, mas que não são endêmicos para o vírus.

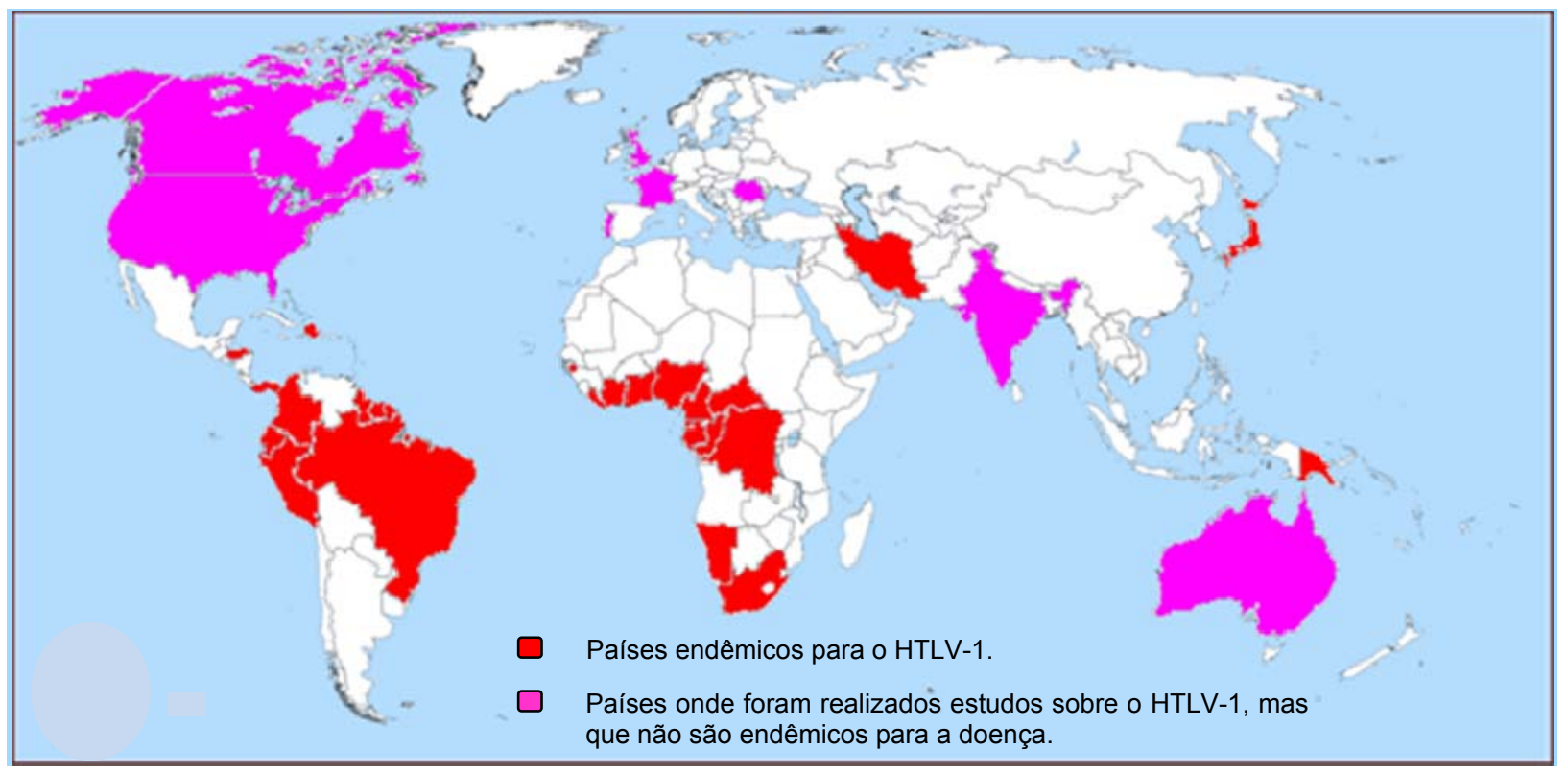

Figura 2.2- Distribuição geográfica do HTLV-1 no mundo (Adaptada de PROIETTI et al., 2005)

No Brasil estimativas realizadas através de comunicação oral, contabilizaram cerca de 2,5 milhões de pacientes infectados pelo HTLV-1, tornando-o o pais com o maior número absoluto de casos (CARNEIRO-PROIETTI et al., 2002). O HTLV tipo 2 é identificado em maior número em populações indígenas (CARNEIRO-PROIETTI et al. 2002; MURPHY et al., 2005). Ainda nao foram identificados casos de HTLV-3 e HTLV-4 em território brasileiro. A Tabela 2.1 apresenta a distribuicao geografica do HTLV no Brasil. 
Tabela 2.1- Distribuição geográfica do HTLV no Brasil

\begin{tabular}{|c|c|c|}
\hline Estado & Incidência (\%) & Referência \\
\hline$A M$ & $0,08-H T L V-1$ & CARNEIRO-PROIETTI et al., 2002 \\
\hline$P A$ & 1,61 - HTLV & CARNEIRO-PROIETTI et al., 2002 \\
\hline$C E$ & $0,12-1,21-H T L V-1$ & BROUTET et al., 1996 \\
\hline$R N$ & $0,10-H T L V-1$ & CARNEIRO-PROIETTI et al., 2002 \\
\hline$P E$ & 0,82- HTLV-1 & CARNEIRO-PROIETTI et al., 2002 \\
\hline$S E$ & $0,40-\mathrm{HTLV}-1$ & CARNEIRO-PROIETTI et al., 2002 \\
\hline$B A$ & 1,7- HTLV-1 & DOURADO et al., 2003 \\
\hline MG & 0,32- HTLV-1 & CARNEIRO-PROIETTI et al., 2002 \\
\hline RJ & $0,44-\mathrm{HTLV}-1$ & CARNEIRO-PROIETTI et al., 2002 \\
\hline$S P$ & $5,8-\mathrm{HTLV}-1$ & JACOB et al., 2007 \\
\hline MS & 0,1- HTLV & FIGUEIRÓ-FILHO et al., 2007 \\
\hline sc & $0,08-H T L V-1$ & CARNEIRO-PROIETTI et al., 2002 \\
\hline RS & 2,4-HTLV & BARCELLOS et al., 2006 \\
\hline
\end{tabular}




\subsection{Modos de transmissão}

A transmissão pelo HTLV em geral ocorre do mesmo modo que em outros retrovírus, tanto o HTLV-1 como o HTLV-2, podem ser transmitidos através das vias vertical, parenteral e sexual (EDLICH; ARNETTE; WILLIAMS, 2000; MURPHY et al., 2005).

$\mathrm{Na}$ transmissão vertical a amamentação é o meio mais eficaz de contaminação, uma vez que em análises realizadas foi constatada a presença de linfócitos T infectados no leite materno (EDLICH; ARNETTE; WILLIAMS, 2000). Moriuchi e Moriuchi demonstraram em 2001 que a lactoferrina pode induzir à replicação do HTLV-1 em linfócitos de pacientes assintomáticos e via cordão umbilical in vitro, sugerindo que a interação entre esta proteína do leite e o HTLV-1 poderia facilitar a transmissão pela amamentação (MORIUCHI; MORIUCHI, 2001; MORIUCHI; MORIUCHI, 2006).

Um estudo prospectivo avaliou 115 casais sorodiscordantes, sendo que 30 pessoas eram soropositivas para o HTLV-1 e 55 para o HTLV-2 e foi observada a contaminação homem-mulher como sendo a mais eficaz, embora esta diferença não tenha sido considerada estatisticamente significante. (ROUCOUX et al., 2005).

A transfusão de sangue e hemoderivados podem resultar em soroconversão em mais de $40 \%$ dos casos (MANNS et al., 1992). Países como EUA, Japão, Canadá e alguns países europeus realizam screenings rotineiros em seus bancos de sangue (BANGHAM, 2000; ZERVOU et al., 2004). No Brasil os testes anti-HTLV são mandatórios nos hemocentros desde 1993 (CATALAN-SOARES; CARNEIROPROETTI; PROIETTI et al., 2005). 


\subsection{Diagnóstico}

O diagnóstico do HTLV é executado em duas etapas: triagem e confirmação (PROIETTI et al., 2005).

Para a triagem é utilizado o ensaio imunoenzimático (EIA) onde inicialmente usava-se somente o lisado de células infectadas. Na segunda geração foram adicionados peptídeos sintéticos e proteínas recombinantes (THORSTENSSON; ALBERT; ANDERSSON, 2002). Atualmente para aumentar a sensibilidade principalmente para a detecção do HTLV-2, são utilizadas proteínas especificas para o HTLV-2 (THORSTENSSON; ALBERT; ANDERSSON, 2002).

O Western Blot (WB) é o teste mais utilizado para confirmação de diagnostico. Outros exames confirmatórios como a imunofluorescência indireta (IFI) e a radioimunoprecipitação (RIPA) também podem ser usados como testes confirmatórios. A reação de polimerase em cadeia (PCR) é utilizada para a diferenciação entre HTLV-1 e HTLV-2 (PROIETTI et al., 2005).

\subsection{Patogenia}

O principal alvo da infecção pelo HTLV-1 são os linfócitos TCD4+ de memória e secundariamente os linfócitos TCD8+, monócitos, macrófagos, megacariócitos, células dendríticas e células da glia (BANGHAM, 2003; MANEL et al., 2005; SWAINSON et al., 2005). 
Aparentemente as partículas virais do HTLV-1 (RNAm, vírions e proteínas) não são encontradas em quantidade considerável no sangue de pacientes portadores do vírus e, considerando que mais de $30 \%$ das células mononucleares do sangue periférico serão infectadas com o vírus e mais de $50 \%$ das células CD4 poderão estar contaminadas com o vírus, acredita-se que a carga proviral é mantida, predominantemente, por expansão clonal das células hospedeiras (CAVROIS et al., 1998; BANGHAM; OSAME, 2005).

Uma vez que os vírions extracelulares produzidos possuem baixo grau infeccioso, o HTLV-1 utiliza a própria mobilidade celular do hospedeiro para sua disseminação, em um processo especializado vírus-induzido chamado de sinapse viral (CAVROIS et al., 1998; BANGHAM, 2003).

Estudos demonstram que a relação entre a quantidade das células CD8+ ou linfócitos T citotóxicos (LTCs) e a carga viral do hospedeiro são inversamente proporcionais, podendo contribuir para o desenvolvimento de doenças inflamatórias como a TSP/HAM, mas ainda não existem estudos que comprovem a eficácia antiviral das células CD8+ frente ao HTLV-1 (ASQUITH et al., 2005; BANGHAM; OSAME, 2005; VINE et al., 2004).

\subsection{Doenças associadas}

O HTLV-1 tem sido associado definitivamente a dois tipos distintos de doenças incuráveis a TSP/HAM e a ATLL. Os pacientes assintomáticos apresentam 
menos de $5 \%$ de chance de desenvolver estas doenças (EDLICH; ARNETTE; WILLIAMS, 2000).

A infecção pelo HTLV-1 também tem sido relacionada a outras alterações menos freqüentes como as polimiosites, artropatias, dermatites infecciosas, uveítes, imunossupressão, pneumopatias e síndrome de Sjögren (SS) (Tabela 2.2) (NAKAMURA et al., 1997; EDLICH; ARNETTE; WILLIAMS, 2000; VERDONCK et al., 2007).

Tabela 2.2- Doenças associadas ao HTLV (Adaptado de VERDONCK et al., 2007)

\section{Doenças associadas ao HTLV}

De origem inflamatória

TSP/HAM

Artropatias

Polimiosites

Síndrome de Sjögren

Pneumopatias

Alveolites de células T

Tireoidites

Uveítes
Neoplasias malignas

ATLL

Linfoma cutâneo de células $\mathrm{T}$
Doenças infecciosas

Estrongiloidíase

Dermatites infecciosas

Tuberculose

\subsubsection{ATLL}

A ATLL é uma neoplasia hematopoiética dos linfócitos T CD4+ de progressão rápida e prognóstico ruim. Os pacientes que desenvolvem a ATLL apresentam uma taxa de sobrevida média de 24 meses (TSUKASAKI; KOEFFLER; TOMONAGA , 2000). É mais freqüente em países onde o HTLV-1 é endêmico, como o sudoeste japonês (PROIETTI et al., 2005) e acomete geralmente 
pacientes que apresentam mais de 20 anos de infecção pelo HTLV-1 (PROETTI et al., 2005).

As manifestações clínicas observadas na ATLL são o mal estar, febre, linfadenopatia, hepatoesplenomegalia, perda de peso, lesões cutâneas, icterícia, sede, fatiga e imunossupressão (BANGAHAM, 2000; TSUKASAKI; KOEFFLER; TOMONAGA , 2000).

No sangue periférico é observada a alteração da morfologia nuclear do linfócito T que apresenta um núcleo multilobulado com o aspecto de 'flor' (flower cells). Outros achados laboratoriais incluem alterações como hipercalcemia e altas concentrações de dehidrogenase lática. As células leucêmicas em análise imunoistoquímica possuem marcação positiva para CD4 na grande maioria dos casos e geralmente positiva para CD25 (positivo para receptor a de IL-2) (BANGAHAM, 2000; CARNEIRO-PROIETTI et al., 2002).

\subsubsection{ATLL em cavidade bucal}

Relatos de caso descreveram o surgimento de ATLL em cavidade oral, onde na maioria dos casos foi verificado que os pacientes acometidos pela ATLL não possuíam soropositividade conhecida para o HTLV-1 (ALBUQUERQUE et al., 2005; OBAMA et al., 2004; SEGAMI et al., 1990; TAKASE et al., 2005; TONG et al., 2004). A Tabela 2.3 mostra os casos de ATLL em cavidade oral relatados na literatura. 
Tabela 2.3- ATLL em cavidade bucal

\begin{tabular}{|c|c|c|c|c|}
\hline Autores & Ano & Localização & $\begin{array}{c}\text { Soropositividade } \\
\text { para o HTLV }\end{array}$ & País \\
\hline Segami et al & 1990 & Língua & Desconhecida & Japão \\
\hline Obama et al & 2004 & Glândula Parótida & Desconhecida & Japão \\
\hline Tong et al & 2004 & Glândula Parótida & Desconhecida & Japão \\
\hline Albuquerque et al & 2005 & Palato & Desconhecida & Brasil \\
\hline Takase et al & 2005 & $\begin{array}{l}\text { Glândulas Parótida e } \\
\text { submandibulares }\end{array}$ & Conhecida & Japão \\
\hline
\end{tabular}

\subsubsection{TSP/HAM}

A TSP/HAM é uma doença inflamatória crônica progressiva desmielinizante que acomete os pacientes portadores do HTLV-1 após um longo período de incubação. A TSP/HAM afeta a medula espinhal torácica e a substância branca do cérebro resultando no espessamento leptomeníngeo e atrofia medular (CASSEB; PENALVA de OLIVEIRA, 2000; RIBAS; MELO, 2002).

Os principais sinais e sintomas da TSP/HAM são a paraparesia espástica progressiva, distúrbios esfincterianos, com leve ou nenhuma perda sensorial, disfunção erétil no homem e ausência de compressão na medula espinhal (CASSEB; PENALVA de OLIVEIRA, 2000).

Histologicamente, a TSP/HAM apresenta infiltração linfocitária perivascular, desmielinização, degeneração axonal e gliose (OSAME, 2002). 
2.7.4 Patogênese das doenças inflamatórias associadas ao HTLV-1

A patogênese das doenças inflamatórias relacionadas ao HTLV-1 ainda não foi totalmente desvendada, sendo que a hipótese mais aceita é a resposta autoimune vírus induzida. As células T CD4+ em contato com o HTLV -1 produzem a interleucina-2 (IL-2) que estimula a produção dos linfócitos T citotóxicos (LTCs). A proteína tax viral transativa a IL-2 (receptor da IL- 2 e a IL-15), evento que irá prejudicar a produção, manutenção e expansão de memória das LTCs, que se tornarão ineficazes frente ao vírus, aumentando assim a CV e a expressão da tax, aumentando também a quantidade das células T CD4+ infectadas ou sensibilizadas para o HTLV, podendo estabelecer um foco inflamatório com liberação de produtos que irão provocar a destruição tecidual (BANGHAM; OSAME, 2005).

Na TSP/HAM o estímulo de tax também irá facilitar a transposição das células CD4+ sensibilizadadas/infectadas frente à barreira hemato-encefálica contaminando assim o sistema nervoso central (SNC) (BANGHAM, 2003; CRAVOIS et al., 2000).

\subsubsection{Alterações bucais relacionadas ao HTLV}

Mesmo que na literatura não sejam evidenciados trabalhos que verifiquem as alterações bucais em pacientes soropositivos para o HTLV, além dos poucos relatos de caso de ATLL em cavidade bucal, alguns autores relacionam o HTLV-1 à SS (TERADA et al., 1994). 
A SS é uma doença autoimune, caracterizada pela inflamação das glândulas exócrinas e produção sistêmica de auto-anticorpos sendo que os pacientes acometidos apresentam queratoconjuntivite e Sicca - presença de mucosas oculares e orais ressecadas (JORDAN et al., 1995; TALAL, 1992).

A SS interfere diretamente no manejo odontológico. O paciente acometido pela SS apresenta dificuldade de deglutição e fonação, risco de cárie e doença periodontal aumentados e a predisposição a doenças oportunistas como candidíase (KASSAN; MOUTSOPOULOS, 2004). A SS também é associada ao risco aumentado para o desenvolvimento de linfomas não - Hodgkin (LNH) (JORDAN et al., 1995).

Terada et al. (1994) avaliaram somente pacientes do sexo feminino, sendo que 74 eram portadoras da SS, 71 com lúpus eritematoso eram o controle sistêmico e 27.294 eram o controle normorreativo. A proposição do trabalho era investigar a prevalência do HTLV-1 nos grupos estudados. A prevalência de HTLV-1 foi maior no grupo formado por mulheres positivas para SS (TERADA et al., 1994).

Esse estudo gerou subsídios que influenciaram trabalhos que foram realizados posteriormente.

Nakamura et al. (1997), compararam 6 pacientes soropositivos para o HTLV1, SS e para a TSP/HAM, 20 pacientes soropositivos para o HTLV-1 e para SS e 20 pacientes soronegativos para o HTLV-1 e positivos para a SS. Em todos os grupos a maior parte dos pacientes analisados eram do sexo feminino, foram comparados testes para verificação de auto-anticorpos no sangue (anti SS-A, anti SS-B e fator reumatóide), testes imunoistoquímicos (em biópsias de glândulas salivares menores) e foi concluído que a presença de auto-anticorpos se mostrava semelhantes em todos os grupos estudados assim como a análise imunoistoquímica das biópsias 
coletadas em 6 pacientes do primeiro grupo, 3 do segundo grupo e 10 do terceiro grupo, onde os as células CD3 e CD4 os tipos celulares mais identificados nos infiltrados inflamatórios glândulas salivares menores correspondentes (NAKAMURA et al., 1997).

No mesmo ano, Yamano e colaboradores realizaram uma investigação sobre a presença dos vírus HIV e HTLV-1 através da técnica da PCR-RT no infiltrado inflamatório de glândulas salivares menores em 15 pacientes do sexo feminino portadoras da SS, o grupo controle era formado por 10 necrópsias de glândulas salivares menores obtidas de pacientes saudáveis. Nenhuma paciente apresentou sopositividade para o HTLV-1 e para o HIV, também não foram identificados os genes alvo (p24 gag) para o HIV e HTLV-1 e foi concluído que os achados deste estudo não foram conclusivos para que os retrovírus possam ser considerados como agentes causais para o desenvolvimento da SS (YAMANO et al., 1997).

Posteriormente em 1999, Merle et al. analisaram um grupo de pacientes formado por 15 pacientes soropositivos (13 mulheres e 2 homens) para o HTLV-1, TSP/HAM e queratoconjuntivite seca, onde foram estudados os aspectos clínicos e imunológicos destes pacientes. Foram realizados exames clínicos e laboratoriais para possível identificação de co-morbidades. Testes oculares, análise histológica das glândulas salivares menores de acordo com o critério de Chisholm e Mason, oriundas de biópsias de todos os pacientes. Foram realizados também exames imunológicos (anti-SS-A, anti-SS-B e fator reumatóide). Todos os pacientes deste estudo foram negativos para a presença de auto-anticorpos, logo, nenhum paciente era portador da SS (MERLE et al., 1999).

Em um trabalho publicado em 1999, Hida e colaboradores analisaram a prevalência de auto-anticorpos (anti-SS-A, anti-SS-B, fator reumatóide, anticorpos 
anti-núcleo e anticorpos anti-centrômero) em pacientes portadores da SS soropositivos ou não para o HTLV-1. O grupo teste incluiu 135 (8 homens e 127 mulheres) pacientes portadores de SS primária e 97 (10 homens e 87 mulheres) pacientes portadores da SS secundária. O secundo grupo era formado por pacientes com artrite reumatóide, lúpus eritematoso e outras doenças auto-imunes. Foram executados testes sorológicos para a identificação do HTLV-1, onde 50 pacientes foram reagentes para o vírus. Quando foram comparados os grupos portadores da SS negativos e positivos para o HTLV-1, foi verificada que a presença dos autoanticorpos foi semelhantes em todos os pacientes estudados, exceto pela menor prevalência de anticorpos anti-centrômero no soro de pacientes positivos para o HTLV-1 e a SS (HIDA et al., 1999).

Nakamura et al., em 2000, compararam as características histopatológicas das biópsias de glândulas salivares menores em 13 pacientes portadores da SS e do HTLV-1, 9 pacientes soropositivos para o HTLV-1 e não portadores da SS e 60 e soronegativos para o HTLV-1 e portadores da SS. Os resultados sugeriram que pacientes soropositivos para a SS e para o HTLV-I apresentaram um grau de infiltrado inflamatório mononuclear maior em glândulas salivares menores se comparados com pacientes portadores da SS e negativos para o HTLV1(NAKAMURA et al., 2000).

Os trabalhos investigativos sobre a relação entre o HTLV-1 e o possível desenvolvimento da SS foram realizados envolvendo geralmente pacientes portadores da SS com sorologia desconhecida para o HTLV onde foram aplicados e comparados testes sorológicos, imunológicos (auto-anticorpos) e análises histológicas e exames biomoleculares de glândulas salivares menores e na maioria destes estudos foi constatado que não haviam diferenças significativas entre os 
pacientes estudados (CARTIER; VERGARA; RAMÍREZ, 2005; EGUCHI et al., 1992; OHYAMA et al., 1998; SASAKI et al., 2000;).

Estes estudos geralmente foram desenvolvidos no sudoeste japonês, que é considerado a região mais endêmica para o vírus no mundo (PROIETTI et al., 2005). Estes trabalhos foram caracterizados muitas vezes por amostragens pequenas e participantes do sexo feminino localizadas geralmente, na $3^{a}$ ou $4^{a}$ década de vida, pacientes que apresentam predisposição para 0 desenvolvimento da $S S$ (CASSOLATO; TUNRBULL, 2003).

Recentemente foi realizado na Bahia um estudo onde foram avaliados 115 (66 homens e 49 mulheres) pacientes soropositivos do HTLV-1 não portadores da TSP/HAM e 115 (66 homens e 49 mulheres) pacientes soronegativos para o HTLV1, cujo objetivo foi determinar a prevalência de manifestações clínicas associadas ao HTLV-1. Neste trabalho os pacientes responderam um questionário desenvolvido para o estudo e foram submetidos a exames clínicos. Os pacientes foram examinados por uma dentista que avaliou a presença da gengivite através de aspecto visual (tumefação, sangramento e eritema) e verificação de mobilidade dental. Foram analisados também os relatos da presença da sensação de boca seca (xerostomia). Os principais achados bucais deste estudo foram a xerostomia $(20,8 \%)$ e o sangramento gengival (34,2\%) (CASKEY et al., 2007). 


\section{PROPOSIÇÃO}

O objetivo deste trabalho é conhecer melhor uma população HTLV+, identificando alterações bucais estomatológicas e determinando a possibilidade epidemiológica destas estarem vinculadas com a infecção pelo vírus. 


\section{MATERIAL E MÉTODOS}

O projeto desta pesquisa foi aprovado pelo Comitê de Ética em Pesquisa do Instituto de Infectologia Emílio Ribas (IIER) em 23 de fevereiro de 2005 (parecer $\mathrm{N}^{\circ}$ 057/04 - anexo A).

Foram avaliados os pacientes soropositivos para o HTLV atendidos no Instituto de Infectologia Emílio Ribas, no período de abril de 2005 a setembro de 2006, sendo que alguns deles faziam tratamento dentário no Centro de Atendimento a Pacientes Especiais (CAPE) da Faculdade de Odontologia da Universidade de São Paulo (FOUSP).

Todos os pacientes, antes de serem submetidos à avaliação clínica (anexo B), assinaram o termo de consentimento livre e esclarecido (anexo C).

A avaliação odontológica foi executada por 1 cirurgiã dentista, com experiência clínica no diagnóstico de lesões bucais. O exame odontológico foi realizado em ambulatório médico, com o auxílio de luz artificial (lanterna) e espátulas de madeira.

A avaliação odontológica constou de anamnese e exame físico, seguindo ficha específica para a colheita de dados desenvolvida para este estudo (anexo B).

$\mathrm{Na}$ anamnese foram colhidas as seguintes informações: nome, endereço, cidade telefone, sexo, década de vida, cor da pele, naturalidade, nacionalidade, estado civil, ascendência, profissão, tipo de HTLV, positividade para TSP/HAM, presença de sintomatologia associada ao TSP/HAM (constipação, incontinência, dor em membros inferiores e superiores, parestesia em membros inferiores e superiores, 
lombalgias), data do teste para sorologia do HTLV, motivo do teste, meio de transmissão, co-morbidades: cardiopatias, doenças gastrintestinais, hipertensão arterial sistêmica (HAS), anemias, diabetes, doenças dermatológicas, co-infecções: vírus da imunodeficiência humano (HIV), vírus da hepatite tipo C e B (HCV e HBV) hábitos deletérios (tabagismo, etilismo e uso de drogas), os tipos e a freqüência de uso de medicações, valores de CD4, CD8 e CV.

Os pacientes que apresentaram lesões estomatológicas passíveis de diagnóstico histopatológico foram encaminhados para o ambulatório de odontologia do IIER para a execução de biópsia. O material colhido, fixado em formol a 10\%, era posteriormente enviado ao Laboratório de Patologia Cirúrgica da Disciplina de Patologia Bucal da Faculdade de Odontologia da Universidade de São Paulo para processamento.

Os dados colhidos durante a anamnese e exame físico foram transferidos para um programa de computador desenvolvido pelo CDC (Centers For Disease Control \& Prevention), o Epi Info ${ }^{\mathrm{TM}}$, versão 3.3 .2 (Centers for Disease Control \& Prevention \& World Health Organization, 2005).

Dentro desse programa foi desenvolvido um banco de dados, a partir das informações presentes na ficha clínica do paciente. A cada variável foi atribuído um campo em branco que foi preenchido com um valor. Esse valor poderia ser numérico (números de 0 a 9); uma data (3 pares de números separados por 2 barras); uma letra (significando sim ou não) ou diversas letras para a construção de palavras.

As análises estatísticas foram realizadas utilizando o pacote estatístico SPSS - Statistical Package for Social Sciences (v16.0). Para a comparação entre as variáveis qualitativas foi utilizado o teste exato de Fisher para tabelas $2 \times 2$ e o método de simulação de Monte-Carlo para a estimativa do valor de $p$ em tabelas 
3x2. Para comparação de dados quantitativos foi utilizadol o Teste de KrusKalWallis. O nível de significância foi estabelecido como 0,05 ou $5 \%$. Também foi executada regressão Logística Multivariada para identificação de risco independente entre alterações bucais e as variáveis do estudo. 


\section{RESULTADOS}

Foram tabulados os dados demográficos, os dados médico-clínicos relativos à infecção pelo HTLV e os dados relativos às alterações bucais de 139 pacientes HTLV+.

5.1 Dados demográficos

Os dados demográficos permitiram a obtenção de informações sobre sexo, faixa etária, cor da pele, grau de instrução, estado civil e naturalidade.

A colheita dessas informações está vinculada a transmissão e a incidência do HTLV.

Dos 139 pacientes HTLV+ avaliados, 86 (61,9\%) eram do sexo feminino e 53 $(38,1 \%)$ do sexo masculino (Figura 5.1). 


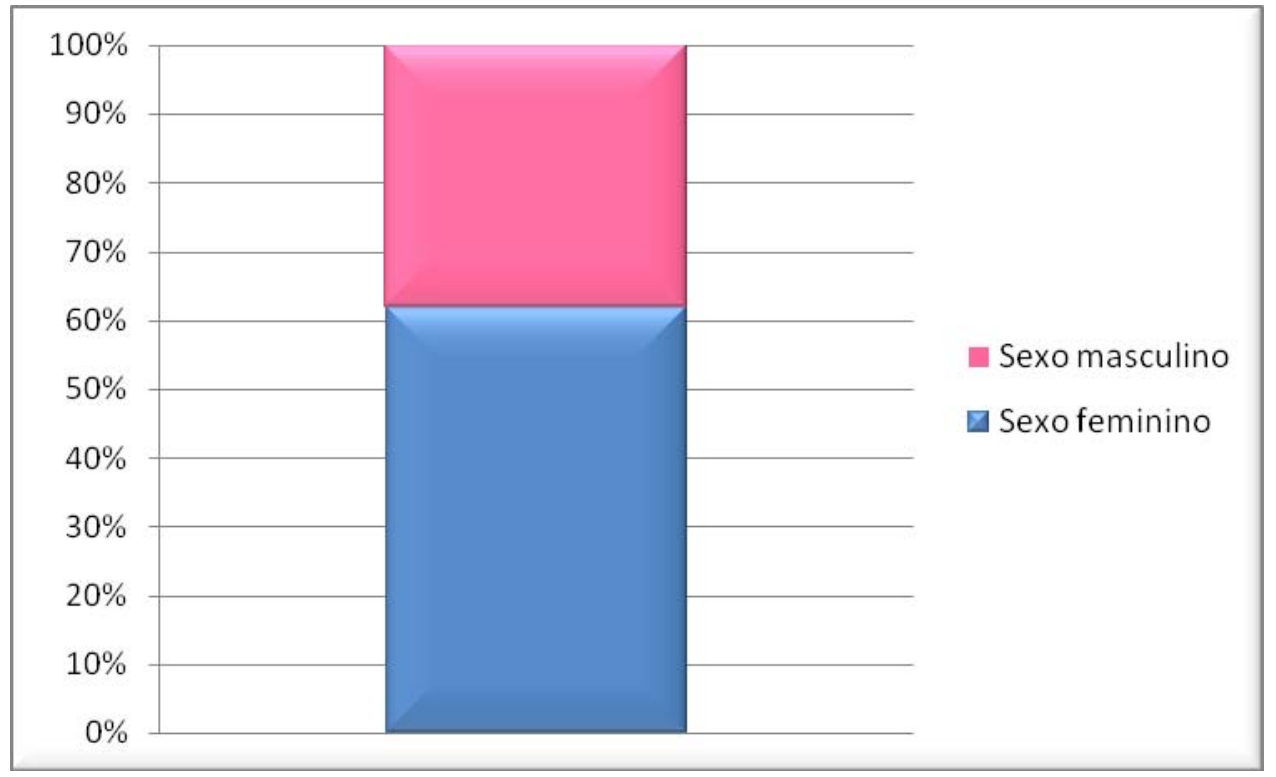

Figura 5.1- Distribuição em porcentagem de 139 pacientes HTLV+ segundo o sexo

Quanto à idade, os pacientes foram divididos em faixas etárias, de acordo com a década de vida em que se encontravam. A prevalência de pacientes HTLV+ em cada faixa etária está demonstrada na Figura 5.2. Um paciente apresentava-se abaixo da primeira década de vida $(0,7 \%), 6$ na primeira $(4,3 \%), 36$ na segunda (25,9\%), 48 na terceira $(34,5 \%), 37$ na quarta $(26,6 \%), 8$ na quinta $(5,8 \%)$ e 3 pacientes $(2,2 \%)$ apresentava-se na sexta. 


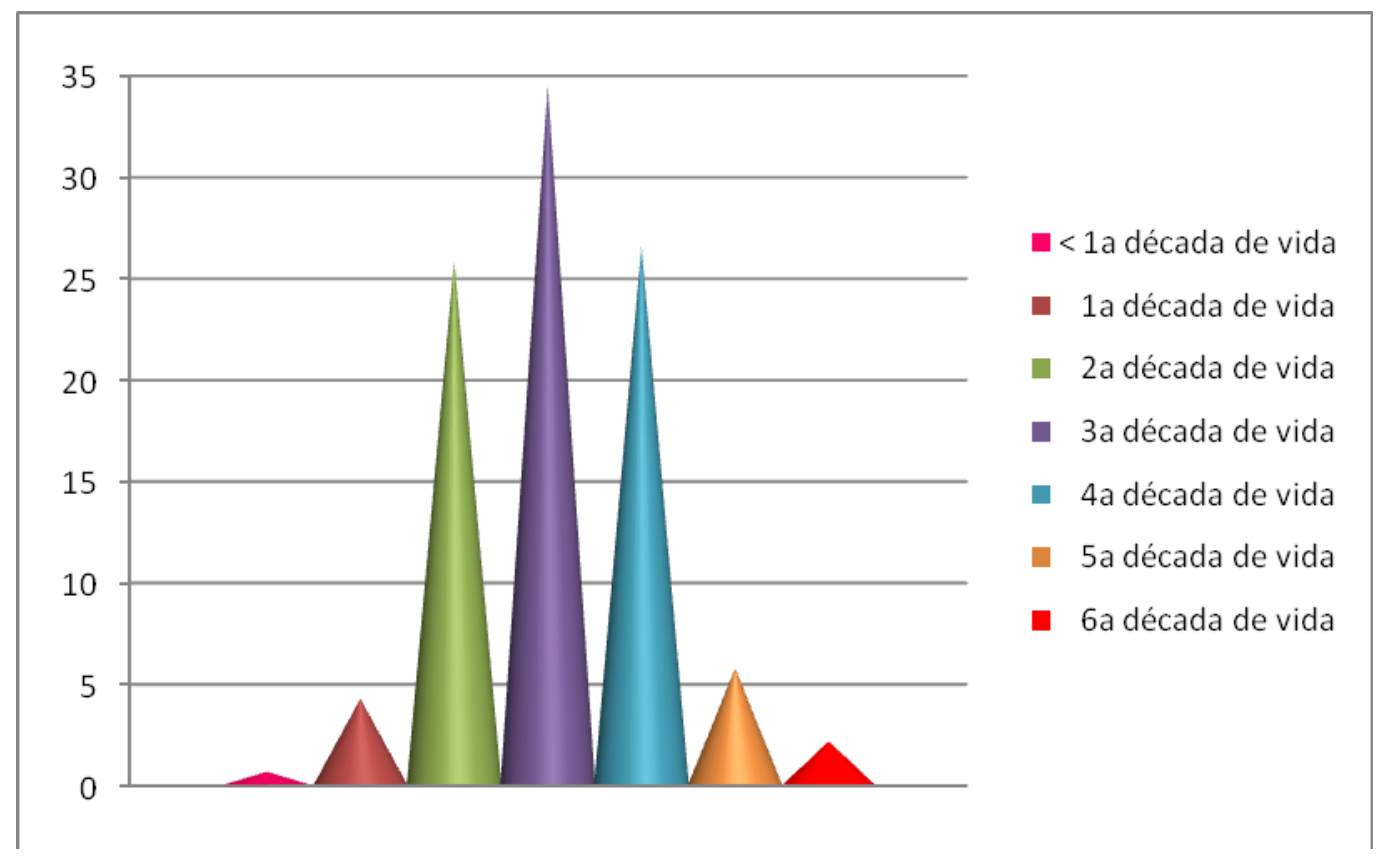

Figura 5.2- Distribuição em porcentagem dos pacientes HTLV+ segundo a década de vida $(n=139)$.

A prevalência de faixa etária também foi avaliada segundo o sexo dos pacientes (Tabela 5.1).

Tabela 5.1- Prevalência de pacientes HTLV+ segundo a faixa etária e o sexo em números absolutos e porcentagem $(n=139)$

\begin{tabular}{|c|c|c|c|c|c|c|c|c|}
\hline \multirow[t]{2}{*}{ Sexo } & \multicolumn{7}{|c|}{ Década de Idade } & \multirow{2}{*}{ TOTAL } \\
\hline & $<1^{\mathrm{a}}$ & $1^{a}$ & $2^{a}$ & $3^{a}$ & $4^{a}$ & $5^{a}$ & $6^{a}$ & \\
\hline Feminino & 0 & 6 & 20 & 28 & 24 & 7 & 0 & 86 \\
\hline Linha \% & 0,0 & 7,0 & 23,3 & 32,6 & 27,9 & 8,1 & 1,2 & 100,0 \\
\hline Coluna \% & 0,0 & 100,0 & 54,1 & 58.3 & 64,9 & 87,5 & 33,3 & 60,9 \\
\hline Masculino & 1 & 0 & 16 & 20 & 13 & 1 & 2 & 53 \\
\hline Linha \% & 1,9 & 0,0 & 30,2 & 37,7 & 24,5 & 1,9 & 3,8 & 100,0 \\
\hline Coluna \% & 100,0 & 0,0 & 44,4 & 42,9 & 35,1 & 12,5 & 100,0 & 38,1 \\
\hline TOTAL & 1 & 6 & 36 & 48 & 37 & 8 & 3 & 139 \\
\hline Linha \% & 0,7 & 4,3 & 25,9 & 34,5 & 26,6 & 5,8 & 2,2 & 100,0 \\
\hline Coluna \% & 100,0 & 100,0 & 100,0 & 100,0 & 100,0 & 100,0 & 100,0 & 100,0 \\
\hline
\end{tabular}


Quanto a cor da pele $57,6 \% \quad(n=80)$ eram leucodermas, $23,7 \% \quad(n=33)$ feodermas, $15,1 \%(n=21)$ melanodermas e apenas 3,6\% $(n=5)$ xantodermas (Figura $5.3)$

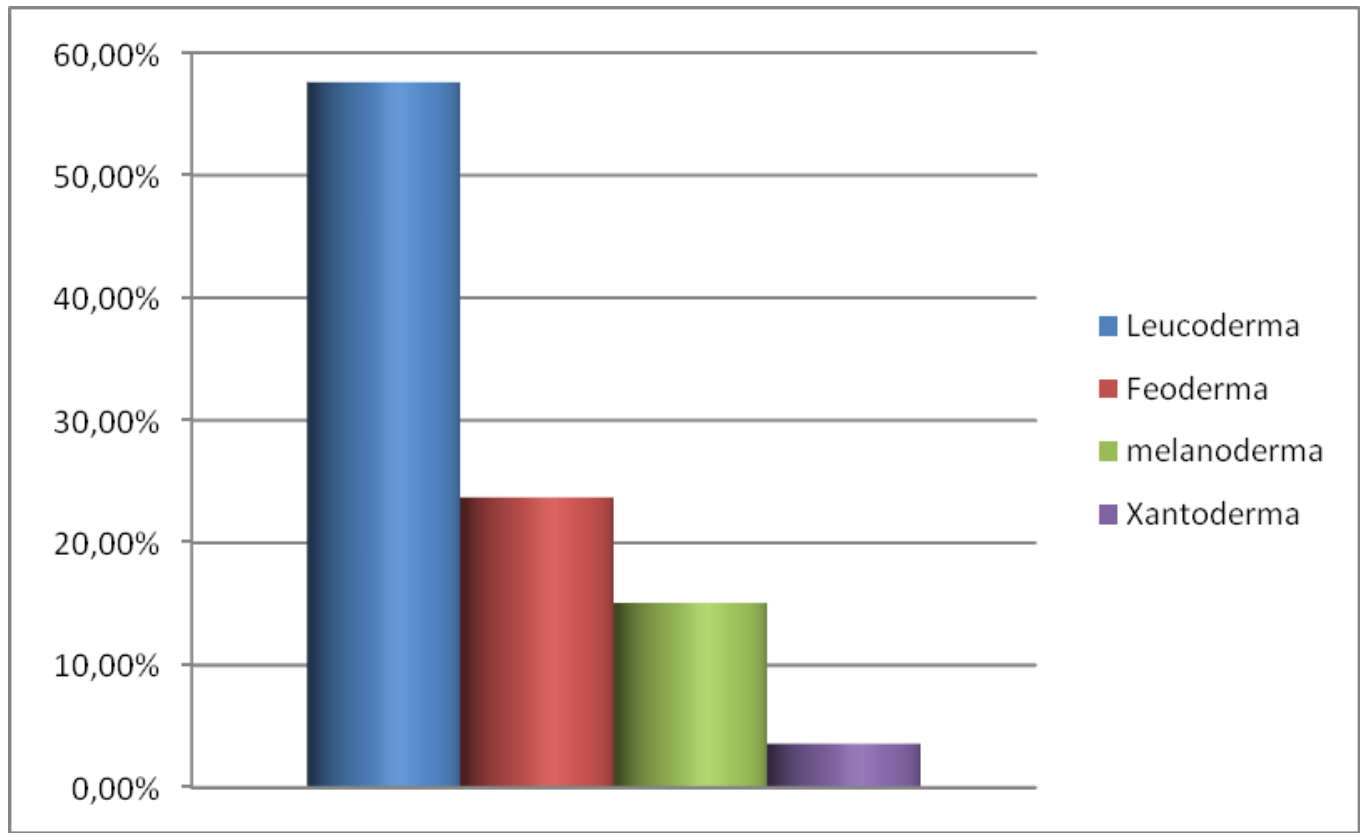

Figura 5.3- Distribuição porcentual dos pacientes HTLV+ segundo a cor da pele $(n=139)$

Quando solicitamos informações sobre o grau de instrução dos 139 pacientes, cinco não responderam. Entre os 134 que responderam a esta pergunta $54,4 \%$ tinham até o primeiro grau de instrução, seguidos de $34,3 \%$ com até o segundo grau, 6,7\% com nível superior e $4,4 \%$ de analfabetos (Tabela 5.2). 
Tabela 5.2- Grau de instrução declarado por 134 pacientes HTLV+ segundo o sexo

\begin{tabular}{lccc}
\hline \multicolumn{1}{c}{ ESCOLARIDADE } & \multicolumn{2}{c}{ SEXO } & \multirow{2}{*}{ TOTAL } \\
\cline { 2 - 3 } & FEMININO & MASCULINO & N (\%) \\
\cline { 2 - 3 } & $\mathbf{N}(\%)$ & $\mathbf{N}(\%)$ & $73(54,4 \%)$ \\
Até o primeiro grau & $44(32,8 \%)$ & $29(21,6 \%)$ & $46(34,3 \%)$ \\
\hline Até o segundo grau & $30(22,3 \%)$ & $16(11,9 \%)$ & $6(4,4 \%)$ \\
Analfabeto & $3(2,2 \%)$ & $3(2,2 \%)$ & $9(6,7 \%)$ \\
Superior & $6(4,4 \%)$ & $3(2,2 \%)$ & $134(100 \%)$ \\
\hline TOTAL & 83 & 51 & \\
\hline
\end{tabular}

Com relação ao estado civil dos pacientes, apenas 130 responderam a essa pergunta, sendo 55 pacientes casados $(42,3 \%), 41$ se declararam solteiros $(31,5 \%)$, 19 viúvos $(14,6 \%)$ e 15 divorciados $(11,5 \%)$ (Tabela 5.3$)$.

Tabela 5.3- Estado civil dos pacientes HTLV+ segundo o sexo

\begin{tabular}{rrrr}
\hline Civil & Feminino & Masculino & \multicolumn{1}{r}{ TOTAL } \\
\hline Casado & 35 & 19 & 54 \\
linha \% & 64,8 & 35,2 & 100,0 \\
Coluna \% & 42,7 & 39,6 & 41,5 \\
Divorciado & 9 & 60,0 & 15 \\
linha \% & 60,0 & 12,5 & 100,0 \\
Coluna \% & 11,0 & 20 & 11,5 \\
Solteiro & 22 & 47,6 & 42 \\
& 52,4 & 41,7 & 100,0 \\
Linha \% & 26,8 & & 32,3 \\
Coluna \% & & 3 & 19 \\
Viúvo & 16 & 15,8 & 100,0 \\
Linha \% & 84,2 & 6,3 & 14,6 \\
Coluna \% & 19,5 & & 130 \\
TOTAL & & 48 & 100,0 \\
Linha \% & 82 & 36,9 & 100,0 \\
Coluna \% & 100,0 & 100,0 & \\
\hline
\end{tabular}


A naturalidade do paciente foi outra avaliação demográfica executada, sendo revelada por 136 pacientes. Ainda que a maioria dos pacientes $(47,1 \%)$ fosse oriunda da cidade de São Paulo, o IIER também recebia pacientes nascidos em outros estados do Brasil. A tabela 5.4 evidencia a freqüência de pacientes segundo sua naturalidade.

Tabela 5.4 - Distribuição geográfica em território brasileiro de 136 pacientes soropositivos para o HTLV, segundo sua naturalidade

\begin{tabular}{lccc}
\hline NATURALIDADE & FREQUÊNCIA & PORCENTUAL & $\begin{array}{c}\text { PORCENTAGEM } \\
\text { CUMULATIVA }\end{array}$ \\
\hline ALAGOAS & 5 & $3,7 \%$ & $3,7 \%$ \\
\hline BAHIA & 22 & $16,2 \%$ & $19,9 \%$ \\
\hline CEARÁ & 2 & $1,5 \%$ & $21,3 \%$ \\
\hline ESPÍRITO SANTO & 1 & $0,7 \%$ & $22,1 \%$ \\
\hline MARANHÃO & 1 & $0,7 \%$ & $22,8 \%$ \\
\hline MINAS GERAIS & 9 & $6,6 \%$ & $29,4 \%$ \\
\hline PARAÍBA & 4 & $2,9 \%$ & $32,4 \%$ \\
\hline PERNAMBUCO & 10 & $7,4 \%$ & $39,7 \%$ \\
\hline PIAUÍ & 1 & $0,7 \%$ & $40,4 \%$ \\
\hline PARANÁ & 7 & $5,1 \%$ & $45,6 \%$ \\
RIO DE JANEIRO & 4 & $2,9 \%$ & $48,5 \%$ \\
\hline RIO GRANDE DO NORTE & 2 & $1,5 \%$ & $50,0 \%$ \\
\hline RIO GRANDE DO SUL & 2 & $1,5 \%$ & $51,5 \%$ \\
\hline SÃO PAULO & 64 & $47,1 \%$ & $98,5 \%$ \\
\hline SUIÇA & 1 & $0,7 \%$ & $99,3 \%$ \\
\hline TRIBO INDÍGENA & 1 & $0,7 \%$ & $100,0 \%$ \\
\hline TOTAL & 136 & $100,0 \%$ & $100,0 \%$ \\
\hline
\end{tabular}


Assim, a região sudeste foi a região de origem mais prevalente entre os pacientes $57,1 \%(n=78)$, seguida da região nordeste com $34,8 \%$ pacientes $(n=47)$ e pela região sul com 6,7\% (n=9) (Figura 5.4).

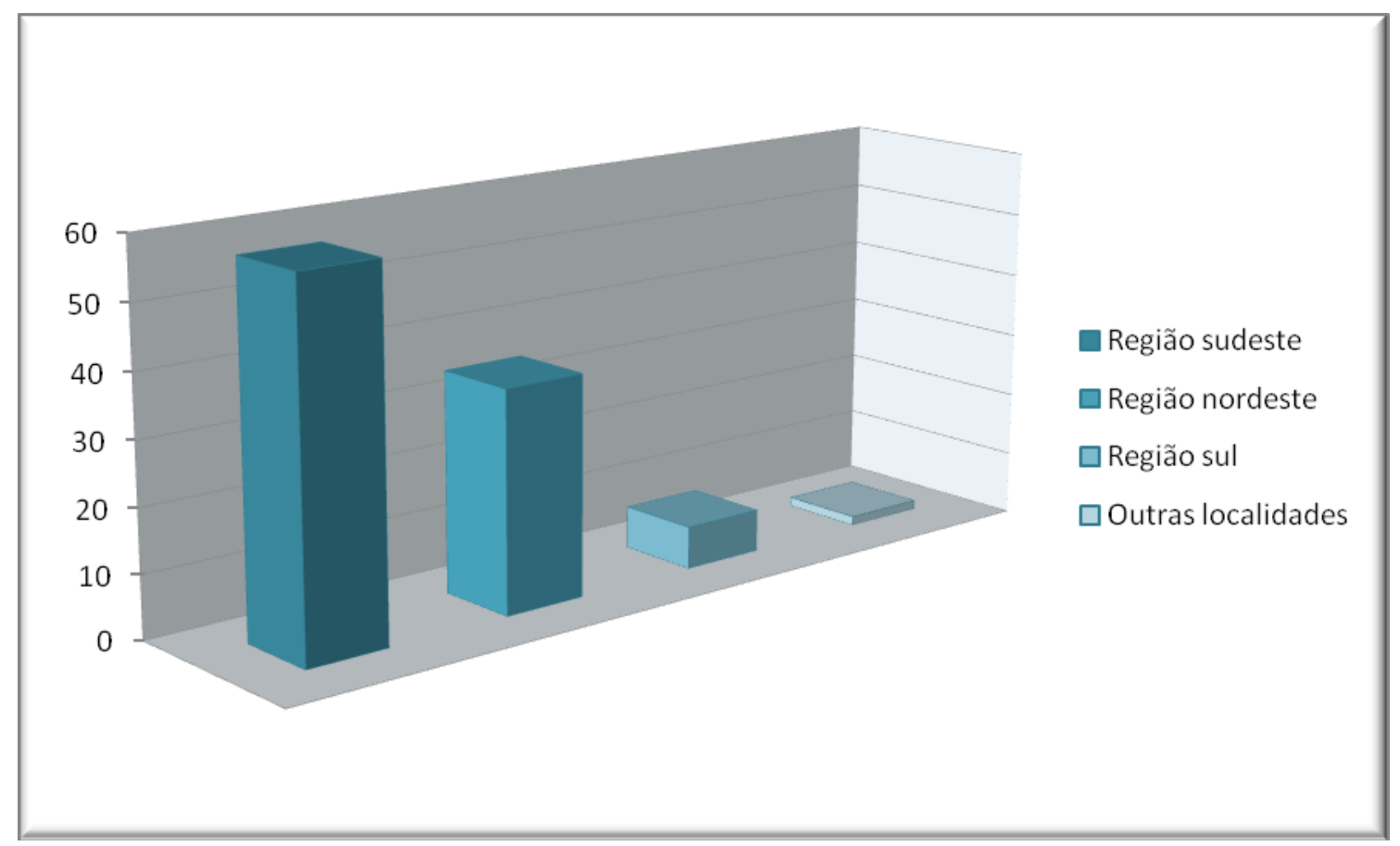

Figura 5.4- Regiões brasileiras de maior prevalência nos pacientes estudados (em porcentagem)

\subsection{Dados médico-clínicos relativos à infecção pelo HTLV}

Foram tabulados os seguintes dados clínicos dos pacientes, relativos à infecção pelo HTLV: categoria de exposição ao vírus, motivo de execução da sorologia, presença de co-morbidades e co-infecções, medicações em uso, níveis de CD4, CD8 e carga viral, tempo de seguimento do paciente no ambulatório e subtipos virais. 
Ao serem inquiridos sobre a possível forma de contaminação com o vírus $59,7 \%$ (n=83) dos pacientes não sabiam identificar a provável categoria de exposição. Os restantes relataram 4 diferentes vias prováveis: sexual $(18 \% ; n=25)$, transfusão $(7,9 \% ; n=11)$, uso de drogas injetáveis (UDI) $(7,9 \% ; n=11)$, transmissão vertical $(6,5 \% ; n=9)$ (Figura 5.5).

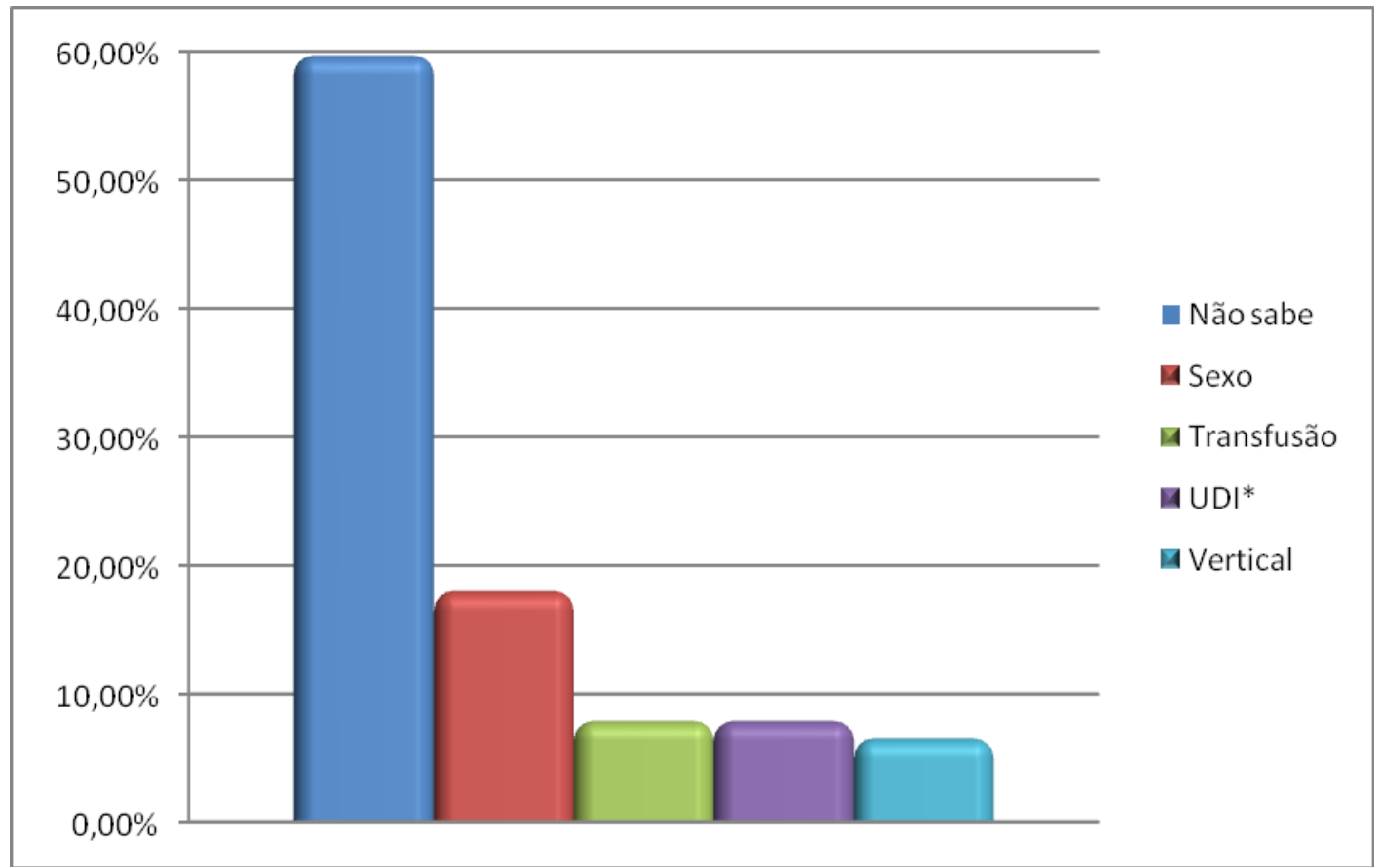

Figura 5.5- Distribuição porcentual da categoria de exposição ao HTLV relatada pelos pacientes $(n=139)$

* Uso de drogas injetáveis.

A categoria de contaminação predominantemente relatada pelos pacientes foi avaliada também segundo o sexo (tabela 5.5). Os meios de exposição mais prevalentes observados em mulheres foram através da via sexual $(20,9 \%)$, transfusão $(9,3 \%)$ e transmissão vertical $(5,8 \%)$. 
Já os pacientes do sexo masculino relataram como possíveis vias de contaminação o uso de drogas injetáveis $(15,1 \%)$, a via sexual $(13,2 \%)$ e a vertical $(7,5 \%)$.

Tabela 5.5- Categoria de transmissão relatada pelos pacientes HTLV+ segundo o sexo $(n=139)$

\begin{tabular}{rrrrrrr}
\hline Gênero & Não sabe & Sexo & Transfusão & UDI & Vertical & Total \\
\hline Feminino & 52 & 18 & 8 & 3 & 5 & 86 \\
Linha \% & 60,5 & 20,9 & 9,3 & 3,5 & 5,8 & 100,0 \\
Coluna \% & 62,7 & 72,0 & 72,7 & 27,3 & 55,6 & 61,9 \\
& & & & & & 53 \\
Masculino & 31 & 7 & 3 & 8 & 4 & 100,0 \\
Linha \% & 58,5 & 13,2 & 5,7 & 15,1 & 7,5 & 38,1 \\
Coluna\% & 37,3 & 28,0 & 27,3 & 72,7 & 44,4 & 139 \\
TOTAL & 83 & 25 & 11 & 11 & 9 & 100,0 \\
Linha \% & 59,7 & 18,0 & 7,9 & 7,9 & 6,5 & 100,0 \\
Coluna \% & 100,0 & 100,0 & 100,0 & 100,0 & 100,0 & \\
\hline
\end{tabular}

Dentre os motivos que levaram 139 pacientes HTLV+ a executar a sorologia, o principal foi a doação de sangue $(38,8 \%)$. Os motivos que levaram os pacientes a executar a sorologia para o HTLV estão listados na tabela 5.6. 
Tabela 5.6- Freqüência do motivo da realização do teste anti-HTLV em 139 pacientes soropositivos para o HTLV

\begin{tabular}{lccc}
\hline Teste & Freqüência & $\%$ & $\%$ Cumulativo \\
\hline Companheiro HIV + & 2 & $1,4 \%$ & $1,4 \%$ \\
\hline Companheiro HTLV + & 7 & $5,1 \%$ & $6,5 \%$ \\
\hline Dificuldade ambulação & 11 & $8,0 \%$ & $14,5 \%$ \\
\hline Dificuldade urinar & 1 & $0,7 \%$ & $15,2 \%$ \\
\hline Doação de sangue & 54 & $38,4 \%$ & $53,6 \%$ \\
\hline Dor coluna & 1 & $0,7 \%$ & $54,3 \%$ \\
\hline Dor lombar & 1 & $0,7 \%$ & $55,1 \%$ \\
\hline Dor mmii * & 15 & $10,9 \%$ & $65,9 \%$ \\
\hline Emagrecimento súbito & 1 & $0,7 \%$ & $66,7 \%$ \\
\hline Exame anti HIV & 2 & $1,4 \%$ & $68,1 \%$ \\
\hline Exames pré-operatórios & 3 & $2,2 \%$ & $70,3 \%$ \\
\hline Exames rotina & 12 & $8,7 \%$ & $79,0 \%$ \\
\hline Filho HTLV+ & 3 & $2,2 \%$ & $81,2 \%$ \\
\hline Internação & 6 & $4,3 \%$ & $85,5 \%$ \\
\hline Mãe positiva & 3 & $2,2 \%$ & $87,7 \%$ \\
\hline Não respondeu & 10 & $7,2 \%$ & $94,9 \%$ \\
\hline Não sabe & 1 & $0,7 \%$ & $95,7 \%$ \\
\hline Suspeita médica & 6 & $4,3 \%$ & $100,0 \%$ \\
\hline Total & 139 & $100,0 \%$ & $100,0 \%$ \\
\hline
\end{tabular}

* membros inferiores

Muitos dos pacientes soropositivos para o HTLV também apresentavam outras doenças sistêmicas. Em 87 (62,5\%) pacientes foram identificadas comorbidades e co-infecções. As co-morbidades, identificadas em 80 pacientes, foram diabetes, hepatopatias, doenças renais, cardiopatias, hipertensão arterial sistêmica (HAS), doenças gastrintestinais e doenças dermatológicas (Figura 5.6). 


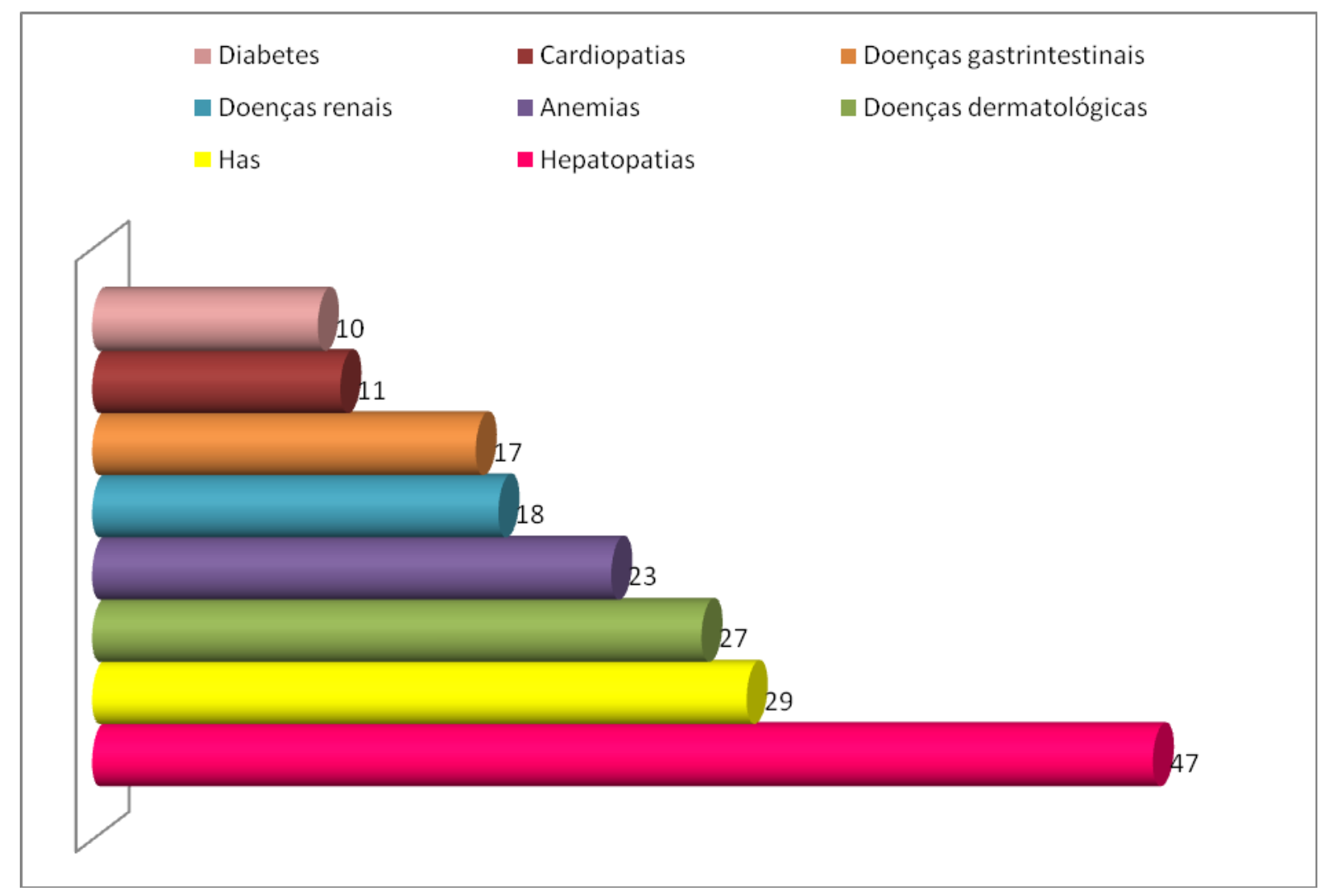

Figura 5.6- Freqüência de co-morbidades apresentadas por 80 pacientes soropositivos para o HTLV

As co-infecções foram identificadas em 52 pacientes, sendo os principais tipos virais observados o HIV, o HBV e o HCV (figura 5.7). 


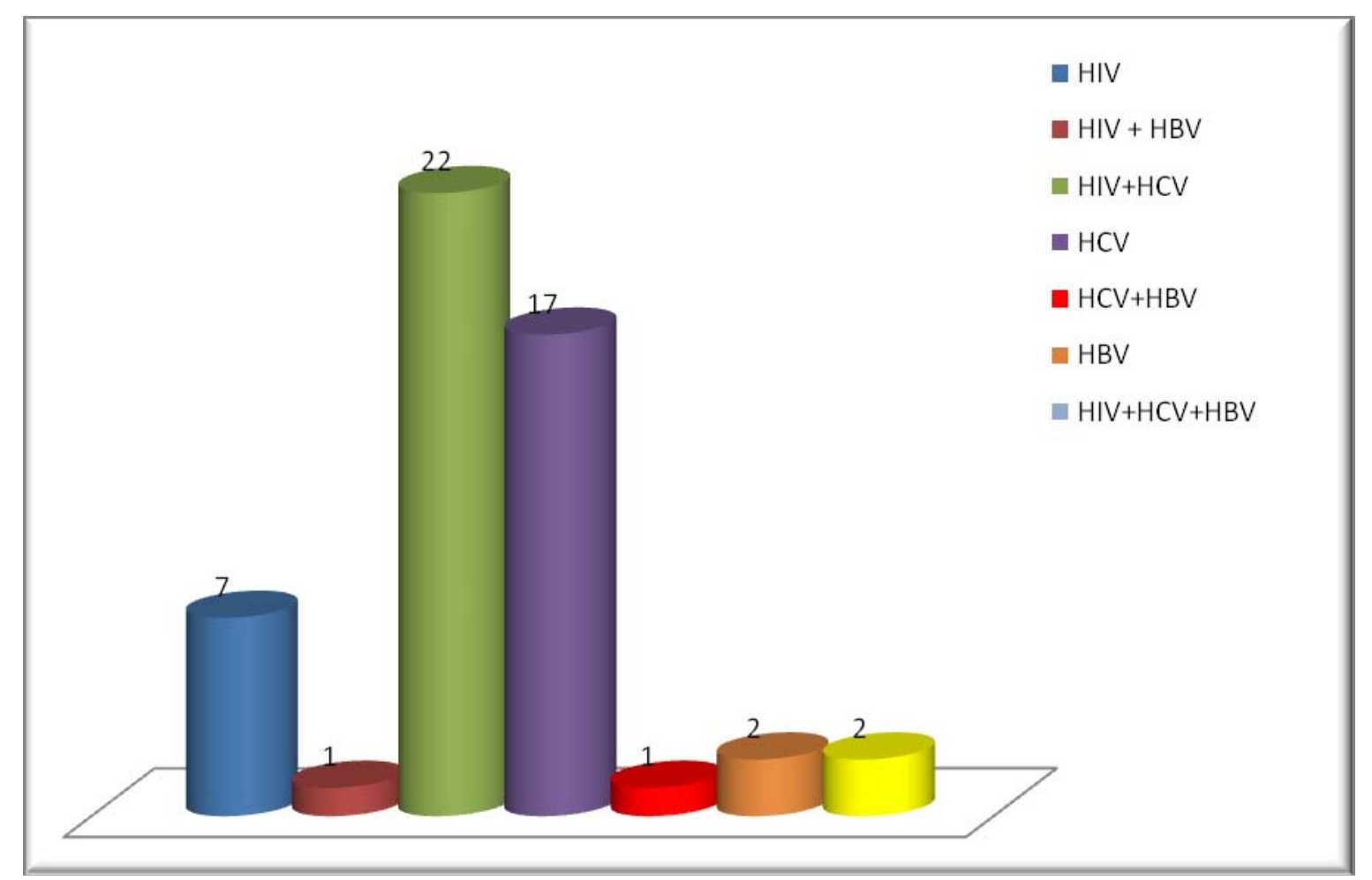

Figura 5.7- Freqüência de co-infecções apresentadas por 52 pacientes portadores do HTLV

Em decorrência da presença dessas co-morbidades e co-infecções por outros vírus, bem como da necessidade de tratamento para as manifestações do HTLV, 97 pacientes $(69,7 \%)$ faziam uso regular de medicações. As principais drogas utilizadas por esses pacientes estão representadas na figura 5.8 . 


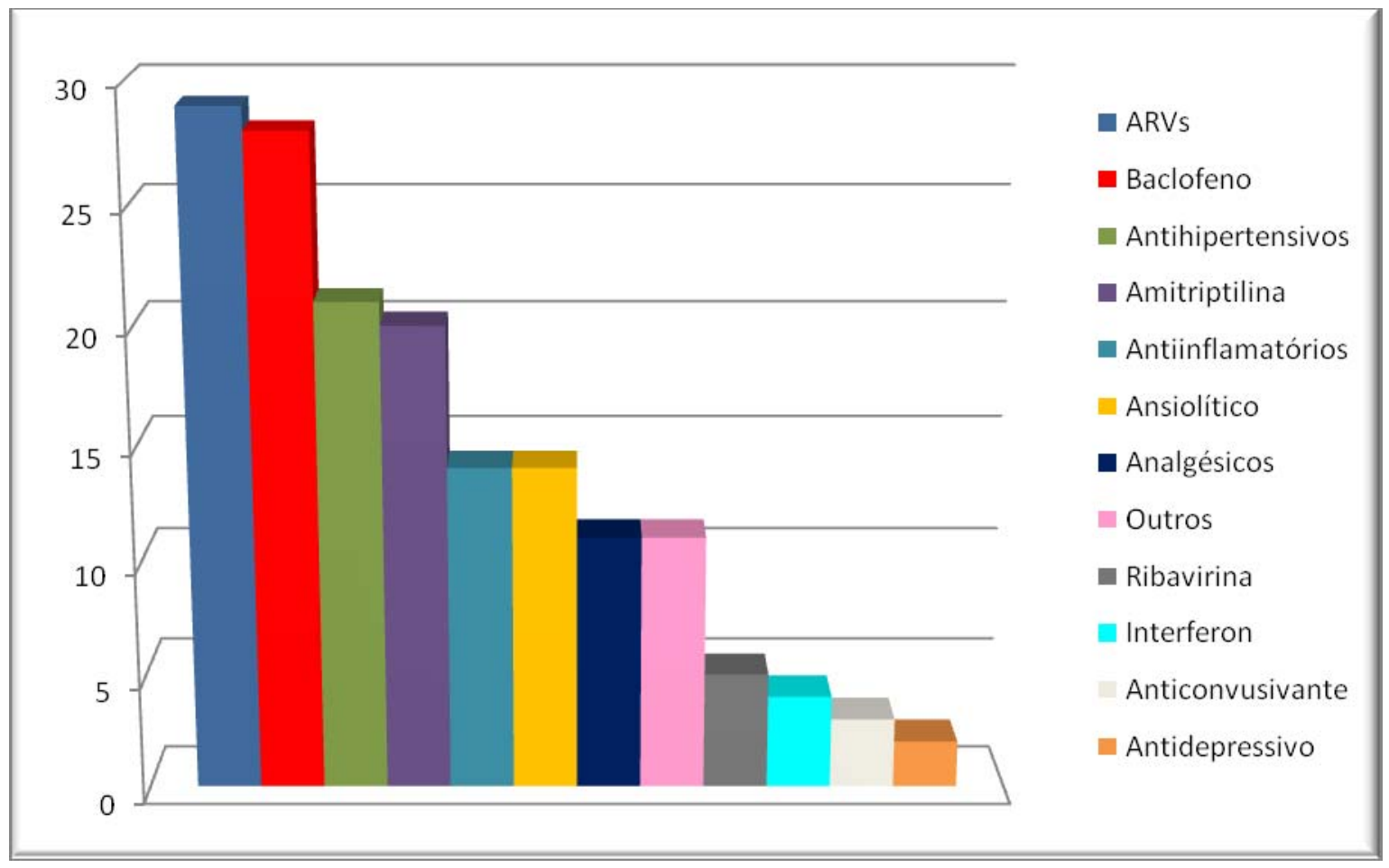

Figura 5.8- Drogas utilizadas por 97 pacientes HTLV+ que faziam uso regular de medicações

O seguimento clínico dos pacientes também incluía, em alguns casos, execução de contagens de CD4, CD8 e carga viral. Os valores referentes a essas contagens estão representados na tabela 5.7 . 
Tabela 5.7- Valores de CD4, CD8 e carga viral dos pacientes estudados

\begin{tabular}{|c|c|}
\hline Contagens & Pacientes (n) \\
\hline \multicolumn{2}{|l|}{ CD4 $(n=114)$} \\
\hline Nível 1 - < 500 & 12 \\
\hline Nível 2 - 500 - 1000 & 50 \\
\hline Nível $3-1000$ - 2000 & 47 \\
\hline$>2000$ & 5 \\
\hline \multicolumn{2}{|l|}{ CD8 $(n=107)$} \\
\hline$<500$ & 31 \\
\hline $500-1000$ & 63 \\
\hline $1000-2000$ & 11 \\
\hline$>2000$ & 2 \\
\hline \multicolumn{2}{|l|}{$C V(n=123)$} \\
\hline$<100$ & 71 \\
\hline $100-500$ & 31 \\
\hline $500-2000$ & 18 \\
\hline$>2000$ & 3 \\
\hline
\end{tabular}

A grande maioria dos pacientes $(70,5 \%)$ encontrava-se em seguimento (tabela 5.8) médico no ambulatório do IIER há menos de 5 anos. 
Tabela 5.8- Tempo de seguimento clínico de 139 pacientes HTLV+

\begin{tabular}{lc}
\hline Seguimento & Pacientes $(\mathbf{n})$ \\
\hline$>1$ ano & 17 \\
$\mathbf{1}$ ano & 20 \\
$\mathbf{2}$ anos & 25 \\
$\mathbf{3}$ anos & 12 \\
$\mathbf{4}$ anos & 14 \\
$\mathbf{5}$ anos & 10 \\
$\mathbf{6}$ anos & 10 \\
$\mathbf{7}$ anos & 3 \\
$\mathbf{8}$ anos & 6 \\
$\mathbf{9}$ anos & 4 \\
Não sabe & 3 \\
Total & 15 \\
\hline
\end{tabular}

Com relação aos tipos virais, os pacientes HTLV+ foram divididos em três grupos segundo sua sorologia: HTLV-1+, HTLV-2+ e HTLV-1+ e 2+.

Dos 139, pacientes $112(80,6 \%)$ eram soropositivos para o HTLV-1, dentre esses, $64(57,1 \%)$ eram assintomáticos e $48(42,8 \%)$ apresentavam TSP/HAM (figura 5.9). Entre os pacientes que apresentavam TSP/HAM, 94\% relatavam algum tipo de sinal ou sintoma relacionado a essa manifestação (figura 5.10).

A soropositividade para o HTLV-2 foi identificada em 26 (18,7\%) pacientes (figura 5.9). Nenhum desses pacientes apresentava diagnóstico de TSP/HAM, ainda que alguns apresentassem sintomas compatíveis com a doença (figura 5.10).

Apenas $1(0,7 \%)$ paciente era soropositivo para ambos os tipos virais, apresentando também TSP/HAM (figura 5.10). 


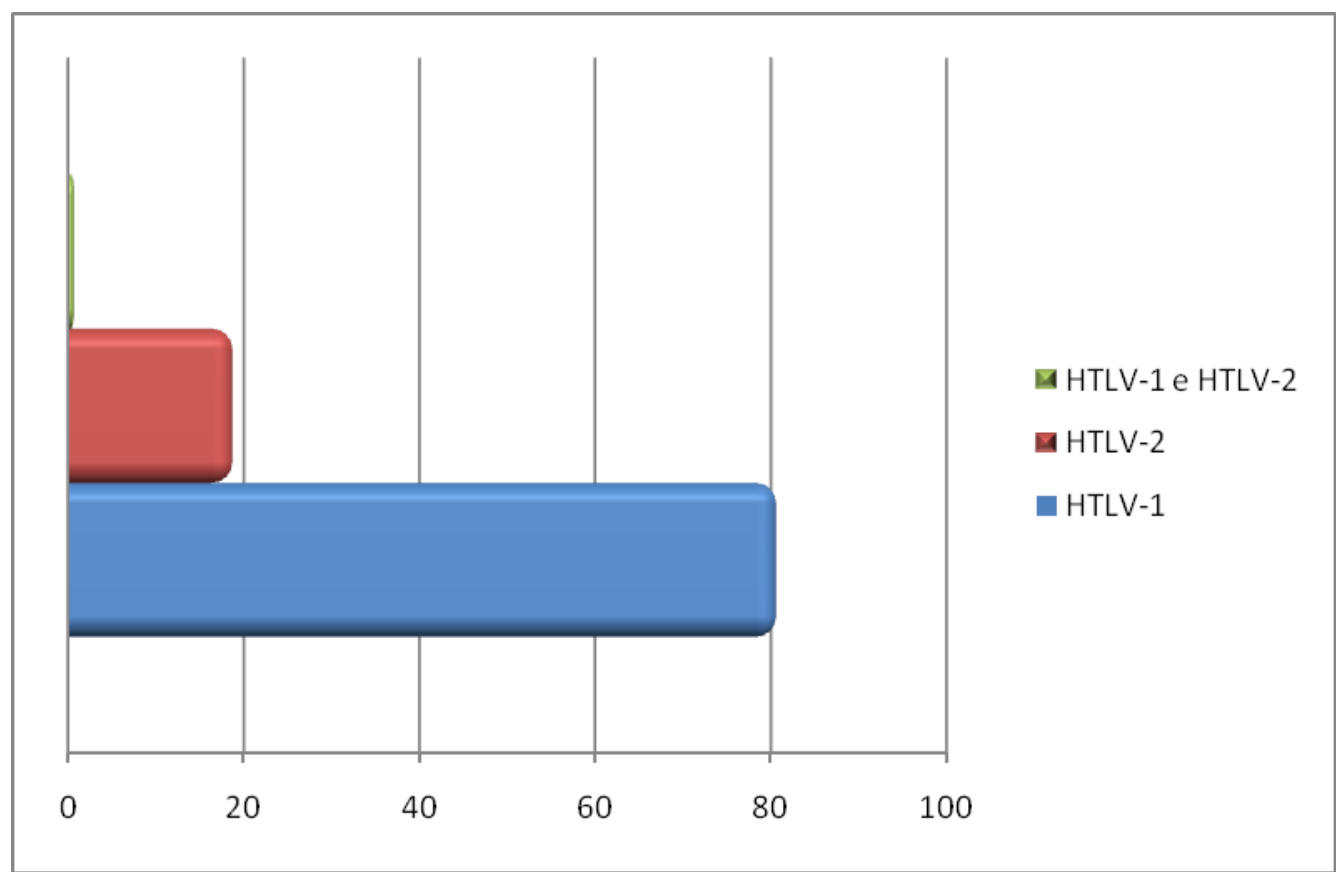

Figura 5.9- Freqüência dos tipos de HTLV entre os pacientes estudados

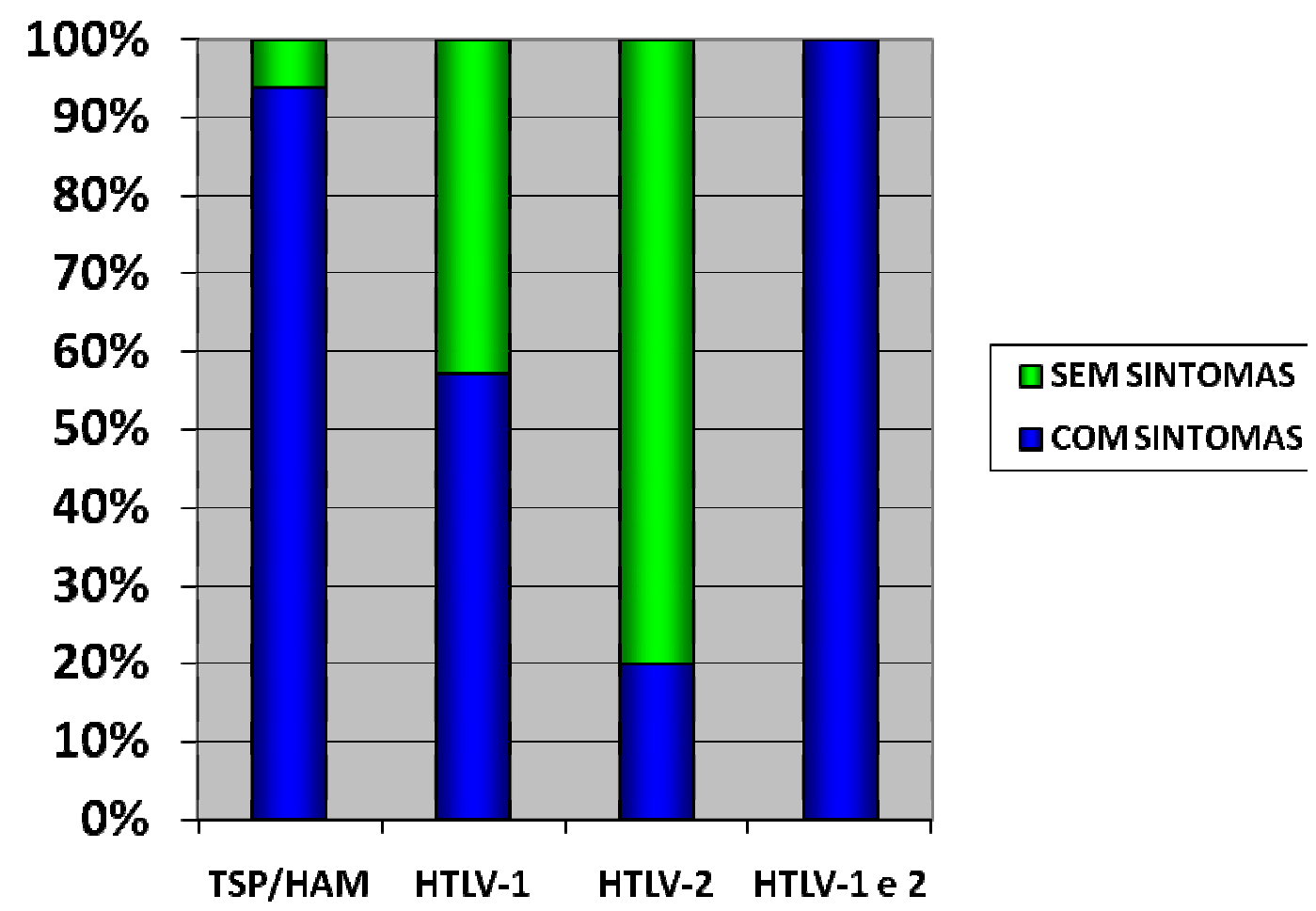

Figura 5.10- Proporção de pacientes com e sem sinais e sintomas relativos à TSP/HAM segundo o tipo viral e a presença de diagnostico prévio de TSP/HAM 
Avaliações também foram executadas no grupo de pacientes com diagnóstico confirmado de TSP/HAM, com a finalidade de caracterizar exclusivamente os pacientes com doenças associadas ao HTLV.

No total 48 pacientes apresentavam TSP/HAM. A maioria dos pacientes era do sexo feminino $(58 \%)$, leucoderma $(71,4 \%)$ e estava na quinta década de vida $(34,7 \%)$. Sessenta e três por cento deles tinham até o primeiro grau de instrução, $47,7 \%$ eram casados e mais da metade não sabia qual a provável via de contaminação $(54,5 \%)$.

Os sinais e sintomas relativos à TSP/HAM apresentados pelos pacientes entrevistados foram: parestesia em membros inferiores e superiores $(n=36)$, dor em membros inferiores e superiores $(n=30)$, incontinência urinária $(n=15)$, lombalgias ( $n=16)$, constipação $(n=11)$, pele ressecada $(n=11)$, e olhos ressecados $(n=1)$ (tabela 5.9).

Tabela 5.9- Sintomas e sinais presentes em 48 pacientes portadores de HTLV-1 e TSP/HAM

\begin{tabular}{lcc}
\hline Sintomas relatados & Pacientes (n) & Pacientes (\%) \\
\hline Parestesia em membros inferiores e superiores & 6 & 12,2 \\
\hline Dor em membros inferiores e superiores & 30 & 30,6 \\
\hline Incontinência urinaria & 15 & 32,6 \\
\hline Lombalgias & 16 & 22,4 \\
\hline Constipação & 11 & 22,4 \\
\hline Pele ressecada & 11 & 2,2 \\
\hline
\end{tabular}


Em relação ao tratamento, $43(87,7 \%)$ faziam uso regular de algum medicamento. As principais drogas utilizadas estão apresentadas na figura 5.11.

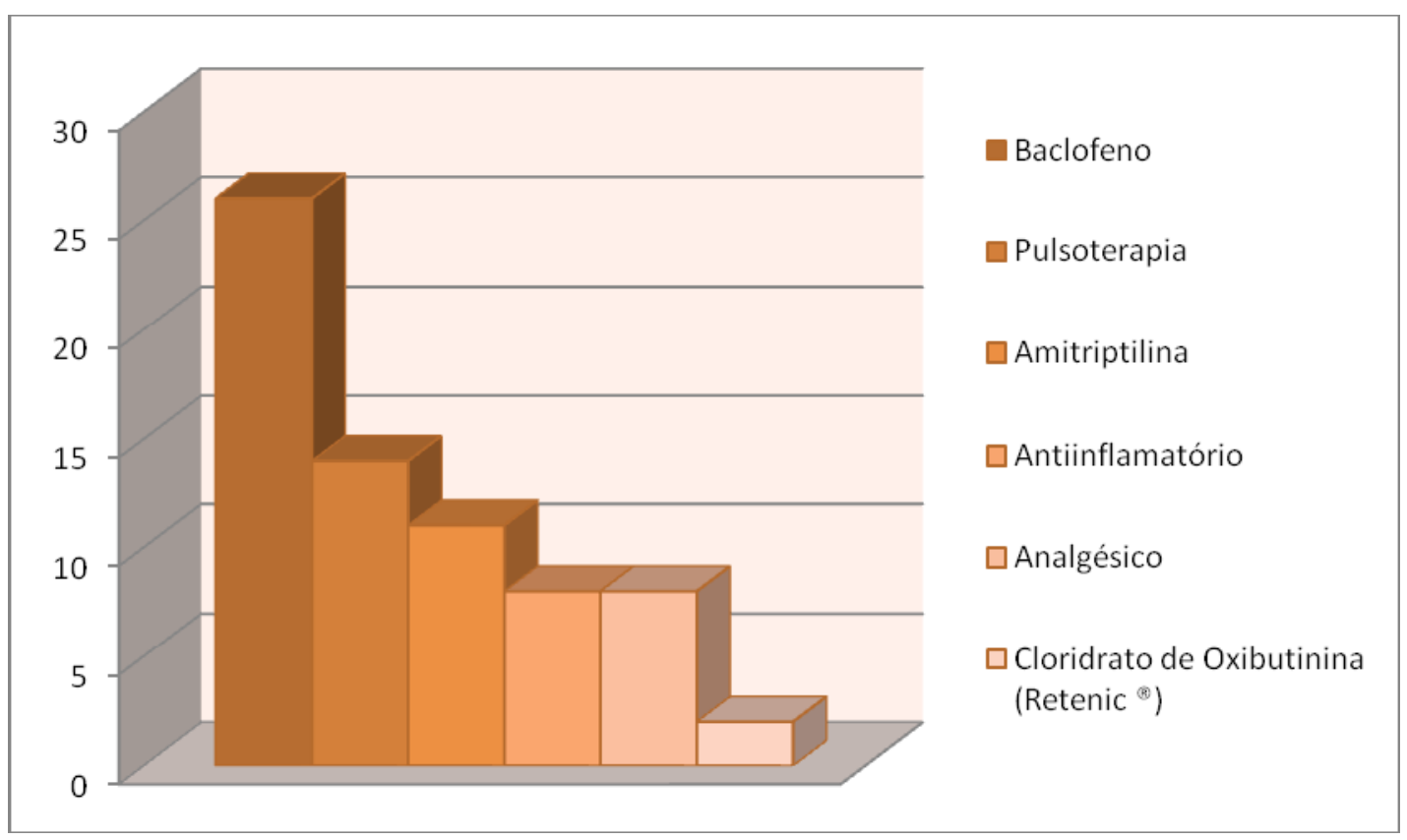

Figura 5.11- Drogas utilizadas no tratamento sintomático de 48 pacientes portadores de HTLV-1 com TSP/HAM

Todos os pacientes apresentavam dificuldade de ambulação, mas apenas $18,3 \%(n=9)$ utilizavam muletas e $12,2 \%(n=6)$ cadeira de rodas.

\subsection{Dados relativos às alterações bucais}

Com relação à saúde bucal dos 139 pacientes $\mathrm{HTLV+,} \mathrm{a} \mathrm{anamnese}$ possibilitou verificar que $62(44,6 \%)$ pacientes relataram terem ido ao dentista após o conhecimento de sua sorologia, mas apenas $18(29 \%)$ declararam seu status 
sorológico ao profissional. Todos os dentistas que atenderam pacientes que declararam sua sorologia (18) fizeram perguntas relativas à infecção pelo HTLV e 11 $(51,1 \%)$ se recusaram a atender o paciente.

Ainda que vários pacientes tenham procurado serviços odontológicos, foram identificadas alterações bucais em 74 pacientes soropositivos para o HTLV. A figura 5.12 apresenta as alterações bucais identificadas nesses pacientes.

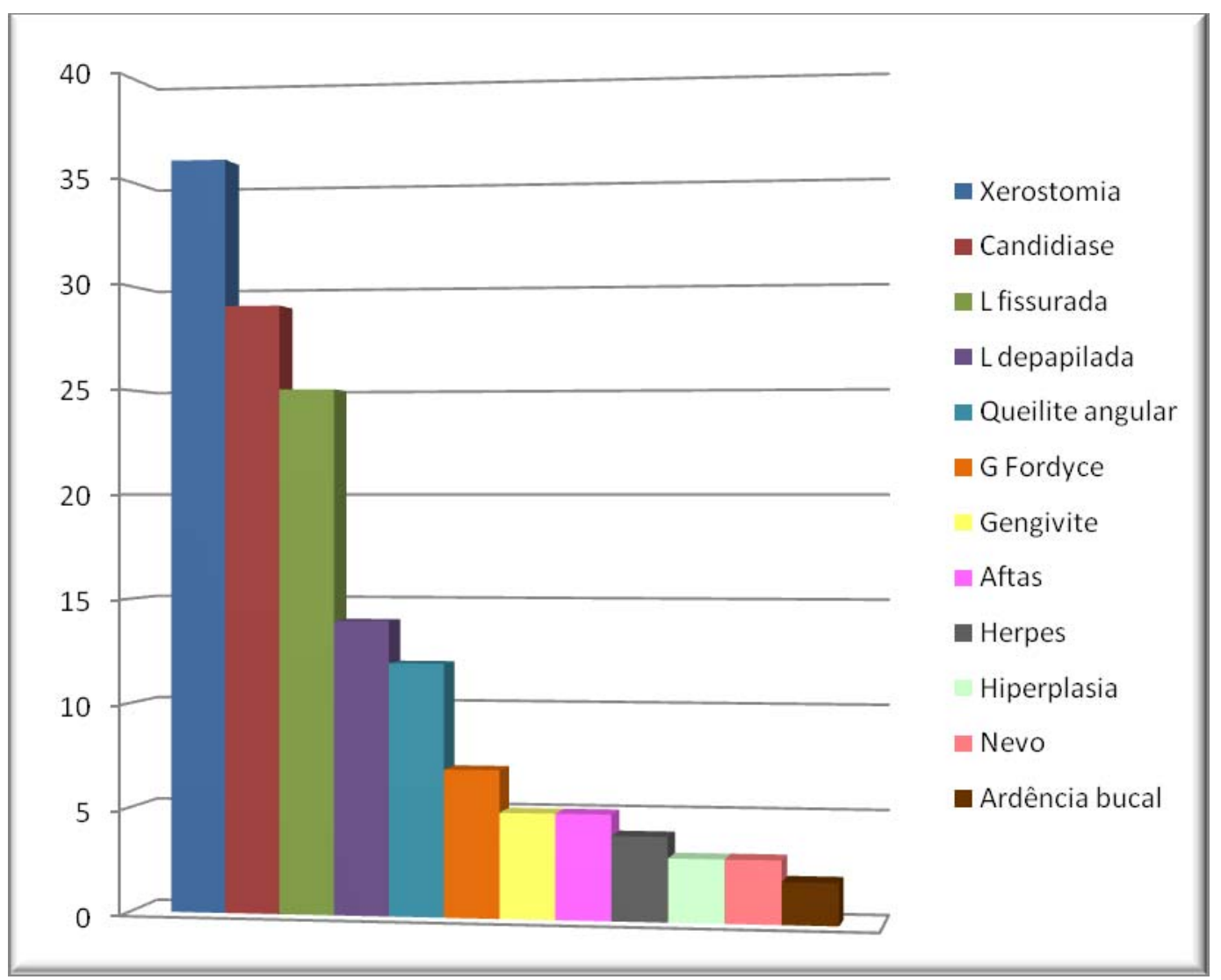

Figura 5.12- Alterações bucais mais freqüentes em 74 pacientes soropositivos para o HTLV 
Dentre os 74 pacientes que apresentaram alterações bucais foi constatado que:

- 59,4\% eram do sexo feminino

$-30 \%$ eram tabagistas

- 35,1\% estavam na quarta década de vida

- $61,6 \%$ eram leucodermas

- 20,8\% relataram terem sido contaminados através da via sexual

- 45,2\% tinham diagnóstico de TSP/HAM

A identificação de alterações bucais nos pacientes HTLV+ foi contabilizada e os dados foram tabulados segundo o tipo viral e a presença de TSP/HAM, a presença de fatores modificadores - fatores que são sabidamente relacionados com a presença de alterações bucais - (uso de medicamentos, tabagismo e presença de co-morbidades e co-infecções) e ao tempo de seguimento do paciente no ambulatório.

Ao avaliarmos a presença de alterações bucais nos pacientes segundo o tipo viral e a presença ou não de TSP/HAM observa-se maior prevalência destas em pacientes com HTLV1+ e com TSP/HAM (Figura 5.13). 


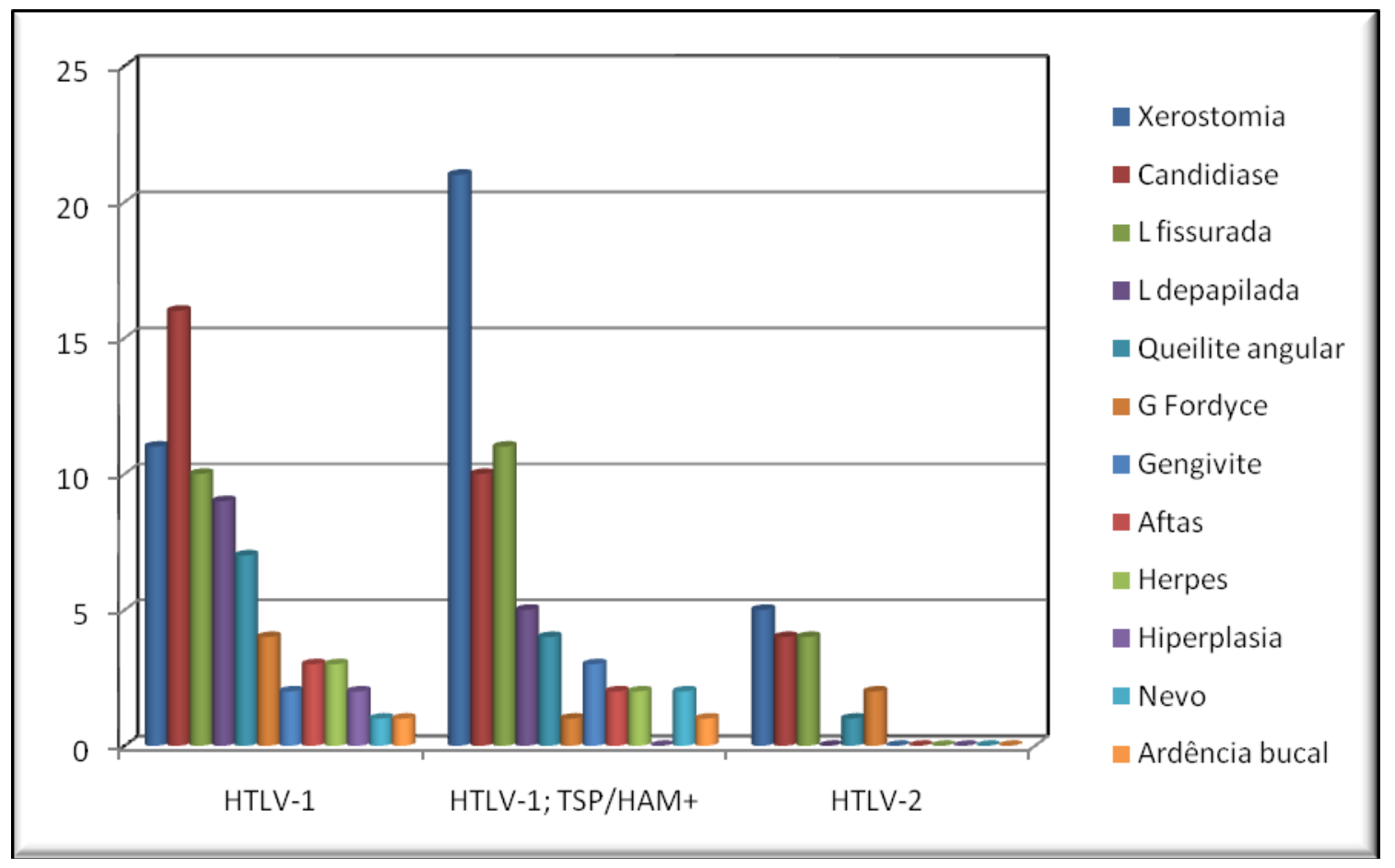

Figura 5.13- Distribuição das alterações bucais encontradas ente os tipos virais estudados

A relação entre as principais manifestações bucais encontradas neste estudo e os fatores modificadores da saliva normal está representada na Figura 5.13.

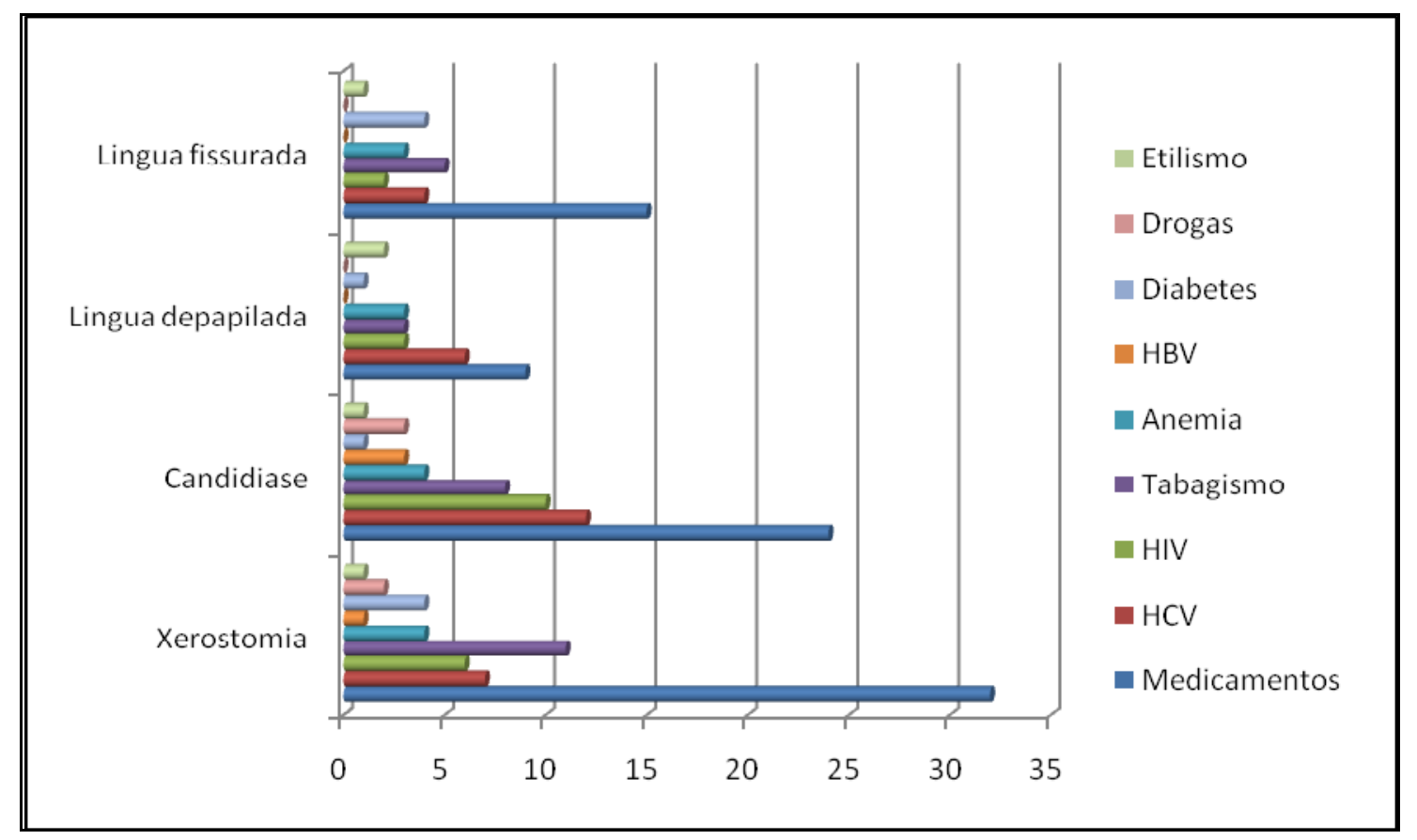

Figura 5.14- Relação entre fatores modificadores e alterações bucais observadas em pacientes soropositivos para o HTLV 
Os pacientes que apresentaram alterações bucais foram divididos em grupos de acordo com o tempo de seguimento clínico no IIER. A incidência de pacientes que apresentaram alterações bucais apresentou uma tendência de aumento nos grupos de pacientes com maior tempo de seguimento (Figura 5.15).

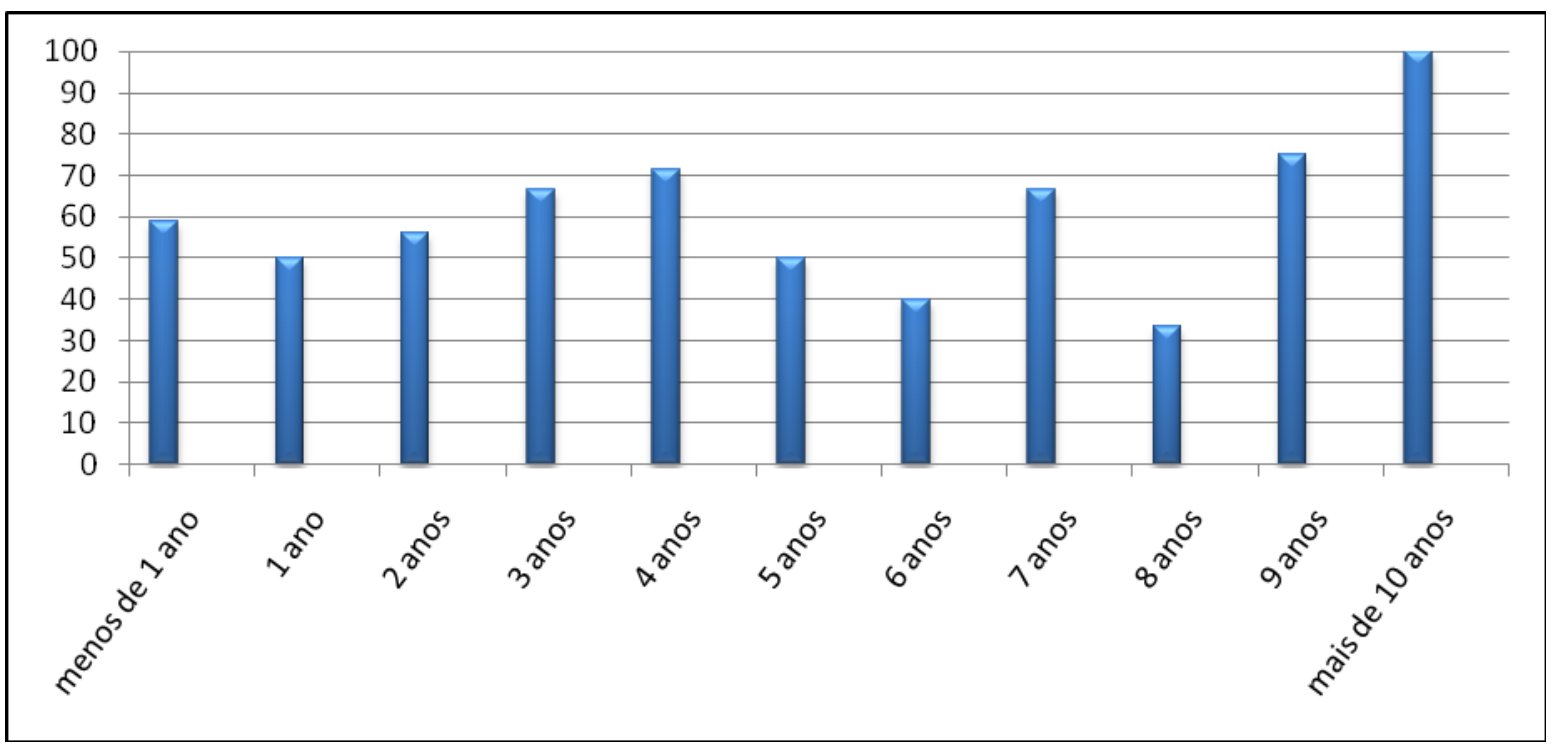

Figura 5.15- Incidência porcentual, segundo o tempo de seguimento no IIER, de pacientes que apresentavam alterações bucais

A presença de alterações bucais era mais freqüente em pacientes portadores do HTLV do tipo 1 (80,6\%), que apresentavam co-morbidades $(57,5 \%)$ e que utilizavam medicamentos regularmente $(69,7 \%)$.

Os parâmetros imunológicos e virológicos, dos 74 pacientes portadores de alterações bucais, revelaram o seguinte perfil: 
- 60 possuíam dados relativos à contagem de linfócitos $T$ CD4+. O menor valor encontrado foi de 75 cels $/ \mathrm{mm}^{3}$ e o maior 3898 céls $/ \mathrm{mm}^{3}$, com média de 990,8833 (desvio padrão 612,4876) e mediana 909,500.

- 56 possuíam dados relativos à contagem de CD8. O menor valor encontrado foi de 54 cels $/ \mathrm{mm}^{3}$ e o maior 2000 céls $/ \mathrm{mm}^{3}$, com média de 649,0536 (desvio padrão $350,3795)$ e mediana 605,5000 .

- 62 possuíam contagem de carga viral. O menor valor encontrado foi de zero e o maior 7451 céls $/ \mathrm{mm}^{3}$, com média de 441,9677 (desvio padrão 1057,1821) e mediana 87,0000 .

Como as alterações bucais mais freqüentes foram a xerostomia, a língua depapilada, a língua fissurada e a candidíase, foi avaliada a possibilidade estatística de interferência das variáveis em estudo (idade, CD4, CD8, CV, positividade para o HTLV-1 e 2, presença de co-morbidades, presença de TSP/HAM, tabagismo, etilismo e uso de medicamentos e drogas ilícitas) na incidência dessas condições.

Para comparação de dados quantitativos, como idade e $\mathrm{CV}$, existem dois tipos de testes que podem ser utilizados: os testes paramétricos e os nãoparamétricos. A escolha baseia-se principalmente na distribuição dos dados. Se essa distribuição apresentar características de normalidade, usamos um teste paramétrico, como a análise de variância. Se não for observada normalidade, utilizamos testes não-paramétricos, como Kruskal-Wallis.

Assim, inicialmente, foram utilizados os testes conhecidos como KolmogorovSmirnov e Shapiro-Wilk para verificar se os dados a serem analisados estão distribuídos de acordo com os padrões de normalidade. Em outras palavras, se o valor de $p$ for $>0,05$, então dizemos que os dados têm uma distribuição normal. 


\subsection{Avaliação de interferência de cv e idade}

Ambas as variáveis (idade e CV) apresentaram valor de $p<0,05$, ou seja, suas distribuições não estão dentro do padrão de normalidade e, para comparação entre os grupos, será utilizado o teste de Kruskal-Wallis.

A tabela 5.10 compara os valores de idade e CV nos indivíduos com e sem alterações bucais. Como os dados não apresentam distribuição normal, além da média e desvio padrão, foram incorporados à tabela, a mediana e os valores mínimos e máximos da distribuição. Esses dados auxiliam na descrição da distribuição dos dados.

Tabela 5.10- Análise Descritiva das variáveis quantitativas nos grupos de estudo, assim como os resultados referentes ao Teste de Kruskal-Wallis comparando os valores dos indivíduos que apresentam ou não a alteração bucal

\begin{tabular}{|c|c|c|c|c|c|c|c|c|c|c|c|c|c|}
\hline & $N$ & Não & & & & & Sim & & & & & Qui- & $p$ \\
\hline & & Média & $\begin{array}{l}\text { Desvio } \\
\text { Padrão }\end{array}$ & Mediana & Mínimo & Máximo & Média & $\begin{array}{l}\text { Desvio } \\
\text { Padrão }\end{array}$ & Mediana & Mínimo & Máximo & & \\
\hline \multicolumn{14}{|c|}{ Xerostomia } \\
\hline Idade & 135 & 3,98 & 1,02 & 4,00 & 1,00 & 7,00 & 4,25 & 1,25 & 4,50 & 2,00 & 7,00 & 2,12 & 0,15 \\
\hline $\mathrm{CV}$ & 120 & 284,90 & 646,26 & 29,50 & 0,00 & 5360,00 & 538,86 & 1498,00 & 78,00 & 0,00 & 7451,00 & 0,02 & 0,89 \\
\hline $\begin{array}{l}\text { Língua } \\
\text { depap }\end{array}$ & & & & & & & & & & & & & \\
\hline Idade & 113 & 4,13 & 1,07 & 4,00 & 2,00 & 7,00 & 3,93 & 1,07 & 4,00 & 2,00 & 6,00 & 0,38 & 0,54 \\
\hline $\mathrm{CV}$ & 98 & 398,90 & 1044,00 & 77,00 & 0,00 & 7451,00 & 349,40 & 552,45 & 5,00 & 0,00 & 1672,00 & 0,01 & 0,94 \\
\hline \multicolumn{14}{|c|}{ Língua } \\
\hline Idade & 113 & 4,09 & 0,98 & 4,00 & 2,00 & 6,00 & 4,16 & 1,34 & 4,00 & 2,00 & 7,00 & 0,01 & 0,93 \\
\hline $\mathrm{CV}$ & 98 & 441,61 & 1110,00 & 79,00 & 0,00 & 7451,00 & 218,71 & 394,59 & 5,00 & 0,00 & 1672,00 & 1,34 & 0,25 \\
\hline \multicolumn{14}{|c|}{ Candidíase } \\
\hline Idade & 114 & 4,09 & 1,11 & 4,00 & 2,00 & 7,00 & 4,14 & 0,92 & 4,00 & 3,00 & 6,00 & 0,05 & 0,81 \\
\hline $\mathrm{CV}$ & 99 & 315,47 & 755,71 & 48,00 & 0,00 & 5360,00 & 662,68 & 1575,00 & 248,00 & 0,00 & 7451,00 & 1,43 & 0,23 \\
\hline
\end{tabular}


Não foi observada diferença estatística entre idade e CV dos indivíduos com diferentes alterações bucais $(p<0,05)$.

\subsection{Variáveis quantitativas}

Em geral, quando queremos comparar freqüências, utilizamos o teste de QuiQuadrado para gerar o valor de $p$. Entretanto, neste projeto decidimos utilizar testes exatos (Teste Exato de Fisher, para tabelas 2x2 e Simulações de Monte Carlo, para tabelas $3 \times 2$ e $7 \times 2)$.

Os testes de Fisher e Monte Carlo são utilizados quando temos classes com valores inferiores a 5, como o número de usuários de droga que tem xerostomia. Isso porque, quando mais de $20 \%$ das células da tabela em análise apresentam um valor menor que 5, o teste do Qui-Quadrado "assintomático" ou "comum" deixa de ser válido (Cochran's rule).

As tabelas completas utilizadas para a análise estão no Anexo D.

$\mathrm{Na}$ tabela 5.11 é apresentado um resumo dos resultados dos testes estatísticos, comparando as freqüências das variáveis nas diferentes alterações bucais.

Tabela 5.11- Comparação das diversas alterações bucais com as variáveis em estudo

\begin{tabular}{|c|c|c|c|c|c|c|c|c|}
\hline & \multicolumn{8}{|c|}{ Xerostomia Língua depapilada Língua fissurada Candidíase } \\
\hline & $p$ & $\mathrm{~N}$ & $p$ & $\mathrm{~N}$ & $p$ & $\mathrm{~N}$ & $p$ & $\mathrm{~N}$ \\
\hline Sexo* & 0,843 & 136 & 1,000 & 113 & 0,818 & 113 & 1,000 & 114 \\
\hline HTLV tipo $1^{*}$ & 0,461 & 136 & 0,072 & 113 & 1,000 & 113 & 0,396 & 114 \\
\hline HTLV tipo $2^{*}$ & 0,341 & 136 & 0,069 & 113 & 1,000 & 113 & 0,584 & 114 \\
\hline TSP/HAM* & 0,004 & 133 & 0,776 & 110 & 0,818 & 110 & 0,658 & 111 \\
\hline Medicamentos ${ }^{*}$ & 0,011 & 136 & 0,346 & 113 & 0,074 & 113 & 0,325 & 114 \\
\hline Níveis de CD4** & 1,000 & 111 & 0,246 & 92 & 0,155 & 92 & 0,032 & 93 \\
\hline Níveis de CD8** & 0,605 & 104 & 0,849 & 86 & 0,705 & 86 & 0,060 & 87 \\
\hline Contaminação** & 0,445 & 132 & 0,287 & 110 & 0,480 & 110 & 0,198 & 111 \\
\hline Comorbidades $^{*}$ & 0,554 & 136 & 1,000 & 113 & 0,227 & 113 & 1,000 & 114 \\
\hline Tabagismo* & 0,508 & 130 & 1,000 & 108 & 1,000 & 108 & 0,802 & 109 \\
\hline Etilismo* & 1,000 & 130 & 0,080 & 108 & 1,000 & 108 & 1,000 & 109 \\
\hline Drogas* & 1,000 & 129 & 1,000 & 108 & 0,198 & 108 & 0,406 & 109 \\
\hline
\end{tabular}

* $\mathrm{p}$ é a probabilidade do teste exato de Fisher.

** p é a probabilidade obtida com Simulação de Monte Carlo (10000 tabelas amostradas). 
$\mathrm{Na}$ alteração bucal xerostomia, foram observadas diferenças significativas nas variáveis TSP/HAM $(p=0,004)$ e uso de medicamentos $(p=0,011)$ e na alteração bucal candidíase, na variável níveis de CD4, $(p=0,032)$.

Ao observar os resultados da tabela 5.11, a descrição dos resultados estatísticos seria a seguinte:

- Pacientes que foram classificados como "sim" para a variável TSP/HAM apresentaram uma freqüência maior de xerostomia $(43,5 \%)$ quando comparados com pacientes que foram classificados como "não" para a variável TSP/HAM $(18,4 \%)(p=0,004)$.

- Pacientes que tomam medicamentos apresentaram uma freqüência maior de xerostomia $(33 \%)$ quando comparados com pacientes que não tomam medicamentos $(11,9 \%)(p=0,011)$.

- Pacientes que apresentam candidíase têm níveis de CD4 inferiores (14,3\% Níveis 1 e 2; e 71,4\% - Nível 3) a pacientes que não têm candidíase $(2,8 \%$ nível 1; 5,6\% nível 2; e 91,7\% - nível 3) ( $p=0,032)$.

- Todas as outras variáveis não apresentaram diferenças significativas nas alterações bucais $(p>0,05)$.

Frente a esses resultados novos questionamentos surgiram.

Como a presença de candidíase pôde ser vinculada estatisticamente a níveis mais baixos de CD4 e existem pacientes co-infectados com o HIV (que apresenta como uma de suas principais manifestações oportunistas a candídiase oral), optamos por realizar avaliações que envolvessem CD4, soropositividade para o HIV e candidíase. 
Na tabela 5.12 pode ser observado que pacientes com HIV tem níveis de CD4 significativamente menores $(p=0,002)$. Ou seja, existe, como esperado uma relação forte entre HIV e CD4 ( $p$ é a probabilidade obtida com Simulação de Monte Carlo 10000 tabelas amostradas).

Tabela 5.12- Relação entre níveis de CD4 em pacientes HIIV positivos

\begin{tabular}{|c|c|c|c|c|c|c|c|}
\hline \multirow[t]{2}{*}{ HIV } & Não & 0 & $0,0 \%$ & 3 & $6,1 \%$ & 46 & $93,9 \%$ \\
\hline & Sim & 5 & $17,2 \%$ & 4 & $13,8 \%$ & 20 & $69,0 \%$ \\
\hline
\end{tabular}

Por outro lado, na tabela 5.13 verificamos que pacientes com HIV não apresentam um número significativamente maior de candidíase $(p=0,450)$. Ou seja, na amostra, não foi observada uma relação entre HIV e candidíase ( $p$ é a probabilidade do teste exato de Fisher).

Tabela 5.13- Relação entre positividade para HIV e candidíase

\begin{tabular}{|c|c|c|c|c|c|}
\hline \multicolumn{5}{|c|}{ HIV } & \\
\hline \multirow{3}{*}{ Candidíase } & & Não & & Sim & \\
\hline & Não & 46 & $76,7 \%$ & 20 & $69,0 \%$ \\
\hline & Sim & 14 & $23,3 \%$ & 9 & $31,0 \%$ \\
\hline
\end{tabular}

Portanto, é natural que se levante a seguinte pergunta: Será que pacientes com HIV e candidíase têm níveis mais reduzidos de CD4? Mas quando fazemos a relação entre candidíase, níveis de CD4 e HIV a análise estatística não é significativa, sugerindo que não existe uma correlação entre HIV, CD4 e candidíase 
$(p=0,327)$ ( $p$ é a probabilidade obtida com Simulação de Monte Carlo - 10000 tabelas amostradas).

Entretanto, vale colocar que a diferença não é estatisticamente significante muito provavelmente devido ao tamanho amostral pequeno, já que pacientes com candidíase e HIV têm sim níveis inferiores de CD4, como pode ser observado na tabela 5.14.

Tabela 5.14- Relação entre níveis de CD4 e candidíase em pacientes HIIV positivos

\begin{tabular}{|c|c|c|c|c|c|c|c|}
\hline \multirow[b]{3}{*}{ Candidíase } & \multirow[b]{3}{*}{ Não } & \multicolumn{6}{|c|}{ Níveis de CD4 } \\
\hline & & \multicolumn{2}{|c|}{1} & \multicolumn{2}{|c|}{2} & \multicolumn{2}{|c|}{3} \\
\hline & & 2 & $11,1 \%$ & 3 & $16,7 \%$ & 13 & $72,2 \%$ \\
\hline & Sim & 3 & $37,5 \%$ & 1 & $12,5 \%$ & 4 & $50,0 \%$ \\
\hline
\end{tabular}

A regressão logística multivariada para identificação de risco independentes foi executada com o intuito de verificar se alguma das variáveis representaria um risco maior de desenvolvimento de uma determinada alteração bucal.

Em primeiro lugar, foi realizada análise regressão logística univariada para cada variável. Apenas as variáveis que apresentaram $p<0,05$ na análise univariada foram incluídas no modelo de regressão logística multivariada, ou seja, para a alteração bucal xerostomia; foram incluídas no modelo, as variáveis TPS/HAM e medicamentos e para a alteração bucal níveis de CD4. 
Tabela 5.15- Modelos de regressão logística multivariada para a alteração xerostomia e candidíase

\begin{tabular}{lcccc}
\hline Xerostomia & $\mathbf{p}$ & Odds Ratio & 95\% Intervalo de Confiança \\
\hline TPS/HAM & $\mathbf{0 , 0 2}$ & $\mathbf{2 , 6 9}$ & $\mathbf{1 , 1 7}$ & $\mathbf{6 , 1 7}$ \\
Medicamentos & 0,07 & 2,67 & 0,91 & 7,82 \\
\hline Candidíase & $\mathbf{p}$ & Odds Ratio & $\mathbf{9 5 \%}$ Intervalo de Confiança \\
& & & & \\
Níveis de CD4 & & ref & & $\mathbf{4 3 , 0 4}$ \\
Níveis de CD4(1) & $\mathbf{0 , 0 4 9}$ & $\mathbf{6 , 6 0}$ & $\mathbf{1 , 0 1}$ & 16,32 \\
\hline Níveis de CD4(2) & 0,14 & 3,30 & 0,67 & \\
\hline
\end{tabular}

Pode ser observado na tabela 5.15, que a associação entre TPS/HAM e xerostomia é independente do uso de medicamentos $(p=0,02)$. Ou seja, a variável TPS/HAM é um fator de risco independente para xerostomia, já que a mesma permanece significativa, mesmo quando a variável "medicamentos" é incluída no modelo. Já a associação entre xerostomia e uso de medicamentos deixa de ser significativa quando a variável TPS/HAM é incluída no modelo. Ou seja, uso de medicamentos não é fator de risco independente para xerostomia $(p=0,07)$.

Em resumo, pacientes com TPS/HAM têm aproximadamente 3 vezes mais chances de desenvolver xerostomia quando comparados com pacientes sem TPS/HAM, mesmo após o controle para o uso de medicamentos $(O R=2,69$; $95 \% I C=1,17-6,17)$.

Paciente com níveis de CD4=1 têm aproximadamente 7 vezes mais chance de desenvolver candidíase quando comparados com pacientes com níveis de $\mathrm{CD} 4=3(\mathrm{OR}=6,60 ; 95 \% \mathrm{IC}=1,01-43,04)$. 


\section{DISCUSSÃO}

A infecção pelo HTLV é considerada uma epidemia global que atinge entre 15 a 20 milhões de pessoas (MURPHY et al., 2005), sendo o Brasil apontado como um dos países endêmicos para o vírus (PROIETTI et al., 2005; VERDONCK et al ., 2007).

Durante muitos anos os estudos epidemiológicos realizados no Brasil indicavam alta incidência do HTLV-1 na região nordeste, notadamente no estado da Bahia (BRITO et al.,1998; CARNEIRO-PROIETTI et al., 2002; CATALAN-SOARES; CARNEIRO-PROETTI; PROIETTI, 2005), mas pesquisas recentes apontam o estado de São Paulo como o mais prevalente para o vírus (JACOB et al., 2007). Este fato justifica a execução de pesquisas epidemiológicas que caracterizem a população infectada no estado de São Paulo.

O presente estudo avaliou uma população de 139 pacientes HTLV+ de uma coorte acompanhada no Instituto de Infectologia Emílio Ribas, localizado na cidade de São Paulo.

No presente estudo, a análise descritiva dos dados demográficos levantados, relativos à população de pacientes HTLV+ estudada, permitiu a caracterização dessa população. A população estudada era constituída predominantemente por mulheres, nascidas na cidade de São Paulo, casadas, leucodermas, com nível de

instrução até o primeiro grau, e que estavam na terceira década de vida (figuras 5.1, $5.2,5.3$ e tabelas 5.2, 5.4).

Embora países endêmicos para o HTLV sejam compostos por uma população de origem negra ou oriental (MURPHY et al., 2005) o presente estudo apresentou 
maior ocorrência do HTLV em pacientes leucodermas $57,2 \%(n=79)$. Esse fato pode ser explicado pela grande miscigenação existente em nosso país. Ainda que a pele dos pacientes aproxime-se mais da cor de pele branca, a maioria da população brasileira é oriunda de misturas de raças que quase sempre envolvem negros. Enquetes epidemiológicas vinculadas à raça da população brasileira apresentam um viés que dificulta a avaliação do tema.

Os pacientes não apresentavam diferenças significativas entre os sexos com relação à faixa etária, mas as o grau de escolaridade apresentava-se inferior no sexo feminino (tabela 5.1 e 5.2). O estado civil desses pacientes também variou quanto ao sexo, sendo que as mulheres declararam-se em sua maioria casadas $(42,7 \%)$ e os homens solteiros $(41,7 \%)$ (tabela 5.3$)$.

O HTLV-1 foi o primeiro retrovírus isolado em humanos associado a malignidades (POIESZ et al., 1980) mas, ainda assim, informações sobre a infecção e sua patogenia são escassas se comparadas com outro retrovírus que foi isolado anos depois, o vírus da imunodeficiência humana. O HIV foi inicialmente denominado HTLV-3 por um grupo de pesquisadores, em decorrência das semelhanças com o HTLV-1 (BRODER; GALLO, 1984). Posteriormente foram descobertas diferenças estruturais significativas entre os dois retrovírus, colocandoos em gêneros diferentes.

Sendo esses os dois retrovírus identificados que causam doenças em humanos, é natural que sejam tecidas comparações entre eles.

O uso da nomenclatura inicialmente conferida ao HIV, ainda confunde pacientes e profissionais da saúde.

A confusão criada com a nomenclatura viral associada ao desconhecimento sobre o vírus, talvez tenham sido os motivos que levaram $61,1 \%$ dos dentistas (que 
receberam pacientes $\mathrm{HTLV+)}$ a deixarem de prestar atendimento odontológico. Outro resultado verificado neste trabalho, que também pode estar vinculado à falta de conhecimento sobre a dinâmica da infecção causada pelo HTLV, pode ser evidenciado na Figura 5.5. Essa figura evidencia que mais de $60 \%$ dos pacientes não sabiam dizer a provável fonte de infecção, ainda que a maioria soubesse precisar quais os motivos que os levaram a executar a sorologia (figura 5.6). Em contrapartida, em pesquisa realizada em 2000 no centro de atendimento a pacientes com necessidades especiais (CAPE), onde foram avaliados 1200 pacientes HIV+, notamos que apenas $2,5 \%$ dos pacientes avaliados não sabiam relatar a via pela qual foram infectados com o vírus (ORTEGA, 2000).

É possível que esses dados estejam apontando uma necessidade de esclarecimento, tanto de profissionais quanto de pacientes, relativa aos mecanismos de transmissão do HTLV.

Apesar do HTLV ter sido isolado há mais de duas décadas, o conhecimento sobre aspectos demográficos e patogênicos deste vírus é ainda recente devido ao fato do HTLV não causar imunodeficiência e produzir doenças em apenas $5 \%$ dos pacientes infectados.

O HTLV e o HIV também diferem na patogenia e no mecanismo de ação. Enquanto o HIV infecta e destrói o linfócito TCD4+, o HTLV imortaliza as células T, evitando apoptose celular, para poder disseminar-se no organismo através de expansão clonal das células hospedeiras.

Embora o HIV e o HTLV apresentem as mesmas categorias de exposição, diferenças são observadas na eficácia do risco de transmissão em cada uma dessas categorias. A amamentação é apontada como uma das principais vias da transmissão vertical pelo HTLV-1. Pesquisadores sugerem que a interação entre a 
lactoferrina e o HTLV-1 pode favorecer a infecção de recém nascidos, em contraste com o HIV que é inibido por essa proteína do leite (MOURIUCHI; MOURIUCHI, 2001; MOURIUCHI; MOURIUCHI, 2006). Na transmissão sexual pelo HTLV, a chance de mulheres serem infectadas é maior em relação aos homens (assim como no HIV), mas o risco desta infecção ocorrer no HTLV é diminuto se comparado com o HIV, uma vez que trabalhos apontam a sorodiscordância entre casais durante um longo período e carga viral geralmente menor devido à baixa capacidade infectante desta via (ROUCOUX et al., 2005).

A presente pesquisa não objetivou a identificação da provável via de contaminação dos pacientes, mas apontou a via pela qual os pacientes acreditavam terem sido contaminados. A maioria dos pacientes acreditava ter sido contaminada através de relações sexuais. Quando dividimos de acordo com o sexo os meios de transmissão pelo HTLV mais relatados pelos entrevistados, podemos observar diferenças significativas. As pacientes do sexo feminino relataram que foram infectadas pelo vírus através de sexo sem proteção, enquanto os homens atribuem sua contaminação ao uso de drogas injetáveis (Tabela 5.5).

A literatura compulsada aponta a mesma diferença encontrada no presente estudo, justificando-a pelo fato da contaminação homem-mulher ser mais eficaz do que a relação contrária (ROUCOUX et al., 2005). Já em trabalhos onde o principal grupo estudado é composto por UDI, é verificada a maior prevalência de pacientes do sexo masculino (GUIMARÃES et al., 2001).

A transmissão vertical também é relatada no presente estudo como uma provável via de contaminação, mas contabiliza apenas $6,5 \%$ dos casos (tabela 5.5).

O Brasil ainda carece de estudos epidemiológicos sobre a real prevalência do HTLV, uma vez que, grande parte dos trabalhos reportados foi baseada em grupos 
formados por doadores de sangue (CATALAN-SOARES; CARNEIRO-PROETTI; PROIETTI, 2005), pacientes que apresentavam comportamento de risco (GUIMARÃES et al., 2001), co-infectados pelo HIV (ETZEL et al., 2001), grupos étnicos isolados (VALLINOTO et al., 2006; VALLINOTO et al., 2004) e pacientes institucionalizados (MACÊDO et al., 2004).

Os testes de triagem nos bancos de sangue ainda são os maiores aliados na investigação do HTLV na população em geral, auxiliando no encaminhamento de pacientes passíveis de estarem infectados com o HTLV para o serviço de infectologia.

O principal motivo que levou os indivíduos analisados a executar a sorologia confirmatória para o HTLV foi a doação de sangue $(38,8 \%)$, seguido de sintomas compatíveis com TSP/HAM em $30 \%$ dos casos.

A análise dos dados médico-clínicos relativos à infecção pelo HTLV colhidos na pesquisa, também proporcionou a confecção de um perfil clínico do paciente infectado.

As co-morbidades e co-infecções estiveram presentes em $62,5 \%(n=87)$ dos pacientes entrevistados, sendo que as doenças sistêmicas mais freqüentes foram as hepatopatias $(n=47)$ e a HAS $(n=29)$ (Figura 5.6) e as co-infecções o HIV e as hepatites virais (Figura 5.7).

A maior prevalência de doenças hepáticas pode estar relacionada à grande quantidade de indivíduos portadores de hepatites virais (Figura 5.7).

Em decorrência da necessidade de tratamento para as manifestações do HTLV, das co-morbidades e co-infecções por outros vírus, 97 pacientes $(69,7 \%)$ faziam uso regular de medicações (Figura 5.8). As medicações de uso regular mais 
observadas entre os entrevistados foram os ARV (antirretrovirais) $(n=29)$, seguidos do baclofeno $(n=28)$ e de anti-hipertensivos $(n=21)$ (Figura 5.8).

Grande parte dos pacientes que possuíam exames de CD4 (n=97) e CD8 ( $\mathrm{n}=73)$ (Tabela 5.7) apresentou resultados compatíveis com os níveis de normalidade (Anexo E).

Apenas 26 pacientes estavam em acompanhamento há mais de 5 anos no IIER (Tabela 5.8) e entre estes, pudemos observar o aumento da incidência de alterações bucais nos pacientes com maior tempo de seguimento (Figura 5.15).

Os indivíduos que participaram do presente estudo portadores do HTLV-1, não positivos para TSP/HAM $(57,1 \%)$, representavam um pouco mais da metade dos casos (Figura 5.10). Mas os pacientes deste grupo mesmo não tendo preenchido todos os critérios de diagnóstico da TSP/HAM, relataram sintomas compatíveis com a doença (Figura 5.10).

Já os pacientes comprovadamente portadores da TSP/HAM, em quase a totalidade $(94 \%)$ dos 48 entrevistados relataram sintomas (Figura 5.10) associados à doença como descrito anteriormente (EDLICH; ARNETTE; WILLIAMS, 2000; VERDONCK et al., 2007), sendo as dores em membros inferiores as queixas mais comuns nestes pacientes (Tabela 5.9).

Devido à existência de sintomas associados à TSP/HAM, o uso regular de medicações foi relatado por $87,7 \%$ dos pacientes (Figura 5.11).

As alterações bucais encontradas e/ou referidas em 74 pacientes do nosso estudo foram a xerostomia $(n=36)$, lesões compatíveis com candidíase $(n=29)$, língua fissurada $(n=25)$ e a língua depapilada $(n=14)$ (Figura 5.12).

Não foram identificadas lesões da ALLT e SS nos pacientes avaliados. 
Caskey e colaboradores em 2007 estudaram a prevalência das diversas manifestações clínicas associadas ao HTLV-1, sendo a xerostomia $(n=39)$ e o sangramento gengival $(n=24)$ as principais alterações bucais relatadas pelos pacientes (CASKEY et al., 2007). A prevalência da xerostomia foi semelhante à encontrada em nossos pacientes (Figura 5.12).

A xerostomia foi a alteração bucal mais freqüentemente relatada pelos pacientes analisados (26,5\%), sendo relatada em especial, por pacientes HTLV-1 soropositivos portadores da TSP/HAM $(p=0,004)$.

Xerostomia é definida como uma sensação subjetiva de boca seca que pode ser causada por alterações na produção ou na qualidade de saliva. Geralmente, a xerostomia acomete com mais freqüência pacientes do sexo feminino, com idade avançada e que utilizam mais de uma medicação de uso regular (CASSOLATO; TURNBULL, 2003).

As principais alterações bucais observadas (xerostomia, língua fissurada, língua depapilada e candidíase) podem estar co-relacionadas entre si, uma vez que a xerostomia pode causar a friabilidade das mucosas gerando a formação de fissuras e úlceras. Conseqüentemente os tecidos orais estarão mais susceptíveis a infecções fúngicas como a candidíase (CASSOLATO; TUNRBULL, 2003).

A xerostomia também pode desencadear o surgimento de outra alteração bucal encontrada neste estudo, a queilite angular (CASSOLATO; TUNRBULL, 2003; VON BÜLTZINGSLÖWEN et al., 2007).

Existem diversos fatores que podem ser considerados como modificadores na produção da saliva normal.

As co-infecções provocadas pelo $\mathrm{HIV}, \mathrm{HCV}$ são relacionadas ao desenvolvimento de sialodenite induzida pela infiltração linfocítica da glândula salivar 
gerando o aparecimento da xerostomia e conseqüente aumento das glândulas parótidas, que são as responsáveis pela produção de saliva serosa do organismo (CARROZZO; GANDOLFO, 2003; VON BÜLTZINGSLÖWEN et al., 2007).

Esta associação também pode ocorrer em pacientes portadores de algumas doenças sistêmicas como a diabetes, onde é sugerida onde ocorre a substituição gradativa do parênquima glandular por tecido fibroso causando a hipertrofia das glândulas parótidas (VON BÜLTZINGSLÖWEN et al., 2007).

Em pacientes soropositivos para o HIV a relação com a infecção por Candida albicans é consagrada na literatura mundial quando associada a estágios de imunossupressão (BACCAGLINI et al., 2007).

O nosso estudo apontou esta associação onde a presença de candidíase se mostrou estaticamente significativa ao relacionarmos o aparecimento da infecção aos baixos níveis de CD4 apresentado pelos pacientes portadores de HTLV coinfectados pelo HIV e foi concluído que os pacientes que apresentaram níveis de CD4 $<500$ possuem aproximadamente 7 vezes mais chance de desenvolver candidíase quando comparados com pacientes que exibem os valores de CD4 $>1000(\mathrm{OR}=6,60 ; 95 \% \mathrm{IC}=1,01-43,04)$.

Hábitos deletérios como o tabagismo e o uso regular de medicamentos também podem contribuir para a ocorrência de alterações em língua e a xerostomia, estes fatores são ainda mais precipitadores destas manifestações orais com o aumento da idade dos pacientes (CASSOLATO; TUNRBULL, 2003; MOORE; GUGGENHEIMER, 2008).

O presente estudo era composto em sua maioria por pacientes com condições favoráveis ao surgimento das alterações bucais descritas, contudo, as análises estatísticas realizadas não demonstraram significância entre a maior parte 
dos fatores modificadores e o aparecimento da língua depapilada e da língua fissurada nos pacientes entrevistados.

Quando foram realizados testes estatísticos exatos (teste exato de Fisher, para tabelas $2 \times 2$ e simulações de Monte Carlo, para tabelas $3 \times 2$ e $7 \times 2$ ), foram observados valores significativos e a ocorrência da xerostomia entre pacientes que desenvolveram a TSP/HAM.

mesmo ocorreu quando foram analisados os pacientes que faziam o uso regular de medicações.

Entretanto, quando foram realizados os testes de regressão logística multivariada foi demonstrado que pacientes portadores da TSP/HAM possuíam aproximadamente 3 vezes mais chances de desenvolver xerostomia quando comparados a pacientes que não são portadores da TSP/HAM, mesmo após o controle para o uso de medicamentos $(\mathrm{OR}=2,69 ; 95 \% \mathrm{IC}=1,17-6,17)$, ou seja, em pacientes soropositivos para o HTLV-1 e portadores da TSP/HAM a presença da xerostomia pode ser considerada um fator de risco independente dos fatores modificadores de saliva normal. 


\section{CONCLUSÕES}

- As alterações bucais mais freqüentemente encontradas em pacientes soropositivos para o HTLV foram a xerostomia, a candidíase, a língua fissurada e a língua depapilada, sendo a xerostomia a alteração mais relatada pelos pacientes estudados;

- Não foram identificadas lesões de ATLL em cavidade bucal nos pacientes estudados;

- Pacientes soropositivos para o HTLV-1 portadores da TSP/HAM apresentaram xerostomia independente da presença de fatores modificadores da saliva normal. 


\section{REFERÊNCIAS ${ }^{1}$}

Albuquerque M, Migliari D, Sugaya N, Kuroishi M, Capuano A, de Sousa S, et al. Adult T-cell leukemia/lymphoma with predominant bone involvement, initially diagnosed by its oral manifestation: A case report. Oral Surg Oral Med Oral Pathol Oral Radiol Endodont 2005;100(3):315-20.

Asquith B, Mosley AJ, Heaps A, Tanaka Y, Taylor GP, McLean AR, et al. Quantification of the virus-host interaction in human $T$ lymphotropic virus I infection. Retrovirology 2005;2:75.

Baccaglini L, Atkinson JC, Patton LL, Glick M, Ficarra G, Peterson DE. Management of oral lesions in HIV-positive patients. Oral Surg Oral Med Oral Pathol Oral Radiol Endod 2007 Mar;103 Suppl:S50.e1-23

Bangham CR. HTLV-I infections. J Clin Pathol 2000; 53(8):581-6.

Bangham CR. The immune control and cell-to-cell spread of human T-lymphotropic virus type 1. J Gen Virol 2003; 84(pt12):3177-89.

Bangham CR, Osame M. Cellular immune response to HTLV-1. Oncogene 2005;24(51):6035-46.

Barcellos NT, Fuchs SC, Mondini LG, Murphy EL. Human T Lymphotropic Virus type I/II infection: prevalence and risk factors in individuals testing for HIV in counseling centers from southern Brazil. Sex Transm Dis 2006; 33(5):302-6.

Britto AP, Galvão-Castro B, Straatmann A, Santos-Torres S, Tavares-Neto J. Infecção pelo HTLV-I/II no Estado da Bahia. Rev Soc Bra Med Trop 1998;31(1):354.

Broder S, Gallo RC. A pathogenic retrovirus (HTLV-III) linked to AIDS. N Engl J Med 1984;311(20):1292-7.

\footnotetext{
${ }^{1}$ De acordo com o Estilo Vancouver. Abreviatura de Periódicos segundo base de dados MEDLINE.I
} 
Broutet N, Queiroz A S, F Basilio P, Sá HL, Simon F, Dabis F. Prevalence of HIV-1, HIV-2 and HTLV antibody, in Fortaleza, Ceara, Brazil,1993 \pm 1994. Int J STD AIDS. 1996 Aug-Sep;7(5):365-9.

Calattini S, Chevalier S A, Duprez R, Bassot S, Froment A, Mahieux R et al. Discovery of a new human T-cell lymphotropic virus (HTLV-3) in Central Africa. Retrovirology 2005;2(1):30.

Carneiro-Proietti AB, Ribas JG, Catalan-Soares BC, Martins ML, Brito-Melo GE, Martins-Filho OA, et al. Infection and disease caused by the human T cell lymphotropic viruses type I and II in Brazil. Rev Soc Bras Med Trop 2002; 35(5):499508.

Carrozzo M, Gandolfo S. Oral diseases possibly associated with hepatitis C virus. Crit Rev Oral Biol Med 2003;14(2):115-27.

Cartier L, Vergara C, Ramírez E. Proteína Tax (HTLV-I), probable factor patogénico y marcador Del síndrome sicca que se asocia a HAM/TSP. Rev Méd Chile 2005;133(10):1183-90.

Caskey MF, Morgan DJ, Porto AF, Giozza SP, Muniz AL, Orge GO et al., Clinical manifestations associated with HTLV type I infection: a cross-sectional study. AIDS Res Hum Retroviruses 2007 Mar;23(3):365-71.

Casseb J, Penalva-de-Oliveira AC. The tropical of spastic paraparesis- Human T cell leukemia type 1-associated myelophaty (TSP/HAM). Braz J Medic Biol 2000;33(12):1395-401.

Cassolato SF, Turnbull RS. Xerostomia: clinical aspects and treatment. Gerodontology 2003;20(2):64-77.

Catalan-Soares B, Carneiro-Proietti AB, Proietti FA.. Heterogeneous geographic distribution of human T-cell lymphotropic viruses I and II (HTLV-I/II): serological screening prevalence rates in blood donors from large urban areas in Brazil. Cad Saúde Pública 2005;21(3):926-31.

Cavrois M, Gessain A, Gout O, Wain-Hobson S, Wattel E. Common human T cell leukemia virus type 1 (HTLV-1) integration sites in cerebrospinal fluid and blood lymphocytes of patients with HTLV-1-associated myelopathy/tropical spastic paraparesis indicate that HTLV-1 crosses the blood-brain barrier via clonal HTLV-1infected cells. J Infect Dis 2000;182(4):1044-50. 
Cavrois M, Leclercq I, Gout O, Gessain A, Wain-Hobson S, Wattel E. Persistent oligoclonal expansion of human T-cell leukemia virus type 1-infected circulating cells in patients with Tropical spastic paraparesis/HTLV-1 associated myelopathy. Oncogene 1998;17(1):77-82.

Dourado I, Alcantara LCJ, Barreto ML, Teixeira MG, Galvão-Castro B. HTLV- I in the general population of salvador, brazil. a city with african ethnic and sociodemographic characteristics. J Acquir Immune Defic Syndr 2003;4(5):527-31.

Edlich RF, Arnette JA, Williams FM. Global epidemic of human T-cell lymphotrophic virus type-I (HTLV-I). J Emerg Med 2000;18(1):109-19.

Eguchi K, Matsuoka N, Ida H, Nakashima M, Sakai M, Sakito S, et al. Primary Sjögren's syndrome with antibodies to HTLV-I: clinical and laboratory features. Ann Rheum Dis 1992 Jun;51(6):769-76.

Etzel A, Shibata GY, Rozman M, Jorge ML, Damas CD, Segurado AA.. HTLV-1 and HTLV-2 Infections in HIV-Infected Individuals From Santos, Brazil: seroprevalence and risk factors. J AIDS 2001;26:185-90.

Feuer G, Green PL. Comparative biology of human T-cell lymphotropic virus type 1 (HTLV-1) and HTLV-2. Oncogene 2005;24(39):5996-6004.

Figueiró-Filho EA, Senefonte FR, Lopes AH, de Morais OO, Souza Júnior VG, et al. Frequency of HIV-1, rubella, syphilis, toxoplasmosis, cytomegalovirus, simple herpes virus, hepatitis $B$, hepatitis $C$, Chagas disease and HTLV I/II infection in pregnant women of State of Mato Grosso do Sul. Rev Soc Bras Med Trop. 2007;40(2):181-7.

Franchini G. Molecular Mechanisms of Human T-cell Leukemia/Lymphotropic VirusType I Infection. Blood 1995;86(10):3619-39.

Gonsalez D, Oliveira JS, Haapalainen E, Kerbauy J. Hairy cell leukemia: a histocytochemical and ultra-structural study. Sao Paulo Med J 1998;116(2):1681-5.

Guimarães ML, Bastos FI, Telles PR, Galvão-Castro B, Diaz RS, Bongertz V, et al. Retrovirus infections in a sample of injecting drug users in Rio de Janeiro City, Brazil: prevalence of HIV-1 subtypes, and co-infection with HTLV-I/II. J Clin Virol 2001 May;21(2):143-51. 
Hida A, Kawabe Y, Kawakami A, Migita K, Tominaga M, Nakamura H et al. HTLV-I associated Sjögren's syndrome is aetiologically distinct from anti-centromere antibodies positive Sjögren's syndrome. Ann Rheum Dis 1999;58(5);320-322.

ICTVdB Management 00.061. Retroviridae. In: ICTVdB - The Universal Virus Database, version 3. Büchen-Osmond, C. (Ed), Columbia University, New York, USA 2006. Disponível em URL: http://www.ncbi.nlm.nih.gov/ICTVdb/ICTVdB/ [2008 mai 12].

Jacob F, Santos-Fortuna E, Azevedo RS, Caterino-De-Araujo A. Performances of HTLV serological tests in diagnosing HTLV infection in high-risk population of São Paulo, Brazil. Rev Inst Med Trop S Paulo 2007;49(6):361-64.

Jordan R, Diss TC, Lench NJ, Isaacson PG, Speight PM. Immunoglobulin gene rearrangements in lymphoplasmacytic infiltrates of labial salivary glands in Sjögren's syndrome a possible predictor of lymphoma development. Oral Surgery Oral Med Oral Pathol Oral Radiol Endod 1995;79(6):723-9.

Kassan SS, Moutsopoulos H M. Clinical manifestations and early diagnosis of Sjögren syndrome. Arch Intern Med 2004;164(12):1275-84.

Macêdo O, Ribeiro-Lima TV, Linhares Ade O, de Moura A, Gomes Mde L, Linhares AC. Human T-cell lymphotropic virus types I and II infections in a cohort of patients with neurological disorders in Belém, Pará, Brazil. Rev Inst Med Trop Sao Paulo 2004 Jan-Feb;46(1):13-7.

Manel N, Batinni JL, Taylor N, Sitbon M. HTLV-1 tropism and envelope receptor. Oncogene 2005;24(39):6016-25.

Manns A, Wilks RJ, Murphy EL, Haynes G, Figueroa JP, Barnett M, et al. A prospective study of transmission by transfusion of HTLV-I and risk factors associated with seroconversion. Int J Cancer 1992;51(6):886-91.

Manual de hematologia Instituto Fleury. Disponível em URL: http://www.fleury.com.br/Medicos/SaudeEmDia/ManualHematologia/Pages/Introdu\% C3\%A7\%C3\%A3o.aspx [2008 Jul 11]

Matsuoka M, Jeang KT. Human T-cell leukemia virus type I induces adult T-cell leukemia: from clinical aspects to molecular mechanisms. Cancer Control 2007;14(2):133-40. 
Merle H, Cabre P, Smadja D, Josset P, Landau M, Vernant JC. Sicca syndrome and HTLV-I-associated myelopathy/tropical spastic paraparesis. Jpn J Ophthalmol 1999;43(6):509-12.

Moore PA, Guggenheimer J. Medication-induced hyposalivation: etiology, diagnosis, and treatment. Compend Contin Educ Dent 2008;29(1):50-5.

Moriuchi $\mathrm{M}$, Moriuchi $\mathrm{H}$. A milk protein lactoferrin enhances human t cell leukemia virus type i and suppresses HIV-1 infection. J Immunol 2001;166 (6):4231-36.

Moriuchi M, Moriuchi $\mathrm{H}$. Induction of lactoferrin gene expression in myeloid or mammary gland cells by human T-cell leukemia virus type 1 (HTLV-1) tax: implications for milk-borne transmission of HTLV-1. J Virol 2006;80(14):7118-26.

Murphy EL, Jacobson S, Franchini G, Taylor GP, Hanchard B, Morgan O, Lairmore M. International Retrovirology Association brings together scientists and clinicians to bridge discoveries about human T-lymphotropic viruses from the laboratory to clinical trials. Retrovirology 2005;2(1):22.

Nakamura H, Kawakami A, Tominaga M, Hida A, Yamasaki S, Migita K, et al. Relationship between Sjogren's syndrome and human T-lymphotropic virus type I infection: follow-up study of 83 patients. J Lab Clin Med 2000;135(2):139-44.

Nakamura H, Eguchi K, Nakamura T, Mizokami A, Shirabe S, Kawakami A, et al. High prevalence of Sjögren's syndrome in patients with HTLV-I associated myelopathy Ann Rheum Dis 1997;56(3):167-72.

Obama K, Saito M, Higuchi I, Tara M, Niina K, Osame M. Adult T-cell leukemia predominantly involving exocrine glands. Eur J Haematol 2004;73(5):332-9.

Ohyama Y, Nakamura S, Hara H, Shinohara M, Sasaki M, Ikebe-Hiroki A, Mouri T, Tsunawaki S, Abe K, Shirasuna K, Nomoto K. Accumulation of human T lymphotropic virus type I-infected $T$ cells in the salivary glands of patients with human T lymphotropic virus type I-associated Sjögren's syndrome. Arthritis Rheum. 1998;41(11):1972-8.

Ortega KL. Aspectos demográficos, clínicos e odontológicos de 1200 pacientes HIV positivos do centro de atendimento a pacientes especiais (CAPE-FOUSP) [Tese de Doutorado]. São Paulo: Faculdade de Odontologia da USP; 2000. 
Osame M. Pathological mechanisms of human T-cell lymphotropic virus type Iassociated myelopathy (HAM/TSP). J NeuroVirol 2002;8(5):359-64.

Poiesz BJ, Ruscetti FW. Godzar AF, Bunn PA, Miuna JD, Gallo RC. Detection and isolation of type $C$ retrovirus particles from fresh and cultured lymphocytes of patient with cutaneous T-cell lymphoma. Natcl USA 1980;415-9.

Proietti FA, Carneiro-Proietti ABF, Catalan-Soares B, Murphy EL. Global Epidemiology of HTLV-I infection and associated diseases. Oncogene 2005; 24(39):6058-68.

Ribas JGR, Melo GCN. Mielopatia associada ao vírus linfotrópico humano de células T do adulto do tipo 1 (HTLV-1). Rev Soc Bras Med Trop 2002;35(4): 377-84.

Roucoux DF, Wang B, Smith D, Nass CC, Smith J, Hutching St et al. A prospective study of sexual transmission of human T lymphotropic virus (HTLV)-I and HTLV-II. J Infect Dis 2005;191(9):1490-7.

Sasaki M, Nakamura S, Ohyama Y, Shinohara M, Ezaki I, Hara H et al. Accumulation of common T cell clonotypes in the salivary glands with human T lymphotropic vírus type I - associated and idiopatic Sjögren`s syndrome. J Immunol 2000;164(5):282331.

Segami N, Hosoda M, Fukuda M, Sugihara T, Yahata Y. Adult T-cell leukemia/lymphoma of the tongue. Oral Surg Oral Méd Oral Pathol 1990;70(2):206-9.

Swainson L, Kinet S, Manel N, Battini JL, Sitbon M, Taylor N. Glucose transporter 1 expression identifies a population of cycling CD4_CD8_ human thymocytes with high CXCR4-induced chemotaxis. PNAS 2005;102 (36):12867-72.

Switzer WM, Qari SH, Wolfe ND, Burke DS, Folks TM, Heneine W. Ancient origin and molecular features of the novel human T-lymphotropic virus type 3 revealed by complete genome analysis. J Virol 2006;80(15):7427-38.

Takase K, Ohyagi Y, Furuya H, Nagashima K, Taniwaki T, Kira J. A case of progressive multifocal leukoencephalopathy presenting white matter MRI lesions extending over the cerebral cortex and a marked decrease in cerebral blood flow on SPECT, and associated with HTLV-I infection. Rinsho Shinkeigaku 2005;45(6):42630. 
Talal N. Sjögren's syndrome: historical overview and clinical spectrum of disease. Rheum Dis Clin N Am 1992;18(3):507-15.

Terada K, Katamine S, Eguchi K, Moriuchi R, Kita M, Shimada H, et al. Prevalence of serum and salivary antibodies to HTLV-I in Sjögren's syndrome. Lancet 1994;344(8930):1116-19.

Thorstensson R, Albert J, Andersson S, Strategies for diagnosis of HTLV-I and -II. Transf 2002;42(6):780-91.

Tong GX, Hernandez O, Yee HT, Zheng SH, Yang GC. Human T-lymphotropic virus type-1 related adult T-cell leukemia/lymphoma presenting as a parotid mass diagnosed by fine-needle aspiration biopsy. Diagn Cytopathol. 2004 Nov;31(5):333-7.

Tsukasaki K, Koeffler P, Tomonaga M. Human T-lymphotropic virus type 1 infection. Bail Clin Haematol 2000;13(2):231-43.

Vallinoto AC, Muto NA, Pontes GS, Machado LF, Azevedo VN, dos Santos SE et al. Serological and molecular evidence of HTLV-I infection among Japanese immigrants living in the Amazon region of Brazil. Jpn J Infect Dis. 2004 Aug;57(4):156-9.

Vallinoto AC, Pontes GS, Muto NA, Lopes IG, Machado LF, Azevedo VN, et al. Identification of human T-cell lymphotropic virus infection in a semi-isolated AfroBrazilian quilombo located in the Marajó Island (Pará, Brazil). Mem Inst Oswaldo Cruz. 2006;101(1):103-5.

Verdonck K, González E, Van Dooren S, Vandamme A, Vanham G, Gotuzzo E. Human T-lymphotropic virus 1: recent knowledge about an ancient infection. Lancet Infect Dis 2007;7(4):266-81.

Vine AM, Heaps AG, Kaftantzi L, Mosley A, Asquith B, Witkover A, et al. The role of CTLs in persistent viral infection: cytolytic gene expression in CD8+ lymphocytes distinguishes between individuals with a high or low proviral load of human $\mathrm{T}$ cell lymphotropic virus type 1. J Immunol 2004;173(8):5121-9.

von Bültzingslöwen I, Sollecito TP, Fox PC, Daniels T, Jonsson R, Lockhart PB, et al. Salivary dysfunction associated with systemic diseases: systematic review and clinical management recommendations. Oral Surg Oral Med Oral Pathol Oral Radiol Endod 2007 Mar;103 Suppl:S57.e1-15. 
Wolfe N D, Heneine W, Carr J K, Garcia A, Shanmugam V, Tamoufe U, et al. Emergence of unique primate T-lymphotropic viruses among central African bushmeat hunters. Proc Natl Acad Sci USA 2005;102(22):7994-9.

Wong-Staal F, Gallo RC. The family of human T-lymphotropic leukemia viruses: HTLV-I as the cause of adult T cell leukemia and HTLV-III as the cause of acquired immunodeficiency syndrome. Blood 1985;65(2):253-63.

Yamano S, Renard JN, Mizuno F, Narita Y, Uchida Y, Higashiyama H, et al. Retrovirus in salivary glands from patients with Sjogren's syndrome. J Clin Pathol 1997;50(3):223-30.

Yoshida M. Discovery of HTLV-1, the first human retrovirus, its unique regulatory mechanisms, and insights into pathogenesis. Oncogene 2005 Sep 5;24(39):5931-7.

Zervou EK, Georgiadou S, Tzilianos M, Georgitsi P, Pournara V, Nousis S et al. Human T-lymphotropic virus type I/II infections in volunteer blood donors from Northern and Western Greece: increased prevalence in one blood bank unit. Eur J Intern Med 2004;15(7):422-7. 
ANEXO A - Parecer do Comitê de Ética em Pesquisa

SECRETARIA DE ESTADO DA SAÚDE COORDENACCÃO DOS SERVIÇOS DE SAÚDE INSTITUTO DE INFECTOLOGIA "EMILIO RIBAS" COMITÊ DE ÉTICA EM PESQUISA

Av. Dr. Arnaldo, 165 - Cerqueira César - São Paulo - SP CEP: $01246-900-$ TEL: $3896-1406$

\section{PARECER}

PROTOCOLO DEPESQUISA N. ${ }^{\circ}$ 54/04 Data da entrada:

PARECER N.o 057/2005 Sessão: 23/02/2005

Titulo da Pesquisa: "Avaliação clínica de alterações bucais em pacientes portadores de HTLV"

Investigador Principal: Dra. Karen Lopez Ortega

CONSIDERAÇÕES: $O$ Comitê de Ética em Pesquisa considera respondidas as pendências do parecer anterior a Aprova o Protocolo.

(X) APROVADO

( ) APROVADO COM RECOMENDAÇÕES

( ) REPROVADO

( ) COM PENDÊNCIAS- OBS.: a ausência de resposta em 60 dias, acarretará em arquivamento do processo por falta de interesse do pesquisador.
TEMÁTICA ESPECIAL
$\square$ SIM
NÃO
$\square$ SIM

CONEP

$\square$ NÃO

SVS (SECRETARIA DE VIGILÂNCIA SANITÁRIA)

$\square$ SIM

$\square$ NÃO

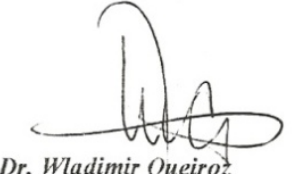

Dr. Wladimir Queiro

Comitê de Etica em Pesquisas - I.I.E.R 
ANEXO B - Ficha clínica elaborada para o estudo

Ficha clínica

$N^{\circ}$ RG IIER

PACIENTES PORTADORES DO HTLV

IDENTIFICAÇÃO

Nome:

Endereço:

Bairro: Cidade: CEP:

Telefone res. Telefone com.

Data de nasc.: Idade: Sexo: Cor: Est. Civil:

Profissão: Nacionalidade: Naturalidade:

Escolaridade:

Filiação:

Responsável:

RG:

São Paulo, de de 


\section{ANAMNESE}

\section{Queixa principal}

\section{História da doença atual}

\section{História médica}

Data do $1^{\circ}$ anti-HTLV Tempo de seguimento Tipo

Porque fez o teste

Via provável de contaminação:

SEXUAL UDI TRANSFUSÃO VERTICAL

Outras formas de transmissão

Doenças/alterações sistêmicas:

\begin{tabular}{|l|l|l|l|}
\hline Hepatopatias ( ) & Nefropatias ( ) & Anemias ( ) & Distúrbios \\
\hline TSP/HAM ( ) & Convulsões ( ) & Hemofilia ( ) & Diabetes ( ) Tipo _ \\
\hline Cardiopatias ( ) & Hipertensão & Problemas gástricos ( ) \\
\hline Doenças dermatológicas ( ) & \\
\hline Outras: & \\
\end{tabular}




\begin{tabular}{|l|l|l|l|}
\hline Sarcoma de Kaposi ( & Meningite ( ) & Hepatite ( ) Tipo - & Pneumonia ( ) \\
\hline PCP ( ) & Tuberculose ( ) & Herpes Zoster ( ) & Toxoplasmose ( \\
\hline Neurotoxoplasmose ( & Criptococose ( ) & Neurocriptococose & Sífilis ( ) \\
\hline Condiloma & Herpes genital ( & Candidíase genital & Gonorréia ( ) \\
acuminado ( ) & ( ) & \\
\hline Micobacteriose ( ) & Linfoma ( ) & Retinite por CMV ( & CMV ( ) \\
\hline Histoplasmose ( ) & Encefalopatia & Neuropatia & Angiomatose \\
\hline Candidíase & HIV ( ) & periférica ( ) & bacilar ( ) \\
esofagiana ( ) & Neoplasias malignas ( ) & \\
\hline Outras ( ) & & & \\
& & & \\
\hline
\end{tabular}

Medicação em uso:

\begin{tabular}{|l|l|l|l|l|}
\hline Nome comercial e farmacológico & Apresentação & Quantidad & $\begin{array}{l}\text { Intervalo } \\
\text { e tempo }\end{array}$ & Duração \\
\hline & & & & \\
\hline & & & & \\
\hline & & & & \\
\hline & & & & \\
\hline
\end{tabular}




\section{História Odontológica}

Problemas para ser atendido após a soropositividade?

Algum problema durante os tratamentos anteriores?

\section{Hábitos}

Tabagismo ( ) Quantidade ao dia Tempo

Etilismo ( ) Quantidade Freqüência

Drogas ( ) Quais?

Observações

EXAME FÍSICO EXTRA BUCAL

Aspecto geral

Linfonodos

EXAME FÍSICO INTRA BUCAL 
NEXO C - Termo de Consentimento Livre e Esclarecido

Secretaria de Estado da Saúde
Coordenação dos Institutos de Pesquisa

Instituto de Infectologia Emilio Ribas

\section{TERMO DE CONSENTIMENTO LIVRE E ESCLARECIDO}

"Avaliação clinica de alterações bucais em pacientes soropositivos para o HTLV."

Você tem um tipo de vírus denominado HTLV e está sendo convidado a participar do estudo "Avaliação clínica de alterações bucais em pacientes portadores do HTLV". Os avanços na área da saúde ocorrem através de estudos como este, por isso a sua participação é importante. O objetivo deste estudo é identificar e diagnosticar alterações na boca de pacientes com HTLV.

Caso você participe, será necessário fazer um exame clínico odontológico, que será feito por dentistas treinados, com a finalidade de identificar doenças na boca de pessoas com HTLV. O exame será executado no ambulatório do Instituto de Infectologia Emílio Ribas, durante a sua consulta médica, em cadeira comum, com luz artificial e os dentistas utilizarão espátulas de madeira para visualizar melhor todas as regiões da boca. Caso seja identificada alguma alteração na sua boca, o dentista poderá executar os procedimentos clínicos rotineiros para o diagnóstico. Esses procedimentos podem ser a solicitação de exames de sangue ou a remoção cirúrgica de um pequeno fragmento da lesão (sob anestesia local) para análise no laboratório. Todos os procedimentos serão executados no ambulatório do Instituto de Infectologia Emílio Ribas. Alguns pacientes podem sentir um leve desconforto passageiro após a remoção cirúrgica, mas não existem riscos envolvidos com estes procedimentos. Não existe outra forma de fazer o diagnóstico de doenças da boca. Esta pesquisa Ihe trará o benefício de saber se você tem ou não alguma doença de boca e, se ela existir, você poderá ser encaminhado para tratá-la.

Você poderá ter todas as informações que quiser sobre a pesquisa e poderá não participar da pesquisa ou retirar seu consentimento a qualquer momento, sem prejuízo no seu atendimento. Também é garantida a possibilidade de conversar com o pesquisador responsável ou com representantes do Comitê de Ética em Pesquisa (CEP) do Instituto de Infectologia Emílio Ribas, em qualquer momento durante a pesquisa. Pela sua participação no estudo, você não receberá qualquer valor em dinheiro, mas terá a garantia de que todas as despesas necessárias para a realização da pesquisa não serão de sua responsabilidade. Seu nome não aparecerá em qualquer momento do estudo, pois você será identificado com um número.

Qualquer dano eventual, diretamente ligado aos procedimentos descritos neste projeto, será absorvido pela Instituição.

\begin{tabular}{|c|c|}
\hline squisador Responsável: & uipe de Pesquisadores: \\
\hline $\begin{array}{l}\text { Dra. Karem López Ortega } \\
\text { culdade de Odontologia da USP } \\
\text { entro de Atendimento a Pacientes Especiais } \\
\text { Av.: Professor Lineu Prestes } 2227 \\
\text { Cidade Universitária }\end{array}$ & $\begin{array}{l}\text { Dr. Fernando Watanuki } \\
\text { Dra. Fabiana Martins e Martins } \\
\text { Dra. Renata Takatu Costa } \\
\text { Dr. Jorge Casseb } \\
\text { Dr. Auqusto César Penalva de Oliveira }\end{array}$ \\
\hline Fones: 30917859 & \\
\hline
\end{tabular}




\section{CONSENTIMENTO LIVRE E ESCLARECIDO}

$\mathrm{Eu}$, li e/ou ouvi a carta de informações anexa e compreendi para que serve o estudo e qual procedimento a que serei submetido. A explicação que recebi esclarece os riscos e benefícios do estudo. Eu entendi que sou livre para interromper minha participação a qualquer momento, sem justificar minha decisão e que isso não afetará meu tratamento. Sei que meu nome não será divulgado, que não terei despesas e não receberei dinheiro por participar do estudo e que devo entrar em contato com a Dra. Karem López Ortega caso tenha alguma dúvida. Eu concordo, voluntariamente, em participar do estudo "Avaliação clínica de alterações bucais em pacientes portadores do HTLV".

\begin{tabular}{|l|l|l}
\hline Assinatura do voluntário (ou responsável legal) & & Número do documento de identidade: \\
\hline \hline Assinatura do pesquisador: & & \\
\hline & & \\
\hline Telefone de contato dos pesquisadores: & \\
\hline \hline Em caso de dúvida em relação a esse documento, você pode entrar em contato com o Comitê \\
\hline Ética em Pesquisa do Instituto de Infectologia Emílio Ribas, Av. Dr. Arnaldo, 165 - Cerqueira \\
\hline César - São Paulo - SP - fone:38961406. , cujo responsável é o Dr. Wladimir Queiroz \\
\hline
\end{tabular}


Por este instrumento, aceito colaborar com o projeto de pesquisa intitulado "Avaliação clinica de alterações bucais em pacientes soropositivos para o HTLV" que tem como principais objetivos:

- Identificar e diagnosticar alterações bucais em pacientes portadores de HTLV.

- No caso da identificação de uma patologia bucal, o paciente poderá ser submetido a exames complementares, tais como biópsia e citologia esfoliativa para diagnóstico final.

Declaro que meu consentimento na participação da pesquisa é voluntário, que não sofri qualquer tipo de pressão ou força. Informaram-me do direito de interromper e terminar a pesquisa a qualquer momento, sem prejuízo para o andamento de meu tratamento.

Fui informado e esclarecido que o trabalho consiste na pesquisa da presença de alterações bucais, que poderão ser identificadas durante o exame clínico.

Estou ciente que a avaliação clínica será realizada no ambulatório do Instituto de Infectologia Emílio Ribas, não sendo cobrado nenhum material ou mão de obra.

Aceito responder um questionário sobre minha saúde geral e bucal, assim como devo preencher os pré-requisitos do projeto para poder participar do mesmo.

Sei que minha identidade não será revelada sob qualquer circunstância, e que os dados e imagens posteriormente publicados em literatura não possibilitarão minha identificação. Informaram-me que qualquer dúvida adicional sobre a pesquisa, poderia entrar em contato com os coordenadores do projeto, (Profa. Dra. Karem López Ortega) pelo telefone 30917859 , durante o horário comercial, para o esclarecimento das mesmas.

Estou ciente que terei como benefício uma avaliação completa das condições bucais presentes.

São Paulo, de de 20

Nome: Assinatura: 
ANEXO D - Números Absolutos e Freqüência das variáveis do estudo

\begin{tabular}{|c|c|c|c|c|c|}
\hline & & Não & Sim & Total & Missing \\
\hline \multirow{2}{*}{ Boca seca } & $\mathbf{N}$ & 100 & 36 & 136 & 3 \\
\hline & $\%$ & 73,5 & 26,5 & & \\
\hline \multicolumn{2}{|c|}{ Língua depapiladi $\mathbf{N}$} & 99 & 14 & 113 & 26 \\
\hline & $\%$ & 87,6 & 12,4 & & \\
\hline \multirow[t]{2}{*}{ Língua fissurada } & $\mathbf{N}$ & 88 & 25 & 113 & 26 \\
\hline & $\%$ & 77,9 & 22,1 & & \\
\hline \multirow[t]{2}{*}{ Candidíase } & $\mathbf{N}$ & 85 & 29 & 114 & 25 \\
\hline & $\%$ & 74,6 & 25,4 & & \\
\hline \multirow[t]{2}{*}{ HTLV tipo 1} & $\mathbf{N}$ & 26 & 113 & 139 & 0 \\
\hline & $\%$ & 18,7 & 81,3 & & \\
\hline \multirow[t]{2}{*}{ HTLV tipo 2} & $\mathbf{N}$ & 112 & 27 & 139 & 0 \\
\hline & $\%$ & 80,6 & 19,4 & & \\
\hline \multirow[t]{2}{*}{ TSP/HAM } & $\mathbf{N}$ & 88 & 48 & 136 & 3 \\
\hline & $\%$ & 64,7 & 35,3 & & \\
\hline \multirow[t]{2}{*}{ Medicamentos } & $\mathbf{N}$ & 43 & 96 & 139 & 0 \\
\hline & $\%$ & 30,9 & 69,1 & & \\
\hline \multirow[t]{2}{*}{ Comorbidades } & $\mathbf{N}$ & 59 & 80 & 139 & 0 \\
\hline & $\%$ & 42,4 & 57,6 & & \\
\hline \multirow[t]{2}{*}{ Tabagismo } & $\mathbf{N}$ & 97 & 36 & 133 & 6 \\
\hline & $\%$ & 72,9 & 27,1 & & \\
\hline \multirow[t]{2}{*}{ Etilismo } & $\mathbf{N}$ & 127 & 6 & 133 & 6 \\
\hline & $\%$ & 95,5 & 4,5 & & \\
\hline \multirow[t]{2}{*}{ Drogas } & $\mathbf{N}$ & 123 & 9 & 132 & 7 \\
\hline & $\%$ & 93,2 & 6,8 & & \\
\hline
\end{tabular}




\section{Xerostomia}

\begin{tabular}{|c|c|c|c|c|c|}
\hline \multirow{4}{*}{ Xerostomia } & \multirow{4}{*}{$\begin{array}{l}\text { Não } \\
\text { Sim }\end{array}$} & \multicolumn{4}{|c|}{ Sexo } \\
\hline & & \multicolumn{2}{|c|}{ feminino } & \multicolumn{2}{|c|}{ masculino } \\
\hline & & 61 & $72,6 \%$ & 39 & $75,0 \%$ \\
\hline & & 23 & $27,4 \%$ & 13 & $25,0 \%$ \\
\hline & & \multicolumn{4}{|c|}{ HTLV tipo 1} \\
\hline & & \multicolumn{2}{|c|}{ Não } & \multicolumn{2}{|c|}{ Sim } \\
\hline \multirow[t]{4}{*}{ Xerostomia } & Não & 21 & $80,8 \%$ & 79 & $71,8 \%$ \\
\hline & Sim & 5 & $19,2 \%$ & 31 & $28,2 \%$ \\
\hline & & \multicolumn{4}{|c|}{ TSP/HAM } \\
\hline & & \multicolumn{2}{|c|}{ Não } & \multicolumn{2}{|c|}{ Sim } \\
\hline \multirow[t]{4}{*}{ Xerostomia } & Não & 71 & $81,6 \%$ & 26 & $56,5 \%$ \\
\hline & Sim & 16 & $18,4 \%$ & 20 & $43,5 \%$ \\
\hline & & \multicolumn{4}{|c|}{ HTLV tipo 2} \\
\hline & & \multicolumn{2}{|c|}{ Não } & \multicolumn{2}{|c|}{ Sim } \\
\hline \multirow[t]{4}{*}{ Xerostomia } & Não & 78 & $71,6 \%$ & 22 & $81,5 \%$ \\
\hline & Sim & 31 & $28,4 \%$ & 5 & $18,5 \%$ \\
\hline & & \multicolumn{4}{|c|}{ Medicamentos } \\
\hline & & \multicolumn{2}{|c|}{ Não } & \multicolumn{2}{|c|}{ Sim } \\
\hline \multirow[t]{4}{*}{ Xerostomia } & Não & 37 & $88,1 \%$ & 63 & $67,0 \%$ \\
\hline & Sim & 5 & $11,9 \%$ & 31 & $33,0 \%$ \\
\hline & & \multicolumn{4}{|c|}{ Comorbidades } \\
\hline & & \multicolumn{2}{|c|}{ Não } & \multicolumn{2}{|c|}{ Sim } \\
\hline \multirow[t]{4}{*}{ Xerostomia } & Não & 36 & $70,6 \%$ & 64 & $75,3 \%$ \\
\hline & Sim & 15 & $29,4 \%$ & 21 & $24,7 \%$ \\
\hline & & \multicolumn{4}{|c|}{ Tabagismo } \\
\hline & & \multicolumn{2}{|c|}{ Não } & \multicolumn{2}{|c|}{ Sim } \\
\hline \multirow[t]{4}{*}{ Xerostomia } & Não & 71 & $75,5 \%$ & 25 & $69,4 \%$ \\
\hline & Sim & 23 & $24,5 \%$ & 11 & $30,6 \%$ \\
\hline & & & & & \\
\hline & & & & & \\
\hline Xerostomia & Não & 91 & $73,4 \%$ & 5 & $83,3 \%$ \\
\hline & Sim & 33 & $26,6 \%$ & 1 & $16,7 \%$ \\
\hline & & & & & \\
\hline & & & & & \\
\hline Xerostomia & Não & 88 & $73,3 \%$ & 7 & $77,8 \%$ \\
\hline
\end{tabular}

Números Absolutos e Freqüência das variáveis em estudo em indivíduos com xerostomia.

\section{Língua Depapilada}




\begin{tabular}{|c|c|c|c|c|c|}
\hline \multirow{4}{*}{\begin{tabular}{|l|} 
Língua depapilada \\
\end{tabular}} & \multirow{4}{*}{$\begin{array}{l}\text { Não } \\
\text { Sim }\end{array}$} & \multicolumn{4}{|c|}{ Sexo } \\
\hline & & \multicolumn{2}{|c|}{ feminino } & \multicolumn{2}{|c|}{ masculino } \\
\hline & & 59 & $86,8 \%$ & 40 & $88,9 \%$ \\
\hline & & 9 & $13,2 \%$ & 5 & $11,1 \%$ \\
\hline & & \multicolumn{4}{|c|}{ HTLV tipo 1} \\
\hline & & \multicolumn{2}{|c|}{ Não } & \multicolumn{2}{|c|}{ Sim } \\
\hline \multirow[t]{4}{*}{ Língua depapilada } & Não & 20 & $100,0 \%$ & 79 & $84,9 \%$ \\
\hline & Sim & 0 & $0,0 \%$ & 14 & $15,1 \%$ \\
\hline & & \multicolumn{4}{|c|}{ TSP/HAM } \\
\hline & & \multicolumn{2}{|c|}{ Não } & \multicolumn{2}{|c|}{ Sim } \\
\hline \multirow[t]{4}{*}{ Língua depapilada } & Não & 56 & $86,2 \%$ & 40 & $88,9 \%$ \\
\hline & Sim & 9 & $13,8 \%$ & 5 & $11,1 \%$ \\
\hline & & \multicolumn{4}{|c|}{ HTLV tipo 2} \\
\hline & & \multicolumn{2}{|c|}{ Não } & \multicolumn{2}{|c|}{ Sim } \\
\hline \multirow[t]{4}{*}{ Língua depapilada } & Não & 78 & $84,8 \%$ & 21 & $100,0 \%$ \\
\hline & Sim & 14 & $15,2 \%$ & 0 & $0,0 \%$ \\
\hline & & \multicolumn{4}{|c|}{ Medicamentos } \\
\hline & & \multicolumn{2}{|c|}{ Não } & \multicolumn{2}{|c|}{ Sim } \\
\hline \multirow[t]{4}{*}{ Língua depapilada } & Não & 24 & $82,8 \%$ & 75 & $89,3 \%$ \\
\hline & Sim & 5 & $17,2 \%$ & 9 & $10,7 \%$ \\
\hline & & \multicolumn{4}{|c|}{ Comorbidades } \\
\hline & & \multicolumn{2}{|c|}{ Não } & \multicolumn{2}{|c|}{ Sim } \\
\hline \multirow[t]{4}{*}{ Língua depapilada } & Não & 33 & $89,2 \%$ & 66 & $86,8 \%$ \\
\hline & Sim & 4 & $10,8 \%$ & 10 & $13,2 \%$ \\
\hline & & \multicolumn{4}{|c|}{ Tabagismo } \\
\hline & & \multicolumn{2}{|c|}{ Não } & \multicolumn{2}{|c|}{ Sim } \\
\hline Língua depapilada & Não & 71 & $89,9 \%$ & 26 & $89,7 \%$ \\
\hline & Sim & 8 & $10,1 \%$ & 3 & $10,3 \%$ \\
\hline & & & & & \\
\hline & & & & & \\
\hline Língua depapilada & Não & 94 & $91,3 \%$ & 3 & $60,0 \%$ \\
\hline & Sim & 9 & $8,7 \%$ & 2 & $40,0 \%$ \\
\hline & & & & & \\
\hline & & & & & \\
\hline Língua depapilada & Não & 89 & $89,0 \%$ & 8 & $100,0 \%$ \\
\hline & Sim & 11 & $11,0 \%$ & 0 & $0,0 \%$ \\
\hline
\end{tabular}

Números Absolutos e Freqüência das variáveis em estudo em indivíduos com Língua Depapilada 


\section{Língua Fissurada}

\begin{tabular}{|c|c|c|c|c|c|}
\hline \multirow{4}{*}{\begin{tabular}{|l|} 
\\
Língua fissurada
\end{tabular}} & \multirow{4}{*}{$\begin{array}{l}\text { Não } \\
\text { Sim }\end{array}$} & \multicolumn{4}{|c|}{ Sexo } \\
\hline & & \multicolumn{2}{|c|}{ feminino } & \multicolumn{2}{|c|}{ masculino } \\
\hline & & 52 & $76,5 \%$ & 36 & $80,0 \%$ \\
\hline & & 16 & $23,5 \%$ & 9 & $20,0 \%$ \\
\hline & & \multicolumn{4}{|c|}{ HTLV tipo 1} \\
\hline & & \multicolumn{2}{|c|}{ Não } & \multicolumn{2}{|c|}{ Sim } \\
\hline \multirow[t]{4}{*}{ Língua fissurada } & Não & 16 & $80,0 \%$ & 72 & $77,4 \%$ \\
\hline & Sim & 4 & $20,0 \%$ & 21 & $22,6 \%$ \\
\hline & & \multicolumn{4}{|c|}{ TSP/HAM } \\
\hline & & \multicolumn{2}{|c|}{ Não } & \multicolumn{2}{|c|}{ Sim } \\
\hline \multirow[t]{4}{*}{ Língua fissurada } & Não & 51 & $78,5 \%$ & 34 & $75,6 \%$ \\
\hline & Sim & 14 & $21,5 \%$ & 11 & $24,4 \%$ \\
\hline & & \multicolumn{4}{|c|}{ HTLV tipo 2} \\
\hline & & \multicolumn{2}{|c|}{ Não } & \multicolumn{2}{|c|}{ Sim } \\
\hline \multirow[t]{4}{*}{ Língua fissurada } & Não & 71 & $77,2 \%$ & 17 & $81,0 \%$ \\
\hline & Sim & 21 & $22,8 \%$ & 4 & $19,0 \%$ \\
\hline & & \multicolumn{4}{|c|}{ Medicamentos } \\
\hline & & \multicolumn{2}{|c|}{ Não } & \multicolumn{2}{|c|}{ Sim } \\
\hline \multirow[t]{4}{*}{ Língua fissurada } & Não & 19 & $65,5 \%$ & 69 & $82,1 \%$ \\
\hline & Sim & 10 & $34,5 \%$ & 15 & $17,9 \%$ \\
\hline & & \multicolumn{4}{|c|}{ Comorbidades } \\
\hline & & \multicolumn{2}{|c|}{ Não } & \multicolumn{2}{|c|}{ Sim } \\
\hline \multirow[t]{4}{*}{ Língua fissurada } & Não & 26 & $70,3 \%$ & 62 & $81,6 \%$ \\
\hline & Sim & 11 & $29,7 \%$ & 14 & $18,4 \%$ \\
\hline & & \multicolumn{4}{|c|}{ Tabagismo } \\
\hline & & \multicolumn{2}{|c|}{ Não } & \multicolumn{2}{|c|}{ Sim } \\
\hline Língua fissurada & Não & 62 & $78,5 \%$ & 23 & $79,3 \%$ \\
\hline & Sim & 17 & $21,5 \%$ & 6 & $20,7 \%$ \\
\hline & & & & & \\
\hline & & & & & \\
\hline Língua fissurada & Não & 81 & $78,6 \%$ & 4 & $80,0 \%$ \\
\hline & Sim & 22 & $21,4 \%$ & 1 & $20,0 \%$ \\
\hline & & & & & \\
\hline & & & & & \\
\hline Língua fissurada & Não & 77 & $77,0 \%$ & 8 & $100,0 \%$ \\
\hline & Sim & 23 & $23,0 \%$ & 0 & $0,0 \%$ \\
\hline
\end{tabular}

Números Absolutos e Freqüência das variáveis em estudo em indivíduos com Língua fissurada 


\section{Candidíase}

\begin{tabular}{|c|c|c|c|c|c|}
\hline \multirow{4}{*}{\begin{tabular}{|l|} 
\\
Candidíase
\end{tabular}} & \multirow{4}{*}{$\begin{array}{l}\text { Não } \\
\text { Sim }\end{array}$} & \multicolumn{4}{|c|}{ Sexo } \\
\hline & & \multicolumn{2}{|c|}{ feminino } & \multicolumn{2}{|c|}{ masculino } \\
\hline & & 51 & $75,0 \%$ & 34 & $73,9 \%$ \\
\hline & & 17 & $25,0 \%$ & 12 & $26,1 \%$ \\
\hline & & \multicolumn{4}{|c|}{ HTLV tipo 1} \\
\hline & & \multicolumn{2}{|c|}{ Não } & \multicolumn{2}{|c|}{ Sim } \\
\hline \multirow[t]{4}{*}{ Candidíase } & Não & 17 & $85,0 \%$ & 68 & $72,3 \%$ \\
\hline & Sim & 3 & $15,0 \%$ & 26 & $27,7 \%$ \\
\hline & & \multicolumn{4}{|c|}{ TSP/HAM } \\
\hline & & \multicolumn{2}{|c|}{ Não } & \multicolumn{2}{|c|}{ Sim } \\
\hline \multirow[t]{4}{*}{ Candidíase } & Não & 48 & $72,7 \%$ & 35 & $77,8 \%$ \\
\hline & Sim & 18 & $27,3 \%$ & 10 & $22,2 \%$ \\
\hline & & \multicolumn{4}{|c|}{ HTLV tipo 2} \\
\hline & & \multicolumn{2}{|c|}{ Não } & \multicolumn{2}{|c|}{ Sim } \\
\hline \multirow[t]{4}{*}{ Candidíase } & Não & 68 & $73,1 \%$ & 17 & $81,0 \%$ \\
\hline & Sim & 25 & $26,9 \%$ & 4 & $19,0 \%$ \\
\hline & & \multicolumn{4}{|c|}{ Medicamentos } \\
\hline & & \multicolumn{2}{|c|}{ Não } & \multicolumn{2}{|c|}{ Sim } \\
\hline \multirow[t]{4}{*}{ Candidíase } & Não & 24 & $82,8 \%$ & 61 & $71,8 \%$ \\
\hline & Sim & 5 & $17,2 \%$ & 24 & $28,2 \%$ \\
\hline & & \multicolumn{4}{|c|}{ Comorbidades } \\
\hline & & \multicolumn{2}{|c|}{ Não } & \multicolumn{2}{|c|}{ Sim } \\
\hline \multirow[t]{4}{*}{ Candidíase } & Não & 28 & $73,7 \%$ & 57 & $75,0 \%$ \\
\hline & Sim & 10 & $26,3 \%$ & 19 & $25,0 \%$ \\
\hline & & \multicolumn{4}{|c|}{ Tabagismo } \\
\hline & & \multicolumn{2}{|c|}{ Não } & \multicolumn{2}{|c|}{ Sim } \\
\hline Candidíase & Não & 61 & $76,3 \%$ & 21 & $72,4 \%$ \\
\hline & Sim & 19 & $23,8 \%$ & 8 & $27,6 \%$ \\
\hline & & & & & \\
\hline & & & & & \\
\hline Candidíase & Não & 78 & $75,0 \%$ & 4 & $80,0 \%$ \\
\hline & Sim & 26 & $25,0 \%$ & 1 & $20,0 \%$ \\
\hline & & & & & \\
\hline & & & & & \\
\hline Candidíase & Não & 77 & $76,2 \%$ & 5 & $62,5 \%$ \\
\hline & Sim & 24 & $23,8 \%$ & 3 & $37,5 \%$ \\
\hline
\end{tabular}

Números Absolutos e Freqüência das variáveis em estudo em indivíduos com Candidíase 


\begin{tabular}{|c|c|c|c|c|c|c|c|}
\hline & & & & & $\overline{\mathrm{CD} 4}$ & & \\
\hline & & & & & & & \\
\hline Boca seca & Não & 4 & $4,9 \%$ & 5 & $6,1 \%$ & 73 & $89,0 \%$ \\
\hline & Sim & 1 & $3,4 \%$ & 2 & $6,9 \%$ & 26 & $89,7 \%$ \\
\hline & & & & & CD8 & & \\
\hline & & & & & & & \\
\hline Boca seca & Não & 36 & $46,8 \%$ & 38 & $49,4 \%$ & 3 & $3,9 \%$ \\
\hline & Sim & 14 & $51,9 \%$ & 11 & $40,7 \%$ & 2 & $7,4 \%$ \\
\hline & & & & & CD4 & & \\
\hline & & & & & & & \\
\hline Língua depapilada & Não & 5 & $6,1 \%$ & 5 & $6,1 \%$ & 72 & $87,8 \%$ \\
\hline & Sim & 0 & $0,0 \%$ & 2 & $20,0 \%$ & 8 & $80,0 \%$ \\
\hline & & & & & CD8 & & \\
\hline & & & & & & & \\
\hline Língua depapilada & Não & 34 & $44,2 \%$ & 38 & $49,4 \%$ & 5 & $6,5 \%$ \\
\hline & Sim & 5 & $55,6 \%$ & 4 & $44,4 \%$ & 0 & $0,0 \%$ \\
\hline & & & & & CD4 & & \\
\hline & & & & & & & \\
\hline Língua fissurada & Não & 5 & $6,8 \%$ & 4 & $5,5 \%$ & 64 & $87,7 \%$ \\
\hline & Sim & 0 & $0,0 \%$ & 3 & $15,8 \%$ & 16 & $84,2 \%$ \\
\hline & & & & & CD8 & & \\
\hline & & & & & & & \\
\hline Língua fissurada & Não & 30 & $44,8 \%$ & 32 & $47,8 \%$ & 5 & $7,5 \%$ \\
\hline & Sim & 9 & $47,4 \%$ & 10 & $52,6 \%$ & 0 & $0,0 \%$ \\
\hline & & & & & CD4 & & \\
\hline & & & & & & & \\
\hline Candidíase & Não & 2 & $2,8 \%$ & 4 & $5,6 \%$ & 66 & $91,7 \%$ \\
\hline & Sim & 3 & $14,3 \%$ & 3 & $14,3 \%$ & 15 & $71,4 \%$ \\
\hline & & & & & CD8 & & \\
\hline & & & & & & & \\
\hline Candidíase & Não & 35 & $50,7 \%$ & 30 & $43,5 \%$ & 4 & $5,8 \%$ \\
\hline & Sim & 4 & $22,2 \%$ & 13 & $72,2 \%$ & 1 & $5,6 \%$ \\
\hline
\end{tabular}

Números Absolutos e Freqüência das variáveis em estudo em indivíduos com diferentes manifestações bucais. 


\begin{tabular}{|c|c|c|c|c|c|c|c|c|c|c|c|c|c|c|c|}
\hline \multirow{3}{*}{\begin{tabular}{|l|} 
\\
Boca seca
\end{tabular}} & \multirow[b]{3}{*}{ Não } & \multicolumn{14}{|c|}{ Contaminação } \\
\hline & & \multicolumn{2}{|c|}{ amamentação } & \multicolumn{2}{|c|}{ marido + HIV } & \multicolumn{2}{|c|}{ não sabe } & \multicolumn{2}{|c|}{ sexo } & \multicolumn{2}{|c|}{ transfusão } & \multicolumn{2}{|c|}{ udi } & \multicolumn{2}{|c|}{ vertical } \\
\hline & & 1 & $1,0 \%$ & 1 & $1,0 \%$ & 60 & $61,9 \%$ & 13 & $13,4 \%$ & 8 & $8,2 \%$ & 9 & $9,3 \%$ & 5 & $5,2 \%$ \\
\hline & Sim & 0 & $0,0 \%$ & 0 & $0,0 \%$ & 17 & $48,6 \%$ & 10 & $28,6 \%$ & 3 & $8,6 \%$ & 2 & $5,7 \%$ & 3 & $8,6 \%$ \\
\hline & & \multicolumn{14}{|c|}{ Contaminação } \\
\hline & & \multicolumn{2}{|c|}{ amamentação } & \multicolumn{2}{|c|}{ marido + HIV } & \multicolumn{2}{|c|}{ não sabe } & \multicolumn{2}{|c|}{ sexo } & \multicolumn{2}{|c|}{ transfusão } & \multicolumn{2}{|c|}{ udi } & \multicolumn{2}{|c|}{ vertical } \\
\hline Língua & Não & 1 & $1,0 \%$ & 1 & $1,0 \%$ & 52 & $54,2 \%$ & 18 & $18,8 \%$ & 11 & $11,5 \%$ & 10 & $10,4 \%$ & 3 & $3,1 \%$ \\
\hline \multirow[t]{3}{*}{ depapilada } & Sim & 0 & $0,0 \%$ & 0 & $0,0 \%$ & 8 & $57,1 \%$ & 4 & $28,6 \%$ & 0 & $0,0 \%$ & 0 & $0,0 \%$ & 2 & $14,3 \%$ \\
\hline & & \multicolumn{14}{|c|}{ Contaminação } \\
\hline & & \multicolumn{2}{|c|}{ amamentação } & \multicolumn{2}{|c|}{ marido + HIV } & \multicolumn{2}{|c|}{ não sabe } & \multicolumn{2}{|c|}{ sexo } & \multicolumn{2}{|c|}{ transfusão } & \multicolumn{2}{|c|}{ udi } & \multicolumn{2}{|c|}{ vertical } \\
\hline Língua & Não & 1 & $1,2 \%$ & 1 & $1,2 \%$ & 45 & $52,3 \%$ & 18 & $20,9 \%$ & 8 & $9,3 \%$ & 10 & $11,6 \%$ & 3 & $3,5 \%$ \\
\hline \multirow[t]{3}{*}{ fissurada } & Sim & 0 & $0,0 \%$ & 0 & $0,0 \%$ & 15 & $62,5 \%$ & 4 & $16,7 \%$ & 3 & $12,5 \%$ & 0 & $0,0 \%$ & 2 & $8,3 \%$ \\
\hline & & \multicolumn{14}{|c|}{ Contaminação } \\
\hline & & \multicolumn{2}{|c|}{ amamentação } & \multicolumn{2}{|c|}{ marido + HIV } & \multicolumn{2}{|c|}{ não sabe } & \multicolumn{2}{|c|}{ sexo } & & usão & & & & \\
\hline Candidíase & Não & 1 & $1,2 \%$ & 1 & $1,2 \%$ & 47 & $56,6 \%$ & 16 & $19,3 \%$ & 10 & $12,0 \%$ & 4 & $4,8 \%$ & 4 & $4,8 \%$ \\
\hline & Sim & 0 & $0,0 \%$ & 0 & $0,0 \%$ & 14 & $50,0 \%$ & 6 & $21,4 \%$ & 1 & $3,6 \%$ & 6 & $21,4 \%$ & 1 & $3,6 \%$ \\
\hline
\end{tabular}

Números Absolutos e Freqüência da variável "Contaminação" nas diferentes manifestações bucais. 
ANEXO E - Valores Laboratoriais Referenciais de CD4 e CD8

\section{CD3+/CD4+ (T auxiliadores)}

Mediana:43\% - 880

5\% :31\%- 507

95\% :56\%- 1496

CD3+/CD8+ (T supressores)

Mediana:27\%-572

$5 \%: 17 \%-303$

95\%:41\%-1008

relação CD4/CD8=1,6(0,9-2,6)

* Idade: ADULTOS

Adaptado de: Manual de exames Instituto Fleury. 